\title{
ABORDAGEM BAYESIANA NA ANÁLISE GENÉTICA DE POPULAÇÕES UTILIZANDO DADOS DE MARCADORES MOLECULARES
}

\author{
ALEXANDRE SIQUEIRA GUEDES COELHO
}

Tese apresentada à Escola Superior de Agricultura

"Luiz de Queiroz", Universidade de São Paulo, para obtenção do título de Doutor em Agronomia, Área de Concentração: Genética e Melhoramento de Plantas.

P I R A C I C A B A

Estado de São Paulo - Brasil

Julho - 2002 


\title{
ABORDAGEM BAYESIANA NA ANÁLISE GENÉTICA DE POPULAÇÕES UTILIZANDO DADOS DE MARCADORES MOLECULARES
}

\section{ALEXANDRE SIQUEIRA GUEDES COELHO}

Engenheiro Agrônomo

\author{
Orientador: Prof. Dr. ROLAND VENCOVSKY
}

\begin{abstract}
Tese apresentada à Escola Superior de Agricultura
"Luiz de Queiroz", Universidade de São Paulo, para obtenção do título de Doutor em Agronomia, Área de Concentração: Genética e Melhoramento de Plantas.
\end{abstract}

P I R A C I C A B A

Estado de São Paulo - Brasil

Julho - 2002 
Dados Internacionais de Catalogação na Publicação (CIP)

DIVISÃo DE BIBLIOTECA E DOCUMENTAÇÃO - ESALQ/ USP

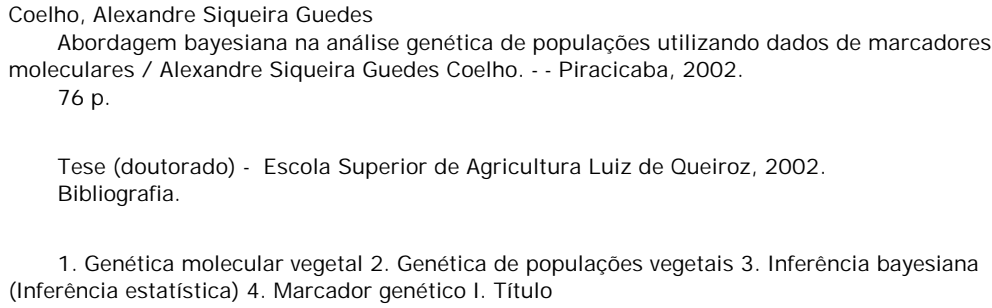

1. Genética molecular vegetal 2. Genética de populações vegetais 3. Inferência bayesiana (Inferência estatística) 4. Marcador genético I. Título

CDD 575.1

"Permitida a cópia total ou parcial deste documento, desde que citada a fonte - $\mathrm{O}$ autor" 
Aos meus filhos,

Ana Júlia e Pedro,

pela felicidade e pelo sentido

que trouxeram à minha vida,

EU DEDICO. 


\section{AGRADECIMENTOS}

Ao Professor Dr. Roland Vencovsky pela orientação, pela grande amizade, pelo incentivo e sobretudo pelo exemplo;

Ao Professor Dr. José Branco de Miranda Filho pela acolhida calorosa em Piracicaba, pelos ensinamentos, pelo incentivo e pelas inúmeras horas de convívio e amizade;

A todos os colegas de pós-graduação, e em especial aos amigos de todas as horas: Alexandre Magno Sebbenn, Américo José dos Santos Reis, André Jalles Monteiro, Aurélio Mendes Aguiar, Denise Garcia de Santana, Fernanda Amato Gaiotto, Heyder Diniz Silva, Luciana Aparecida Carlini, Maria Aldete Justiniano da Fonseca Ferreira, Maria Imaculada Zucchi, Paulo Barroso e Phellippe A. Santos Marbach;

Aos professores e funcionários dos Departamentos de Genética e de Ciências Exatas da ESALQ/USP pelos ensinamentos e pelos agradáveis momentos de convívio;

À Universidade Federal de Goiás pelo apoio e estímulo;

À Coordenação de Aperfeiçoamento de Pessoal de Nível Superior (CAPES), pelo apoio, sob a forma de bolsa de estudos, durante todo o período de realização deste trabalho; e sobretudo à minha família, em especial à Betina, pelo carinho, compreensão e afeto, sempre presentes ao longo desta jornada;

meus profundos agradecimentos. 


\section{SUMÁRIO}

Página

LISTA DE FIGURAS $\ldots \ldots \ldots \ldots \ldots \ldots \ldots \ldots \ldots \ldots \ldots$ viii

LISTA DE TABELAS $\ldots \ldots \ldots \ldots \ldots \ldots \ldots \ldots \ldots \ldots \ldots \ldots \ldots \ldots \ldots \ldots$

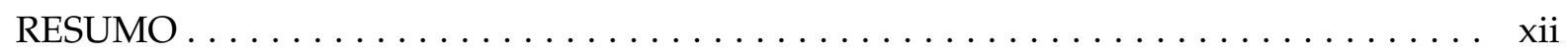

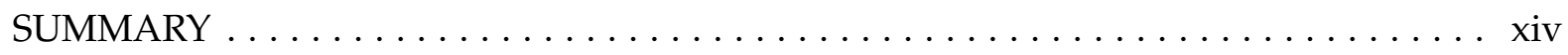

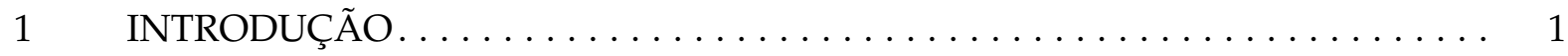

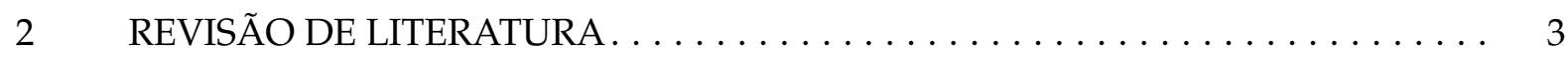

2.1 Equilíbrios Genéticos de Populações decorrentes do Sistema Reprodutivo. . . . . . 3

2.2 Métodos Clássicos de Estimação do Índice de Fixação Intrapopulacional . . . . . . 5

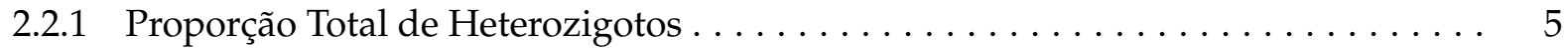

2.2.2 Método de Nei \& Chesser $(1983) \ldots \ldots \ldots \ldots \ldots \ldots \ldots \ldots \ldots \ldots \ldots$

2.2.3 Método de Robertson \& Hill $(1984) \ldots \ldots \ldots \ldots \ldots \ldots \ldots \ldots \ldots \ldots$

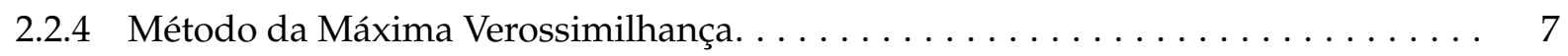

2.3 Estimação da Taxa de Fecundação Cruzada $\ldots \ldots \ldots \ldots \ldots \ldots \ldots \ldots \ldots$

2.3.1 Estimação da Taxa de Fecundação Cruzada Aparente. . . . . . . . . . . . . . 9

2.3.2 Estimação da Taxa de Fecundação Cruzada a Partir de Dados Obtidos de Progênies

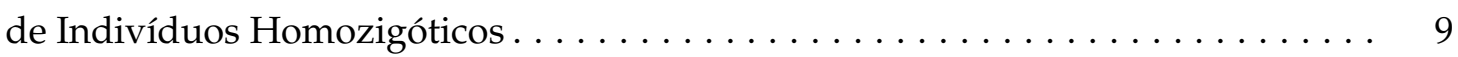

2.3.3 O Método Multiloco para Estimação da Taxa de Fecundação Cruzada . . . . . . . . 10

2.4 A Inferência Bayesiana em Estudos de Genética de Populações . . . . . . . . . . . 13

3 DINÂMICA DO ÍNDICE DE FIXAÇÃO INTRAPOPULACIONAL EM POPULAÇÕES FINITAS COM TAXAS VARIÁVEIS DE FECUNDAÇÃO CRUZADA . . . . 16

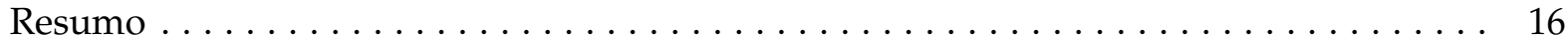




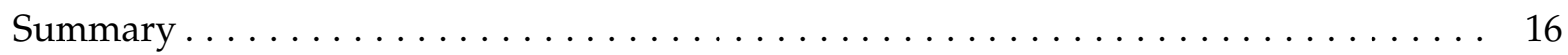

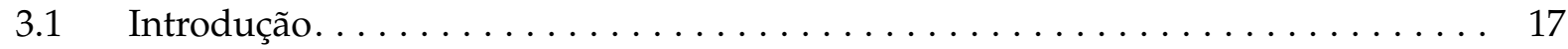

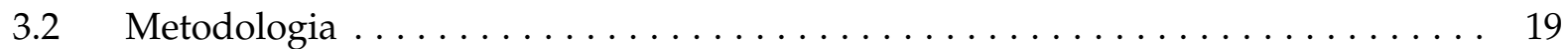

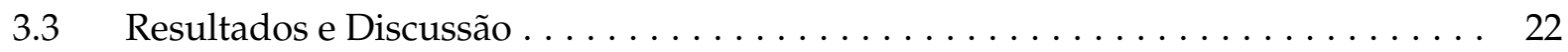

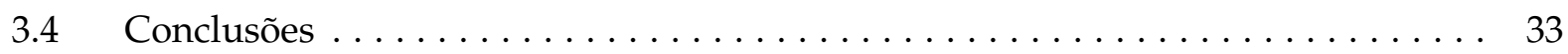

4 ESTIMAÇÃO DO ÍNDICE DE FIXAÇÃO INTRAPOPULACIONAL UTILIZANDO A INFORMAÇÃO DE MÚLTIPLOS LOCOS NÃO LIGADOS - UMA ABOR-

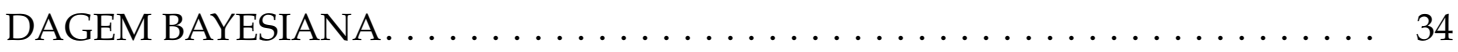

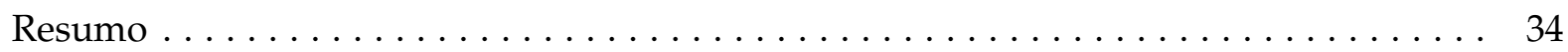

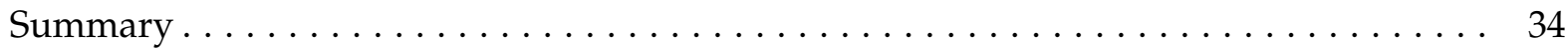

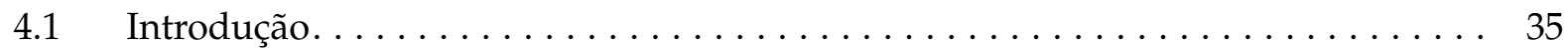

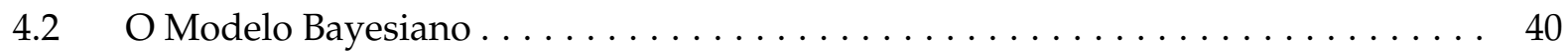

4.2.1 Modelo Probabilístico de Análise de Locos Individuais . . . . . . . . . . . . . . 41

4.2.2 Modelo Probabilístico de Análise de Múltiplos Locos . . . . . . . . . . . . . . . . 42

4.2 .3 Procedimento de Estimação $\ldots \ldots \ldots \ldots \ldots \ldots \ldots \ldots \ldots \ldots \ldots \ldots \ldots$

4.3 Exemplos de aplicação $\ldots \ldots \ldots \ldots \ldots \ldots \ldots \ldots \ldots \ldots \ldots \ldots \ldots \ldots$

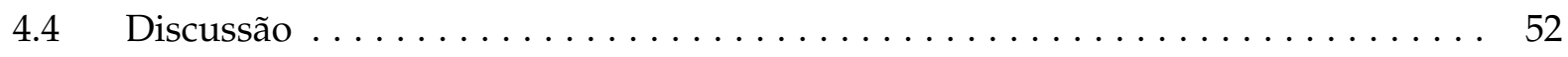

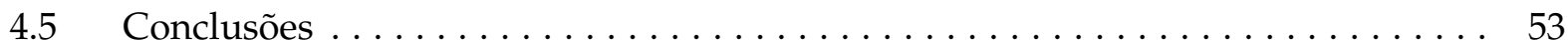

5 UMA ABORDAGEM BAYESIANA PARA A ESTIMAÇÃO DAS TAXAS DE FECUNDAÇÃO CRUZADA E APOMIXIA UTILIZANDO A INFORMAÇÃO DE

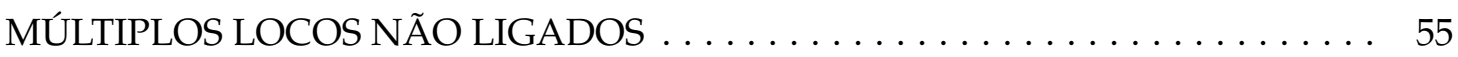

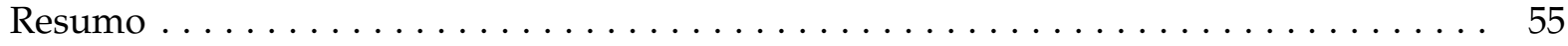

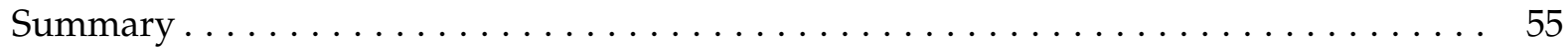

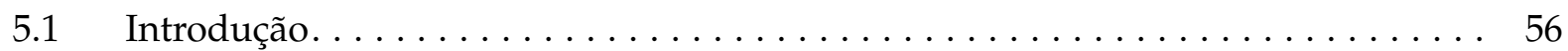

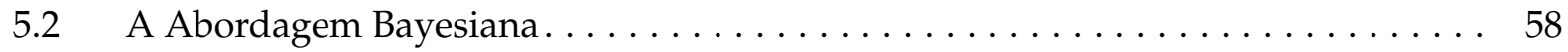

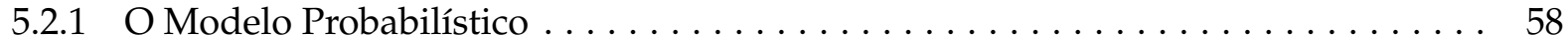

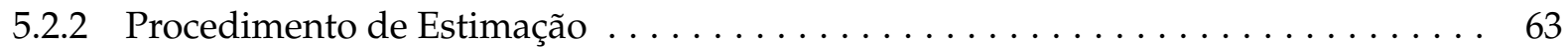

5.3 Exemplos de aplicação $\ldots \ldots \ldots \ldots \ldots \ldots \ldots \ldots \ldots \ldots \ldots \ldots \ldots \ldots \ldots$

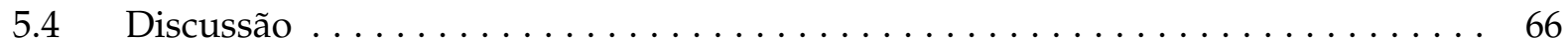

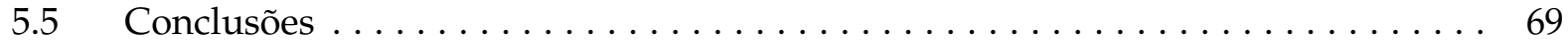




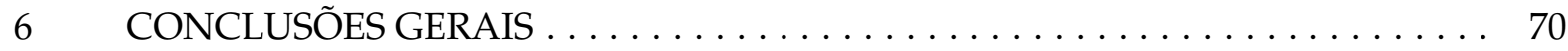

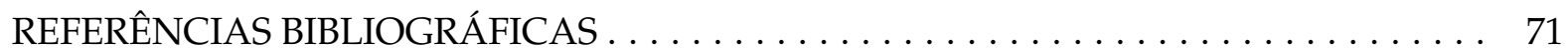




\section{LISTA DE FIGURAS}

Página

1 Distribuições de probabilidade simuladas para diferentes valores atribuídos à média $(\bar{t})$ e à variância $[\operatorname{Var}(t)]$ da taxa de fecundação cruzada. . . . . . . . 21

2 Valores do índice de fixação intrapopulacional em populações de diferentes tamanhos, com diferentes taxas de fecundação cruzada, ao longo de 520 gerações. . . . . . . . . . . . . . . . . . . . . . 23

3 Valores do índice de fixação intrapopulacional em populações com taxas de fecundação cruzada variáveis entre gerações, com média $\bar{t}$ e variância $\operatorname{Var}(t)$, ao longo de 520 gerações $(N=1.000 .000) \ldots \ldots \ldots$. . . . . . . 24

4 Valores do índice de fixação intrapopulacional em populações com taxas de fecundação cruzada variáveis entre indivíduos, com média $\bar{t}$ e variância $\operatorname{Var}(t)$, ao longo de 520 gerações $(N=1.000 .000) \ldots \ldots \ldots \ldots$

5 Distribuições de probabilidade observadas dos valores do índice de fixação intrapopulacional em populações de 10.000 indivíduos, com diferentes taxas de fecundação cruzada, ao longo de 10.000 gerações. A título de comparação, são também apresentadas as funções densidade de probabilidade Beta correspondentes. . . . . . . . . . . . . . . . . 28

6 Distribuições de probabilidade observadas dos valores do índice de fixação intrapopulacional em 10.000 locos de uma população de 1.000 indivíduos, com diferentes taxas de fecundação cruzada. A título de comparação, são também apresentadas as funções densidades de probabilidade Beta correspondentes. . . . . . . . . . . . . . . . . . . . . . . 29 
7 Valores preditos e observados da variância do índice de fixação intrapopulacional $[\operatorname{Var}(\hat{f})]$ entre locos, avaliados em uma única geração de populações com diferentes valores de taxa de fecundação cruzada $(t)$, freqüência alélica $(p)$ e tamanhos populacionais $(N)$. Valores obtidos a partir de 10.000

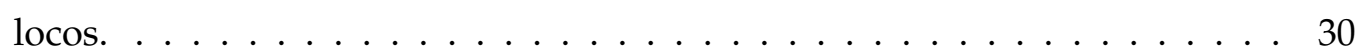

8 Coeficientes de correlação observados entre valores de $\hat{f}$ de diferentes locos ao longo de 1.000 gerações de populações com diferentes valores de média e variância das taxas de fecundação cruzada ao longo das gerações

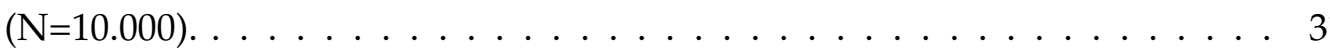

9 Dinâmica do índice de fixação intrapopulacional em dois locos de duas populações de mesmo tamanho $(N=10.000)$, mesma taxa média de fecundação cruzada $(\bar{t}=0,95)$ mas diferentes valores da variância de $t$ entre

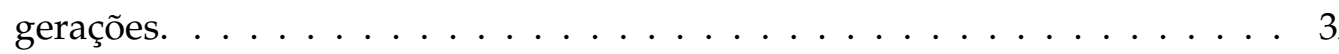

10 Valores do índice de fixação intrapopulacional, condicionais ao polimorfismo, para diferentes tamanhos amostrais e freqüências alélicas populaci-

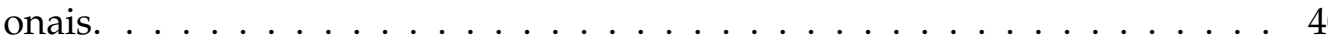

11 Distribuições de probabilidade a posteriori associadas aos graus de credibilidade dos diferentes valores das freqüências alélicas (alelo 1) de quatro locos avaliados em uma população natural de Annona crassiflora. . . . . . . . 47

12 Distribuições de probabilidade a posteriori associadas aos graus de credibilidade dos diferentes valores do índice de fixação intrapopulacional $\left(f_{i}\right)$, em quatro locos avaliados isoladamente em uma população natural de Annona

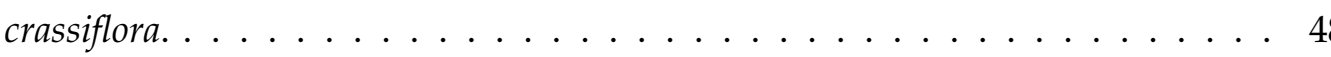

13 Distribuição de probabilidade a posteriori associada aos graus de credibilidade dos diferentes valores do índice de fixação intrapopulacional $(f)$, em quatro locos avaliados em uma população natural de Annona crassiflora. . .

14 Distribuição de probabilidade a posteriori associada aos graus de credibilidade dos diferentes valores do número efetivo de indivíduos reprodutivamente ativos $(N)$ em uma população natural de Annona crassiflora. . . . . . . 
15 Distribuições de probabilidade a posteriori associadas aos graus de credibilidade dos diferentes valores do índice de fixação intrapopulacional $(f)$, em 10 locos avaliados isoladamente (A) e em conjunto (B), aos diferentes valores para no número efetivo de indivíduos reprodutivamente ativos $(N)(\mathrm{B})$ e distribuição estimada para os valores de $f$ em diferentes locos (D), utilizando os valores mais prováveis para os hiperparâmetros $f$ e $N$ e os valores médios das freqüências alélicas $p_{i_{u}} \ldots \ldots \ldots \ldots \ldots$

16 Distribuições de probabilidade a posteriori associadas aos graus de credibilidade dos diferentes valores da taxa de fecundação cruzada $(t)$, da taxa de apomixia $(\alpha)$ e das freqüências alélicas $(p)$, em 10 locos. Dados obtidos por simulação (10 locos bialélicos em 10 progênies de 15 indivíduos, e parâmetros: $t=0,85, \alpha=0,0$ e $p=0,50) \ldots \ldots \ldots \ldots$

17 Distribuições de probabilidade a posteriori associadas aos graus de credibilidade dos diferentes valores da taxa de fecundação cruzada $(t)$, da taxa de apomixia $(\alpha)$ e da freqüência alélica $(p)$, em um loco. Dados obtidos por simulação (3 locos bialélicos em 2 progênies de 15 indivíduos, e parâmetros:

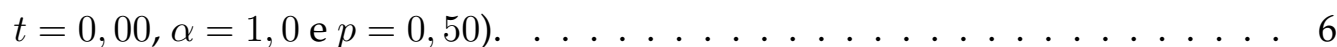

18 Distribuições de probabilidade a posteriori associadas aos graus de credibilidade dos diferentes valores da taxa de fecundação cruzada $(t)$, da taxa de apomixia $(\alpha)$ e das freqüências alélicas $(p)$, em 10 locos. Dados obtidos por simulação (10 locos com 5 alelos em 15 progênies de 15 indivíduos, e parâmetros: $t=0,90, \alpha=0,25$ e $p=0,20) \ldots \ldots \ldots \ldots$ 


\section{LISTA DE TABELAS}

Página

1 Média $(\overline{\hat{f}})$ e variância $\left(s_{\hat{f}}^{2}\right)$ dos valores estimados do índice de fixação intrapopulacional ao longo de 500 gerações em populações finitas e tamanhos $(N)$ variáveis e diferentes taxas de fecundação cruzada. . . . . . . . . . 26

2 Média $(\overline{\hat{f}})$ e variância $\left(s_{\hat{f}}^{2}\right)$ dos valores observados do índice de fixação intrapopulacional ao longo de 500 gerações em populações com taxas médias de fecundação cruzada variáveis entre gerações $(N=1.000 .000)$. . . . . . 26

3 Média $(\overline{\hat{f}})$ e variância $\left(s_{\hat{f}}^{2}\right)$ dos valores observados do índice de fixação intrapopulacional ao longo de 500 gerações em populações com taxas médias de fecundação cruzada variáveis entre indivíduos $(N=1.000 .000)$. . . . . 26

4 Estimativas das heterozigosidades observada $(\hat{H})$ e esperada $(\hat{h})$, do índice de fixação intrapopulacional pelos métodos de Nei \& Chesser $(1983)\left(f_{N C}\right)$, Robertson \& Hill (1984) $\left(f_{R H}\right)$, de Máxima Verossimilhança $\left(f_{M L}\right)$, e dos níveis de significância dos desvios das proporções genotípicas em relação às esperadas na condição de Equilíbrio de Hardy-Weinberg ( $p$ - valor $)$, de quatro locos isoenzimáticos, em uma população natural de Araticunzeiro (Annona crassiflora) . . . . . . . . . . . . . . . . . 46 


\title{
ABORDAGEM BAYESIANA NA ANÁLISE GENÉTICA DE POPULAÇÕES UTILIZANDO DADOS DE MARCADORES MOLECULARES
}

\author{
Autor: ALEXANDRE SIQUEIRA GUEDES COELHO \\ Orientador: Prof. ROLAND VENCOVSKY
}

\section{RESUMO}

Dentre os diversos aspectos geralmente observados na caracterização genética de populações naturais, a avaliação do grau de estruturação da variabilidade genética entre e dentro dos indivíduos e a obtenção de estimativas de parâmetros genéticos indicadores do sistema reprodutivo da espécie assumem grande importância. Os parâmetros de maior interesse neste caso são o índice de fixação intrapopulacional $(f)$ e a taxa de fecundação cruzada $(t)$. Pelo uso de simulações computacionais, este trabalho demonstra o caráter dinâmico do índice de fixação intrapopulacional em diferentes locos ao longo das gerações em decorrência do caráter finito da população e de variação nas taxas médias de fecundação cruzada entre gerações. Sugere-se que este caráter dinâmico representa uma explicação para a elevada variação, comumente reportada na literatura, das estimativas de $f$ obtidas com locos diferentes avaliados em uma mesma população. Utilizando a abordagem Bayesiana, um modelo hierárquico de análise é proposto para a estimação de $f$, incorporando as informações obtidas de múltiplos locos não ligados, levando-se em conta a condicionalidade do processo de estimação ao polimorfismo dos locos utilizados. O modelo proposto incorpora o caráter dinâmico de $f$ para diferentes locos e permite a estimação do número efetivo de indivíduos reprodutivamente ativos em uma população. Propõe-se ainda um modelo Bayesiano para a estimação da taxa de fecundação cruzada 
com base na informação de múltiplos locos, admitindo-se a possibilidade de ocorrência de apomixia. Os modelos propostos são avaliados por simulação e exemplos de aplicação a dados reais de marcadores moleculares codominantes são discutidos. Os resultados obtidos demonstram a aplicabilidade das metodologias propostas e o elevado potencial de aplicação da estatística Bayesiana em estudos de genética de populações. 


\title{
BAYESIAN APPROACH TO THE GENETIC ANALYSIS OF POPULATIONS USING MOLECULAR MARKERS DATA
}

\author{
Author: ALEXANDRE SIQUEIRA GUEDES COELHO \\ Adviser: Prof. ROLAND VENCOVSKY
}

\section{SUMMARY}

Among the various aspects generally considered in the genetic characterization of natural populations of plant species, the evaluation of the degree of genetic structure within and among individuals and the estimation of parameters related to the species mating system are of great importance. In general, considerable effort is focused on the estimation of the intrapopulation fixation index $(f)$ and the outcrossing rate $(t)$. Using computer simulated data, the dynamic nature of $f$ for different loci along generations is illustrated. The dynamic nature of $f$ is shown to result from the finite condition of populations and from the variation in the mean values of the outcrossing rates among generations. It is suggested that this dynamic behavior explains the inconsistency, commonly reported in the literature, of $f$ estimates obtained for different loci in a given population. Using a Bayesian approach, we propose a hierarchical model for the estimation of $f$, incorporating information obtained from different unlinked loci and considering the conditionality of the estimation process to genetic polymorphism. The proposed model incorporates the dynamic nature of $f$ values for different loci and allows the estimation of the effective number of reproductively active individuals in a given population. Using a similar approach, a Bayesian model is also proposed for estimating the outcrossing rate 
using multiple loci information and incorporating the possibility of apomixis. The models proposed are evaluated by computer simulations and examples using real data from codominant molecular markers are presented. Results obtained illustrate the applicability of the proposed methods and reveal the great potential of use of Bayesian statistics in population genetic studies. 


\section{INTRODUÇÃO}

Podemos dizer que o desenvolvimento dos marcadores genéticos de natureza bioquímica e molecular, a partir dos anos 60, e principalmente ao longo dos anos 80 e 90, realizou uma verdadeira revolução na área de genética de populações. A disponibilidade de marcadores genéticos para estudos populacionais, antes restrita a poucas espécies modelo, passou a existir para as mais diversas espécies de interesse. Historicamente, embora grande parte dos fundamentos teóricos destes estudos tenham sido estabelecidos pelos geneticistas do início do século XX, a contribuição destas técnicas para o refinamento da caracterização genética de populações tem sido substancial e exigido um forte desenvolvimento, do ponto de vista biométrico, destes métodos de análise.

Atualmente, grande parte dos estudos de genética de populações naturais se dedica à caracterização da estrutura genética existente nas mais diferentes espécies. Estes estudos costumam ser ainda, principalmente no caso de espécies vegetais de interesse agronômico, acompanhados de uma caracterização do sistema reprodutivo predominante. Tal fato se justifica, já que as informações daí obtidas podem contribuir de modo decisivo para o estabelecimento de estratégias mais adequadas para a conservação, o manejo e o melhoramento genético das espécies de interesse.

Cabe salientar no entanto que, apesar deste avanço, os métodos atualmente disponíveis, via de regra, admitem como verdadeiras diversas pressuposições básicas que nem sempre são válidas para as espécies típicas de biomas brasileiros. Os pressupostos de inexistência de reprodução assexuada, de não sobreposição de gerações, de constância da taxa de fecundação cruzada (e em alguns casos, da existência de equilíbrio de Wright) e ainda, de que as populações sob estudo são numerosas e muito grandes ("infinitas"), dificilmente podem ser verificados para a maior parte das espécies nativas perenes típicas dos Cerrados, por exemplo. 
Do ponto de vista biométrico, apesar do enorme potencial de aplicação da abordagem Bayesiana, o emprego destes métodos em estudos de genética de populações ainda é tímido, conforme se pode verificar em revisão apresentada por Shoemaker et al. (1999). Estes autores destacam que a abordagem Bayesiana proporciona uma estrutura geral de análise, adequada para representar o grau de conhecimento existente acerca de um determinado conjunto de parâmetros de interesse, ao incorporar as informações previamente disponíveis (explicitamente) no processo de análise. O resultado é um perfil de credibilidade para os diferentes valores de um determinado parâmetro à luz das observações realizadas. Deste modo, a abordagem Bayesiana permite que sejam associadas a diferentes hipóteses de interesse, diferentes níveis de credibilidade, fornecendo de uma maneira bastante intuitiva, os elementos necessários para a tomada de decisões. Um aspecto sob controvérsia, neste caso, é o fato de que na abordagem Bayesiana aos parâmetros são atribuídas distribuições de probabilidade, um procedimento inteiramente restrito às variáveis aleatórias no caso da estatística clássica ou freqüentista. Em estudos genéticos populacionais, no entanto, é atraente a idéia de se associar a um determinado parâmetro uma distribuição de probabilidade e não um único valor fixo. Como os elementos sob caracterização, as populações, estão sujeitos a uma série de fatores estocásticos, é natural se imaginar que os parâmetros que os caracterizem não sejam estáticos.

Neste contexto, este trabalho se propõe a realizar uma avaliação do efeito do não cumprimento dos pressupostos normalmente admitidos nas análises mais comumente utilizadas para se caracterizar geneticamente populações naturais, fornecendo, quando necessário, métodos alternativos mais gerais. Para tanto, foram considerados os seguintes objetivos:

i. Avaliar a adequação do modelo teórico de equilíbrio de Wright para populações finitas e sob taxas de fecundação cruzada variando entre gerações e entre indivíduos de uma mesma geração;

ii. Apresentar uma metodologia para a estimação do índice de fixação intrapopulacional em populações finitas;

iii. Apresentar uma metodologia para a estimação da taxa de fecundação cruzada, incluindo a possibilidade de ocorrência de apomixia. 


\section{REVISÃO DE LITERATURA}

\subsection{Equilíbrios Genéticos de Populações decorrentes do Sistema Reprodutivo}

Em populações infinitas, que se reproduzem por panmixia, na ausência de seleção, migração e mutação, as freqüências gênicas e genotípicas se mantém em equilíbrio, e não se alteram ao longo de gerações, mantendo entre si uma relação expressa por: (Crow \& Kimura, 1970)

$$
\left\{\begin{array}{l}
P_{u u}=p_{u}^{2} \\
P_{u v}=2 p_{u} p_{v}
\end{array}\right.
$$

em que:

$p_{u} \quad$ é a freqüência do alelo $u$;

$P_{u u} \quad$ é a freqüência de homozigotos para o alelo $u$;

$P_{u v} \quad$ é a freqüência de heterozigotos para os alelos $u \mathrm{e} v$.

Estas condições são conhecidas como condições de equilíbrio de Hardy-Weinberg, tendo sido as expressões apresentadas em (1) publicadas independentemente por G. H. Hardy e W. Weinberg em 1908.

Embora na prática seja geralmente difícil de se verificar se todas as condições necessárias para o equilíbrio de Hardy-Weinberg em uma dada população são satisfeitas, a simples manutenção das relações entre as freqüências gênicas e genotípicas, como previstas pelas equações que descrevem este equilíbrio, fornecem várias aplicações importantes em genética de populações.

Estas relações são utilizadas, por exemplo, na estimativa de freqüências alélicas utilizando marcadores genéticos com segregação típica de locos dominantes em populações quando se pode admitir panmixia (Lynch \& Milligan, 1994). Marcadores 
moleculares que exibem este tipo de comportamento, como os marcadores RAPD (Randomly Amplified Polymorphic DNA)(Williams et al., 1990) e AFLP (Amplified Fragment Length Polymorphism) (Vos et al., 1995), nos quais o fenótipo do genótipo heterozigoto é indistinto daquele do genótipo homozigoto dominante, são amplamente utilizados em estudos genéticos populacionais, como por exemplo em Adams et al.(2002), Luo et al. (2002), Esselman et al. (2000), Black-Samuelsson et al. (1997), Gillies et al. (1997), Palacios \& González-Candelas (1997) e Chalmers et al. (1992). Outras aplicações das proporções de equilíbrio de Hardy-Weinberg incluem os estudos de genética forense (Evett \& Weir, 1998).

Wright $(1921$; 1922) demonstrou que o equilíbrio também é alcançado se, mantidas as demais condições de equilíbrio de Hardy-Weinberg, uma população se reproduzir a uma taxa constante de fecundação cruzada $(t)$ e não mais por panmixia. As relações entre as freqüências gênicas e genotípicas são, no entanto, alteradas e passam a ser dadas pelas proporções:

$$
\left\{\begin{array}{l}
P_{u u}=p_{u}^{2}+p_{u}\left(1-p_{u}\right) f \\
P_{u v}=2 p_{u} p_{v}(1-f)
\end{array}\right.
$$

em que $f$ é o coeficiente de endogamia, ou de modo mais geral, é o índice de fixação intrapopulacional definido como sendo a correlação entre as freqüências alélicas de genes em um dado indivíduo. Nos casos em que o parâmetro $f$ é função exclusiva do sistema reprodutivo, seus valores mantém uma relação com aqueles da taxa de fecundação cruzada dada por:

$$
f=\frac{1-t}{1+t}
$$

Sendo que nesta condição, $0 \leq f \leq 1$ e $f$ tem, de fato, uma intepretação como um coeficiente de endogamia (Wright, 1922; Malécot, 1948).

Bennet \& Binet (1956) ressaltam que o equilíbrio de Wright não é atingido com uma única geração, como acontece com o equilíbrio de Hardy-Weinberg, mas é aproximado por uma taxa igual a $-\ln \left(\frac{1}{2} s\right)$. Em que $s$ é a taxa de autofecundação, igual a $1-t$.

Estes autores relatam ainda que na condição de equilíbrio de Wright existe um desequilíbrio genotípico, mesmo entre locos não ligados, decorrente do nível intermediário de endogamia; fato que também é discutido em Weir \& Cockerham (1973). Este 
desequilíbrio está relacionado a um pequeno excesso de duplo homozigotos em relação ao que seria esperado, sob independência, pelo produto das freqüências dos homozigotos de cada loco. Em locos com dois alelos, a razão entre as freqüências de duplo homozigotos em relação ao produto das freqüências de homozigotos para cada um dos locos é dada por:

$$
\frac{4 s(1-s)}{(4-s)(2-s)^{2}} p_{A_{1}} p_{A_{2}} p_{B_{1}} p_{B_{2}}
$$

sendo $p_{A_{u}}$ e $p_{B_{u}}$ as freqüências alélicas nos locos $A$ e $B$, respectivamente. A análise numérica desta relação demonstra que o desequilíbrio genotípico decorrente da condição de sistema misto é máximo com $s=0,6946$.

A relação mantida entre o índice de fixação intrapopulacional e as taxas de fecundação cruzada tem sido utilizada por diversos autores para se estimar estas últimas com base em dados obtidos pelo uso de marcadores moleculares codominantes em populações naturais, procedimento inicialmente sugerido por Fyfe \& Bailey (1951).

\subsection{Métodos Clássicos de Estimação do Índice de Fixação Intrapopulacional}

Embora o procedimento de estimação dos valores de $f$ tenha atraído a atenção de muitos pesquisadores desde os primórdios dos estudos de genética de populações, um estimador com características ótimas (com variância mínima e ausência de viés, mesmo em amostras pequenas) ainda não foi obtido. Dentre os diversos estimadores de $f$ propostos na literatura, muitos conduzem a resultados muito próximos, como é o caso de parte dos revistos por Li \& Horvitz (1953). Outros estimadores com propriedades estatísticas melhor definidas foram obtidos pelo uso de diferentes métodos de estimação e são apresentados, por exemplo, em Nei \& Chesser (1983), Robertson \& Hill (1984) e Weir (1996).

A seguir são apresentados alguns métodos de estimação do índice de fixação intrapopulacional, comumente encontrados na literatura.

\subsubsection{Proporção Total de Heterozigotos}

Conforme salientam Li \& Horvitz (1953), este é o método mais simples de se estimar o índice de fixação intrapopulacional. Consiste na substituição dos parâmetros 
pelos seus valores observados na fórmula "conceitual"de $f$, obtida a partir da expressão que descreve a freqüência de heterozigotos nas condições de equilíbrio Wright, de modo que:

$$
\hat{f}=\frac{\tilde{h}-\tilde{H}}{\tilde{h}}
$$

sendo $\tilde{H}$ a freqüência observada de heterozigotos na amostra e $\tilde{h}$ a freqüência esperada de heterozigotos na condição de equilíbrio de Hardy-Weinberg, dada por: $1-\sum_{u} \tilde{p}_{u}^{2}$, em que $\tilde{p}_{u}$ representa a freqüência observada do alelo $u$ na amostra. A medida $h$ também é conhecida como diversidade genética de Nei $(1973$; 1977; 1986).

Este estimador é também o estimador obtido pela utilização do método de máxima verossimilhança no caso de um loco com dois alelos e embora consistente, fornece estimativas viesadas em amostras pequenas, devendo portanto ser utilizado com cautela (Nei \& Chesser, 1983).

Fife \& Bailey (1951) fornecem uma expressão aproximada para a variância de $\hat{f}$ dada por:

$$
\operatorname{Var}(\hat{f})=\frac{(1-f)^{2}(1-2 f)}{n}+\frac{f(1-f)(2-f)}{2 n p_{u}\left(1-p_{u}\right)}
$$

em que $n$ é o tamanho da amostra.

\subsubsection{Método de Nei \& Chesser (1983)}

No sentido de se atenuar o problema da existência de viés na estimativa de $f$ a partir de amostras pequenas, Nei \& Chesser (1983) propuseram um estimador baseado na utilização de estimadores não viesados para $H$ e $h$. A expressão para o estimador de $f$, obtido pelo método dos momentos, neste caso é dada por:

$$
\hat{f}=\frac{\tilde{h}-\tilde{H}+\frac{\tilde{H}}{2 n}}{\tilde{h}-\frac{\tilde{H}}{2 n}}
$$

O estimador de Nei \& Chesser (1983) é o mais difundido atualmente, sendo sua utilização amplamente documentada na literatura. Este estimador, no entanto, conforme salientam os próprios autores, embora atenue parte do viés existente no estimador não corrigido, só pode ser considerado não viesado na medida em que a razão de dois estimadores não viesados for também considerada um estimador não viesado. 


\subsubsection{Método de Robertson \& Hill (1984)}

Robertson \& Hill (1984) apresentam um estimador para $f$ que, para os valores paramétricos das freqüências alélicas, tem variância mínima. O estimador de $f$ neste caso é dado por:

$$
\hat{f}=\frac{1}{m-1} \sum_{u}\left[\frac{2(2 n-1) n_{u u}-n_{u}\left(n_{u}-1\right)}{2 n_{u}(n-1)}\right]
$$

em que $m$ é o número de alelos do loco em questão, $n_{u u}$ e $n_{u}$ se referem ao número observado de genótipos $u$ e alelos $u$ na amostra, respectivamente. Cumpre salientar que, na prática, em geral, como os valores paramétricos das freqüências alélicas não são conhecidos, a propriedade de variância mínima não pode ser garantida.

\subsubsection{Método da Máxima Verossimilhança}

Embora, no caso de locos com mais de dois alelos, soluções algébricas não possam ser obtidas para o estimador de $f$ utilizando-se o método de máxima verossimilhança, um procedimento iterativo é apresentado em Hill et al. (1995) e pode ser descrito pelos seguintes passos:

i. Atribuir valores para $\hat{f}$ e $\hat{p}_{u}$;

ii. Obter a quantidade $\hat{x}_{u}$ :

$$
\hat{x}_{u}=\frac{\hat{f} \cdot n_{u u}}{\hat{f}+\hat{p}_{u}(1-\hat{f})}
$$

iii. Obter estimativas revisadas para $p_{u}$ e $f$ :

$$
\hat{p}_{u}=\frac{n_{u}-\hat{x}_{u}}{\sum_{u}\left(n_{u}-\hat{x}_{u}\right)} \quad \text { e } \quad \hat{f}=\frac{\sum_{u} x_{u}}{n}
$$

iv. Repetir os passos $i$ e $i$ iii até a convergência.

\subsection{Estimação da Taxa de Fecundação Cruzada}

Conforme já comentado, no que diz respeito à caracterização genética de populações de espécies vegetais, a determinação do sistema reprodutivo predominante na espécie fornece informações de grande importância. O sistema reprodutivo predominante de uma determinada espécie estabelece, em grande parte, todo um conjunto de 
propriedades genéticas de suas populações. Estas propriedades, em última instância, são as que sugerem as estratégias mais adequadas de conservação e melhoramento genético que devem ser utilizadas em cada caso.

Embora a maior parte das espécies cultivadas tenha seu sistema reprodutivo razoavelmente bem caracterizado, pouco ainda se conhece sobre as espécies nativas brasileiras. Neste sentido, o desenvolvimento das técnicas de obtenção de marcadores genéticos baseados em polimorfismo avaliado diretamente ao nível de DNA, tem provocado um avanço considerável nesta área. A utilização de marcadores genéticos para se estimar a taxa de fecundação cruzada em populações naturais, no entanto, não é uma idéia nova. De qualquer modo, a facilidade com que hoje são obtidas informações genotípicas em espécies nunca antes geneticamente caracterizadas permitiu um aumento considerável no potencial de caracterização genética da flora brasileira.

Do ponto de vista biométrico, avanços significativos foram realizados ao longo da década de 1970 e 1980 (Allard et al., 1972; Brown et al., 1975; Clegg et al., 1978; Ritland \& Jain, 1981; Shaw et al., 1981; Cheliak et al., 1983; Yeh \& Morgan, 1987; Ritland, 1989).

Atualmente, a abordagem mais comumente utilizada na obtenção de estimativas de taxas de fecundação cruzada é a metodologia inicialmente proposta em Ritland \& Jain (1981). Exemplos de aplicação desta metodologia podem ser encontrados em Millar et al. (2000) e Bessega et al. (2000).

A metodologia proposta por Ritland \& Jain (1981) utiliza a informação de múltiplos locos para se estimar a taxa de fecundação cruzada e possibilita ainda a obtenção de uma série de outros parâmetros indicadores do sistema reprodutivo, como a taxa de fecundação cruzada entre indivíduos aparentados, a proporção dos descendentes de cruzamentos que são irmãos germanos e o grau de estruturação dos eventos de autofecundação nas progênies.

A seguir são apresentadas algumas abordagens comumente utilizadas para se estimar a taxa de fecundação cruzada. 


\subsubsection{Estimação da Taxa de Fecundação Cruzada Aparente}

Conforme sugerido inicialmente por Fyfe \& Bailey (1951), dada a relação entre os valores do índice de fixação intrapopulacional e os da taxa de fecundação cruzada, admitindo-se que a população sob estudo encontra-se em equilíbrio de Wright, obtém-se o seguinte estimador para a taxa de fecundação cruzada, dita "aparente":

$$
\hat{t}_{a}=\frac{1-\hat{f}}{1+\hat{f}}
$$

em que $\hat{f}$ é uma estimativa do índice de fixação intrapopulacional.

A taxa de fecundação cruzada assim obtida é dita aparente pelo fato de que, em geral, não se pode admitir com segurança a condição de equilíbrio de Wright. Assim, esta taxa é melhor interpretada como sendo a taxa de fecundação cruzada que promove em uma população de referência, em equilíbrio de Wright, o mesmo nível de endogamia encontrado na população em estudo.

Apesar da grande fragilidade em termos de pressupostos, a vantagem de utilização desta metodologia reside na sua simplicidade de aplicação. Dados de uma única geração de indivíduos adultos são suficientes para se produzir uma estimativa, ainda que aparente, da taxa de fecundação cruzada.

\subsubsection{Estimação da Taxa de Fecundação Cruzada a Partir de Dados Obtidos de Progênies de Indivíduos Homozigóticos}

Conforme apresentado em Weir (1996) a progênie de indivíduos homozigóticos pode ser utilizada para a estimação da taxa de fecundação cruzada.

O método se baseia no princípio de que a probabilidade de que um descendente de um indivíduo homozigótico seja heterozigótico é dada pelo produto das probabilidades de ocorrência de dois enventos independentes: o primeiro é a ocorrência de cruzamento, e o segundo é a ocorrência de um alelo diferente daquele presente no indivíduo homozigótico no gameta masculino que dá origem ao descendente.

A aplicação do método de máxima verossimilhança neste caso fornece o seguinte estimador para a taxa de fecundação cruzada:

$$
\hat{t}=\frac{\tilde{H}}{N\left(1-p_{u}\right)}
$$


sendo $\tilde{H}$ a freqüência de indivíduos heterozigóticos na progênie de tamanho $N$ do indivíduo homozigótico para o alelo $u$, e $p_{u}$ a freqüência deste alelo no pool de pólens, considerada conhecida neste caso.

\subsubsection{O Método Multiloco para Estimação da Taxa de Fecundação Cruzada}

Métodos de estimação da taxa de fecundação cruzada utilizando dados de múltiplos locos, avaliados em progênies de indivíduos não necessariamente homozigotos, foram sugeridos por Brown et al. (1975), Clegg et al. (1978), Shaw et al. (1981), Ritland \& Jain (1981), Yeh \& Morgan (1987) e Ritland (1989), sendo o método de Ritland \& Jain (1981), baseado em genótipos multilocos, o de utilização mais difundida.

O método proposto por Ritland \& Jain (1981) constrói a função de verossimilhança para os parâmetros de interesse com base nas freqüências genotípicas observadas em um conjunto de progênies e obtém estimativas para estes parâmetros pelo método de máxima verossimilhança. Embora este método apresente a alternativa de se realizar a estimativa da taxa de fecundação cruzada mesmo quando o genótipo materno não é conhecido a priori, inferindo-se estes genótipos a partir dos dados das progênies, a descrição a seguir admite que os genótipos maternos são conhecidos, afim de tornar mais clara a sua apresentação.

Ritland \& Jain (1981) apresentam a função de verossimilhança associada aos parâmetros de interesse utilizando uma notação matricial. O uso desta notação requer a definição de um vetor g cujos elementos $g_{i}$ são os "nomes"dos genótipos multilocos. Sendo $\mathbf{u}_{\mathbf{k}}$ o vetor de elementos $u_{k_{i}}$ representando os "nomes"associados a um dado loco $k$, de um conjunto de $L$ locos, temos que:

$$
\mathbf{g}=\mathbf{u}_{\mathbf{1}} \otimes \mathbf{u}_{\mathbf{2}} \otimes \cdots \otimes \mathbf{u}_{\mathbf{L}}
$$

em que $\otimes$ denota o "produto"de Kronecker, que associa os "nomes"de genótipos de locos diferentes. Para 2 locos, $A$ e $B$, contendo cada um dois alelos, por exemplo, tem-se que: 


$$
\mathbf{u}_{\mathbf{1}}=\left[\begin{array}{c}
A_{1} A_{1} \\
A_{1} A_{2} \\
A_{2} A_{2}
\end{array}\right] \mathbf{u}_{\mathbf{2}}=\left[\begin{array}{c}
B_{1} B_{1} \\
B_{1} B_{2} \\
B_{2} B_{2}
\end{array}\right] \mathbf{g}=\left[\begin{array}{c}
A_{1} A_{1} B_{1} B_{1} \\
A_{1} A_{1} B_{1} B_{2} \\
A_{1} A_{1} B_{2} B_{2} \\
A_{1} A_{2} B_{1} B_{1} \\
A_{1} A_{2} B_{1} B_{2} \\
A_{1} A_{2} B_{2} B_{2} \\
A_{2} A_{2} B_{1} B_{1} \\
A_{2} A_{2} B_{1} B_{2} \\
A_{2} A_{2} B_{2} B_{2}
\end{array}\right]
$$

Podem ainda ser definidas matrizes $\mathbf{s}_{\mathbf{k}}$ constituídas de elementos $s_{k_{i j}}$ que representam as probabilidades de ocorrência de um genótipo designado por $u_{k_{i}}$ em uma progênie obtida por autofecundação do genótipo $u_{k_{j}}$. De modo que:

$$
\mathbf{S}=\mathbf{s}_{\mathbf{1}} \otimes \mathbf{s}_{\mathbf{2}} \otimes \cdots \otimes \mathbf{s}_{\mathbf{L}}
$$

representa a matriz de elementos $s_{i j}$, em que $s_{i j}$ representa a probabilidade de ocorrência do genótipo designado pelo $i$-ésimo elemento de g dada a ocorrência de autofecundação do genótipo designado pelo $j$-ésimo elemento de g. Para o exemplo de dois locos, com dois alelos cada tem-se que:

$$
\mathbf{s}_{1}=\left[\begin{array}{ccc}
1 & \frac{1}{4} & 0 \\
0 & \frac{1}{2} & 0 \\
0 & \frac{1}{4} & 1
\end{array}\right] \quad \mathbf{S}_{2}=\left[\begin{array}{ccc}
1 & \frac{1}{4} & 0 \\
0 & \frac{1}{2} & 0 \\
0 & \frac{1}{4} & 1
\end{array}\right] \quad \mathbf{S}=\left[\begin{array}{ccccccccc}
0 & \frac{1}{4} & 1 & 0 & \frac{1}{16} & \frac{1}{4} & 0 & 0 & 0 \\
0 & 0 & 0 & \frac{1}{2} & \frac{1}{8} & 0 & 0 & 0 & 0 \\
0 & 0 & 0 & 0 & \frac{1}{4} & 0 & 0 & 0 & 0 \\
0 & 0 & 0 & 0 & \frac{1}{8} & \frac{1}{2} & 0 & 0 & 0 \\
0 & 0 & 0 & \frac{1}{4} & \frac{1}{16} & 0 & 1 & \frac{1}{4} & 0 \\
0 & 0 & 0 & 0 & \frac{1}{8} & 0 & 0 & \frac{1}{2} & 0 \\
0 & 0 & 0 & 0 & \frac{1}{16} & \frac{1}{4} & 0 & \frac{1}{4} & 1
\end{array}\right]
$$

De modo análogo, pode ser definida a matriz $\mathbf{T}=\mathbf{t}_{\mathbf{1}} \otimes \mathbf{t}_{\mathbf{2}} \otimes \cdots \otimes \mathbf{t}_{\mathbf{L}} \mathbf{c o m}$ 
probabilidades associadas aos genótipos em progênies obtidas por fecundação cruzada. No exemplo em questão, esta matriz seria dada por:

$$
\begin{aligned}
& \mathbf{t}_{\mathbf{1}}=\left[\begin{array}{ccc}
p_{11} & \frac{1}{2} p_{11} & 0 \\
p_{12} & \frac{1}{2} & p_{11} \\
0 & \frac{1}{2} p_{12} & p_{12}
\end{array}\right] \quad \mathbf{t}_{2}=\left[\begin{array}{ccc}
p_{21} & \frac{1}{2} p_{21} & 0 \\
p_{22} & \frac{1}{2} & p_{21} \\
0 & \frac{1}{2} p_{22} & p_{22}
\end{array}\right] \\
& \mathbf{T}=\left[\begin{array}{ccccccccc}
p_{11} p_{21} & \frac{1}{2} p_{11} p_{21} & 0 & \frac{1}{2} p_{11} p_{21} & \frac{1}{4} p_{11} p_{21} & 0 & 0 & 0 & 0 \\
p_{11} p_{22} & \frac{1}{2} p_{11} & p_{11} p_{21} & \frac{1}{2} p_{11} p_{22} & \frac{1}{4} p_{11} & \frac{1}{2} p_{11} p_{21} & 0 & 0 & 0 \\
0 & \frac{1}{2} p_{11} p_{22} & p_{11} p_{22} & 0 & \frac{1}{4} p_{11} p_{22} & \frac{1}{2} p_{11} p_{22} & 0 & 0 & 0 \\
p_{12} p_{21} & \frac{1}{2} p_{12} p_{21} & 0 & \frac{1}{2} p_{21} & \frac{1}{4} p_{21} & 0 & p_{11} p_{21} & \frac{1}{2} p_{11} p_{21} & 0 \\
p_{12} p_{22} & \frac{1}{2} p_{12} & p_{12} p_{21} & \frac{1}{2} p_{22} & \frac{1}{4} & \frac{1}{2} p_{21} & p_{11} p_{22} & \frac{1}{2} p_{11} & p_{11} p_{21} \\
0 & \frac{1}{2} p_{12} p_{22} & p_{12} p_{22} & 0 & \frac{1}{4} p_{22} & \frac{1}{2} p_{22} & 0 & \frac{1}{2} p_{11} p_{22} & p_{11} p_{22} \\
0 & 0 & 0 & \frac{1}{2} p_{12} p_{21} & \frac{1}{4} p_{12} p_{21} & 0 & p_{12} p_{21} & \frac{1}{2} p_{12} p_{21} & 0 \\
0 & 0 & 0 & \frac{1}{2} p_{12} p_{22} & \frac{1}{4} p_{12} & \frac{1}{2} p_{12} p_{21} & p_{12} p_{22} & \frac{1}{2} p_{12} & p_{12} p_{21} \\
0 & 0 & 0 & 0 & \frac{1}{4} p_{12} p_{22} & \frac{1}{2} p_{12} p_{22} & 0 & \frac{1}{2} p_{12} p_{22} & p_{12} p_{22}
\end{array}\right]
\end{aligned}
$$

em que $p_{i j}$ representa a freqüência do alelo $j$ no loco $i$.

A função logaritmo da verossimilhança pode então ser escrita como:

$$
\left.L=\ln \frac{n !}{\Pi_{i} x_{i j} !}+\mathbf{1}^{\prime}(\mathbf{X} \circ \ln \mathbf{P}) \mathbf{1}\right]
$$

em que:

1 é o vetor de elementos iguais a 1, com dimensão adequada;

X é a matriz cujos elementos $x_{i j}$ são definidos como sendo os valores observados para as freqüências absolutas correspondentes à ocorrência do genótipo $g_{i}$ na progênie descendente do genótipo $g_{j}$;

$\mathbf{A} \circ \mathbf{B}$ denota o produto de Schur entre matrizes, em que cada elemento da matriz resultante $\left(c_{i j}\right)$ é obtido pelo produto dos elementos correspondentes nas matrizes $\mathbf{A}$ e $\mathbf{B}\left(c_{i j}=a_{i j} b_{i j}\right)$;

$\ln \mathbf{A} \quad$ denota a matriz que tem como elementos os valores correspondentes ao logaritmo neperiano de cada um dos elementos da matriz A; 
denota a matriz cujos elementos $r_{i j}$ representam a probabilidade de ocorrência do genótipo $g_{i}$ na progênie descendente do genótipo $g_{j}$.

A matriz $\mathbf{P}$, neste caso, é obtida como sendo função das matrizes $\mathbf{T}$ e $\mathbf{S}$ e da taxa de fecundação cruzada $(t)$ :

$$
\mathbf{P}=t \cdot \mathbf{T}+(1-t) \cdot \mathbf{S}
$$

Estimativas para a taxa de fecundação cruzada e para as freqüências alélicas são então obtidas maximizando-se a função logaritmo de verossimilhança $L$ através do algoritmo:

i. Atribuir um valor inicial para $\hat{t}$ e para cada uma das freqüências alélicas;

ii. Obter estimativas para as freqüências alélicas por maximização de $L$;

iii. Atualizar o valor de $\hat{t}$ utilizando-se a equação:

$$
\hat{t}_{i+1}=\mathbf{1}^{\prime}\left(\left(X \circ \hat{t}_{i} \mathbf{T} / \mathbf{P} n\right) \mathbf{1}\right.
$$

em que $\mathbf{A} / \mathbf{B}$ denota a operação em que cada elemento de $\mathbf{A}$ é dividido pelo elemento correspondente em B;

iv. Repetir os passos $i$ e $i i i$ até a convergência.

Extensões a esta metodologia, no sentido de se incluir no processo de estimação parâmetros como a proporção de cruzamentos que ocorrem entre indivíduos aparentados, a proporção de cruzamentos que dão origem a irmãos germanos e o grau de estruturação dos eventos de autofecundação ao nível de progênies, são apresentadas em Ritland \& El-Kassaby (1985), Ritland (1989) e Ritland (1990).

\subsection{A Inferência Bayesiana em Estudos de Genética de Populações}

A utilização da abordagem Bayesiana em estudos de genética de populações ainda é bastante tímida, conforme salientam Shoemaker et al. (1999). Exemplos de utilização desta abordagem em estudos de genética de populações são encontrados em Pereira \& Rogatko (1984), Shoemaker et al. (1998), Ayres \& Balding (1998) e MontoyaDelgado et al. (2001). 
Apesar de seu uso ainda restrito em genética de populações, a abordagem Bayesiana fornece uma alternativa que conduz mais facilmente à interpretação das hipóteses sob teste. Conforme salientam Shoemaker et al. (1999), no paradigma Bayesiano a probabilidade é uma medida direta da incerteza, e pode ou não representar a freqüência de ocorrência de um determinado evento a longo prazo. Os resultados neste caso são apresentados como estimativas das distribuições de probabilidade a posteriori que, explicitamente, representam o grau de credibilidade atribuído a cada uma das hipóteses alternativas.

A abordagem Bayesiana, conforme descrevem Shoemaker et al. (1998), consiste em se obter uma distribuição de probabilidade, associada aos diferentes valores que o parâmetro de interesse pode assumir, de modo a representar o grau de credibilidade associado a cada um deles, dado o conjunto de dados observado. O ponto de partida é uma distribuição de probabilidade, dita a priori, obtida de considerações anteriores à observação dos genótipos. Esta distribuição de probabilidade pode então ser atualizada pela utilização do teorema de Bayes, de modo a se considerar as informações obtidas das observações.

Seja $\phi(\theta)$ a função densidade de probabilidade a priori associada a um vetor de parâmetros $(\theta)$. A função densidade de probabilidade a posteriori condicional ao conjunto de dados observados $(X)$, neste caso é expressa por:

$$
\phi(\theta \mid X)=\frac{\phi(\theta) \cdot \phi(X \mid \theta)}{\phi(X)}
$$

A função densidade de probabilidade a priori a ser adotada deve refletir necessariamente o grau de conhecimento disponível acerca dos parâmetros de interesse. É interessante observar que a expressão $\phi(X \mid \theta)$ refere-se à função que descreve a probabilidade de ocorrência dos dados condicional aos valores dos parâmetros que compõem $\theta$, e, em termos práticos, tem a mesma forma da função de verossimilhança dos parâmetros.

Diversos métodos têm sido empregados na obtenção das distribuições de probabilidade a posteriori (Gamerman, 1997). Alguns métodos, por utilizarem funções densidade de probabilidade a priori adequadas, fornecem expressões algébricas explícitas, como em Shoemaker et al. (1998), outros, no entanto, obtém as distribuições de probabilidade empiricamente utilizando algoritmos de randomização via Cadeias de Markov, 
como o de Metropolis-Hastings, utilizado em Ayres \& Balding (1998).

Conforme salientam Baldi \& Brunak (1999), o algoritmo de MetropolisHastings, utilizado para a obtenção da distribuição marginal a posteriori exige somente que a função de verossimilhança seja expressa algebricamente. A função de densidade de probabilidade a priori é levada em consideração na obtenção dos estados sugeridos da Cadeia de Markov, enquanto que a expressão algébrica da função que descreve a probabilidade marginal de ocorrência dos dados não é exigida.

$\mathrm{O}$ algoritmo consiste em se produzir um conjunto de valores simulados para a função densidade de probabilidade a posteriori $\phi(\theta \mid X)$, utilizando uma Cadeia de Markov, em que a probabilidade de transição de um determinado estado $(x)$ para um estado subseqüente $\left(x^{\prime}\right)$ é dada por:

$$
\min \left[\frac{\phi\left(x^{\prime}\right) q\left(x \mid x^{\prime}\right)}{\phi(x) q\left(x^{\prime} \mid x\right)}, 1\right]
$$

em que:

$\phi(x) \quad$ é a densidade de probabilidade associada ao estado $x$;

$q\left(x^{\prime} \mid x\right) \quad$ é a probabilidade de que o estado $x^{\prime}$ seja sugerido, estando-se em $x$. De modo geral, se novos estados são sugeridos por uma distribuição uniforme $q\left(x^{\prime} \mid x\right)=$ $q\left(x \mid x^{\prime}\right)$ e os termos se cancelam.

Assim, a partir de um ponto qualquer do espaço paramétrico $(x)$, valores aleatórios são sugeridos pela distribuição a priori. O novo estado é então aceito ou não com probabilidade dada pela probabilidade de transição. O conjunto final de valores assim obtidos representa uma amostra de observações da distribuição a posteriori. 


\section{DINÂMICA DO ÍNDICE DE FIXAÇÃO INTRAPOPULACIONAL EM POPULA- ÇÕES FINITAS COM TAXAS VARIÁVEIS DE FECUNDAÇÃO CRUZADA}

\section{Resumo}

O fato de que os valores do índice de fixação intrapopulacional $(f)$ e os das taxas de fecundação cruzada ( $t$ ) mantém uma estreita relação entre si é amplamente conhecido. Resultados das análises de marcadores moleculares em populações naturais têm demonstrado uma elevada variação destes valores para locos diferentes avaliados em uma mesma população, sugerindo que outros fatores, além daqueles descritos no modelo de equilíbrio genético de Wright devem estar operando. Pelo uso de simulações, demonstra-se neste trabalho que a condição finita de uma população é suficiente para que os valores estimados de $f$ passem a se estabilizar ao longo de um intervalo de variação e não mais em um único ponto. Demonstra-se ainda que variações nas taxas de fecundação cruzada ao longo das gerações amplificam substancialmente a magnitude deste intervalo. A correlação entre os valores estimados de $f$ obtidos de locos diferentes nestas condições mostrou-se dependente dos valores das taxas de fecundação cruzada e da magnitude da variância destas taxas entre gerações, podendo ser nula sob condições de panmixia e taxas constantes. Estes resultados sugerem que a condição finita das populações associada a pequenas flutuações na taxa média de fecundação cruzada de diferentes gerações, condições tipicamente encontradas na natureza, podem explicar as discrepâncias entre os valores estimados de $f$ de locos diferentes, comumente reportadas na literatura. Os resultados obtidos indicam ainda a possibilidade de que a magnitude da variância entre os valores estimados de $f$ de diferentes locos forneça uma estimativa do número efetivo de indivíduos reprodutivamente ativos em uma dada população. 


\section{Summary}

[Intrapopulation fixation index dynamics in finite populations with variable outcrossing rates.]

The fact that the values of the intrapopulation fixation index $(f)$ are inversely related to those of the outcrossing rate $(t)$ is widely recognized. Results obtained from molecular markers data from natural populations have shown that these values are highly variable even when measured in the same group of individuals suggesting that other factors, besides those described in Wright's genetic equilibrium, must be operating. Using simulated data we show that the finite size condition of a population is sufficient to spread the estimated $f$ values along a range at equilibrium as opposed to keeping them at the theoretical equilibrium point. We show that variation in outcrossing rates can greatly amplify this range. Correlation between estimated $f$ values obtained from different loci in this condition showed to be negatively related to the outcrossing rates and positively related to the variance of these rates along generations. Results herein suggest that the finite size of populations associated with small fluctuations in $t$ mean values over time may explain the usually reported high variation among estimated $f$ values of different loci.

\subsection{Introdução}

Em populações infinitas, que se reproduzem por panmixia, na ausência de seleção, migração e mutação, as freqüências gênicas e genotípicas se mantém em equilíbrio, e não se alteram ao longo de gerações, mantendo entre si uma relação expressa por: (Crow \& Kimura, 1970)

$$
\left\{\begin{array}{l}
P_{u u}=p_{u}^{2} \\
P_{u v}=2 p_{u} p_{v}
\end{array}\right.
$$

em que:

$$
\begin{aligned}
& p_{u} \quad \text { é a freqüência do alelo } u ; \\
& P_{u u} \quad \text { é a freqüência de homozigotos para o alelo } u ; \\
& P_{u v} \quad \text { é a freqüência de heterozigotos para os alelos } u \text { e } v .
\end{aligned}
$$


Estas condições são conhecidas como condições de equilíbrio de Hardy-Weinberg, tendo sido as expressões apresentadas em (20) publicadas independentemente por G. H. Hardy e W. Weinberg em 1908.

Wright (1921; 1922) demonstrou que o equilíbrio também é alcançado se, mantidas as demais condições de equilíbrio de Hardy-Weinberg, uma população se reproduzir a uma taxa constante de fecundação cruzada $(t)$ e não mais por panmixia. As relações entre as freqüências gênicas e genotípicas são, no entanto, alteradas e passam a ser dadas pelas proporções:

$$
\left\{\begin{array}{l}
P_{u u}=p_{u}^{2}+p_{u}\left(1-p_{u}\right) f \\
P_{u v}=2 p_{u} p_{v}(1-f)
\end{array}\right.
$$

em que $f$ é o índice de fixação intrapopulacional (Wright, 1951; 1965). Estas condições são conhecidas como condições de equilíbrio de Wright e assumem grande importância na caracterização genética de populações naturais por fornecerem não só um parâmetro indicador do grau de estruturação da variabilidade genética ao nível de indivíduos, mas ainda, um mecanismo de se estimar as taxas de fecundação cruzada em condições naturais, dispondo-se de dados de uma única geração (Fyfe \& Bailey, 1951). Isso é possível pelo fato de que, nas condições de equilíbrio de Wright, os valores de $f$ e $t$ mantém entre si uma relação que pode ser expressa por: (Bennet \& Binet, 1956)

$$
f=\frac{1-t}{1+t}
$$

A aplicação em larga escala deste conhecimento, no entanto, teve que aguardar o extraordinário desenvolvimento ocorrido nos últimos anos em termos de técnicas de avaliação genotípica ao nível molecular. O desenvolvimento dos marcadores moleculares ao longo dos últimos 30 anos, e notavelmente nos últimos 20 anos, fez com que houvesse uma verdadeira revolução na capacidade de se realizar a avaliação de genótipos em condições naturais. Estas técnicas viabilizaram a utilização das mais variadas espécies de interesse em estudos genéticos, antes restritos a poucas espécies tomadas como modelo.

Atualmente, são abundantes na literatura trabalhos que apresentam a caracterização genética de populações naturais, muitos dos quais apresentam valores estimados do índice de fixação intrapopulacional com base na informação de diferentes 
locos. A avaliação destes resultados demonstra, em geral, que estes valores são bastante variáveis entre locos em uma determinada população.

Diversos autores têm buscado uma explicação para este fato e, na realidade, há todo um conjunto de fatores que pode ser responsável por este fenômeno. Charlesworth (1991), por exemplo, atribui estas variações aos efeitos do desequilíbrio genotípico presente entre locos em populações de sistema misto de reprodução, com níveis intermediários de endogamia (valores de $f$ entre 0 e 1), associado a diferentes pressões seletivas para diferentes regiões genômicas.

Este trabalho procura avaliar, pelo uso de simulações, os efeitos resultantes da condição finita das populações e da variação nas taxas de fecundação cruzada, entre gerações e entre indivíduos de uma mesma geração, sobre os valores estimados do índice de fixação intrapopulacional.

\subsection{Metodologia}

A fim de que diversas condições pudessem ser simuladas e avaliadas, um programa computacional (disponibilizado pelos autores) baseado em linguagem DelphiPascal foi desenvolvido. As simulações foram realizadas utilizando-se o seguinte algoritmo:

i) atribuir a cada um dos $L$ locos dos $N$ indivíduos um genótipo;

ii) identificar um indivíduo aleatoriamente $(i)$;

iii) atribuir um valor à taxa de fecundação cruzada $(t)$;

iv) obter um número aleatório uniformemente distribuído entre 0 e $1(x)$;

v) se $x<t$ obter um segundo indivíduo aleatoriamente $(j)$, caso contrário, $j=i$;

vi) para cada um dos $L$ locos, tomar um alelo aleatoriamente de $i$ e combinar com um alelo tomado aleatoriamente de $j$;

vii) repetir os passos $i i$ a vi $N$ vezes, constituindo os $N$ indivíduos da geração seguinte;

viii) repetir o passo vii pelo número de gerações desejado. 
Os genótipos iniciais foram obtidos considerando-se as freqüências genotípicas esperadas nas condições de equilíbrio de Hardy-Weinberg, sendo os resultados avaliados após a $20^{\mathrm{a}}$ geração, quando prevalecem as condições de equilíbrio de Wright.

Para fins de estudo, foram avaliados os seguintes fatores:

i) tamanho das populações;

ii) variação nas taxas médias de fecundação cruzada de cada geração;

iii) variação nas taxas de fecundação cruzada de indivíduos de uma mesma geração.

Os efeitos da variação na taxa de fecundação cruzada, tanto entre indivíduos de uma única geração como de gerações diferentes, foram avaliados admitindo que a esta taxa é uma variável aleatória $(t)$, restrita ao intervalo $(0,1)$, com uma função densidade de probabilidade Beta dada por:

$$
\phi(t)=\frac{\Gamma(\alpha+\beta)}{\Gamma(\alpha) \Gamma(\beta)} t^{\alpha-1}(1-t)^{\beta-1}
$$

em que:

$\Gamma(\cdot) \quad$ é a função gama;

$\alpha$ e $\beta \quad$ são parâmetros da distribuição, sendo $\alpha>0$ e $\beta>0$.

De modo que os valores para a média e a variância de $t$ são dadas, respectivamente, por:

$$
\bar{t}=\frac{\alpha}{\alpha+\beta} \quad \operatorname{Var}(t)=\frac{\alpha \beta}{(\alpha+\beta)^{2}(\alpha+\beta+1)}
$$

Os parâmetros $\alpha$ e $\beta$ utilizados nas simulações foram definidos de modo a caracterizar espécies com diferentes sistemas reprodutivos. Assim foram realizadas simulações para condições de espécies tipicamente autógamas $(\bar{t}=0,05)$, de sistema de reprodução misto $(\bar{t}=0,50)$ e tipicamente alógamas $(\bar{t}=0,95)$. Distribuições Beta com variâncias iguais a 0,000025 e 0,0025 foram estabelecidas para cada caso, sendo que para a simulação com $\bar{t}=0,50$ se estabeleceu ainda a condição em que a variância era igual a 0,025 (Figura 1). Em cada caso, os valores de $\alpha$ e $\beta$ foram obtidos a partir dos valores definidos para a média e para a variância de $t$ :

$$
\alpha=\frac{\bar{t}^{2}[1-\bar{t}]}{\operatorname{Var}(t)}-\bar{t} \quad \beta=\frac{\alpha}{\bar{t}}-\alpha
$$


$\operatorname{Var}(t)=0,000025$

$\operatorname{Var}(t)=0,0025$

$\operatorname{Var}(t)=0,025$
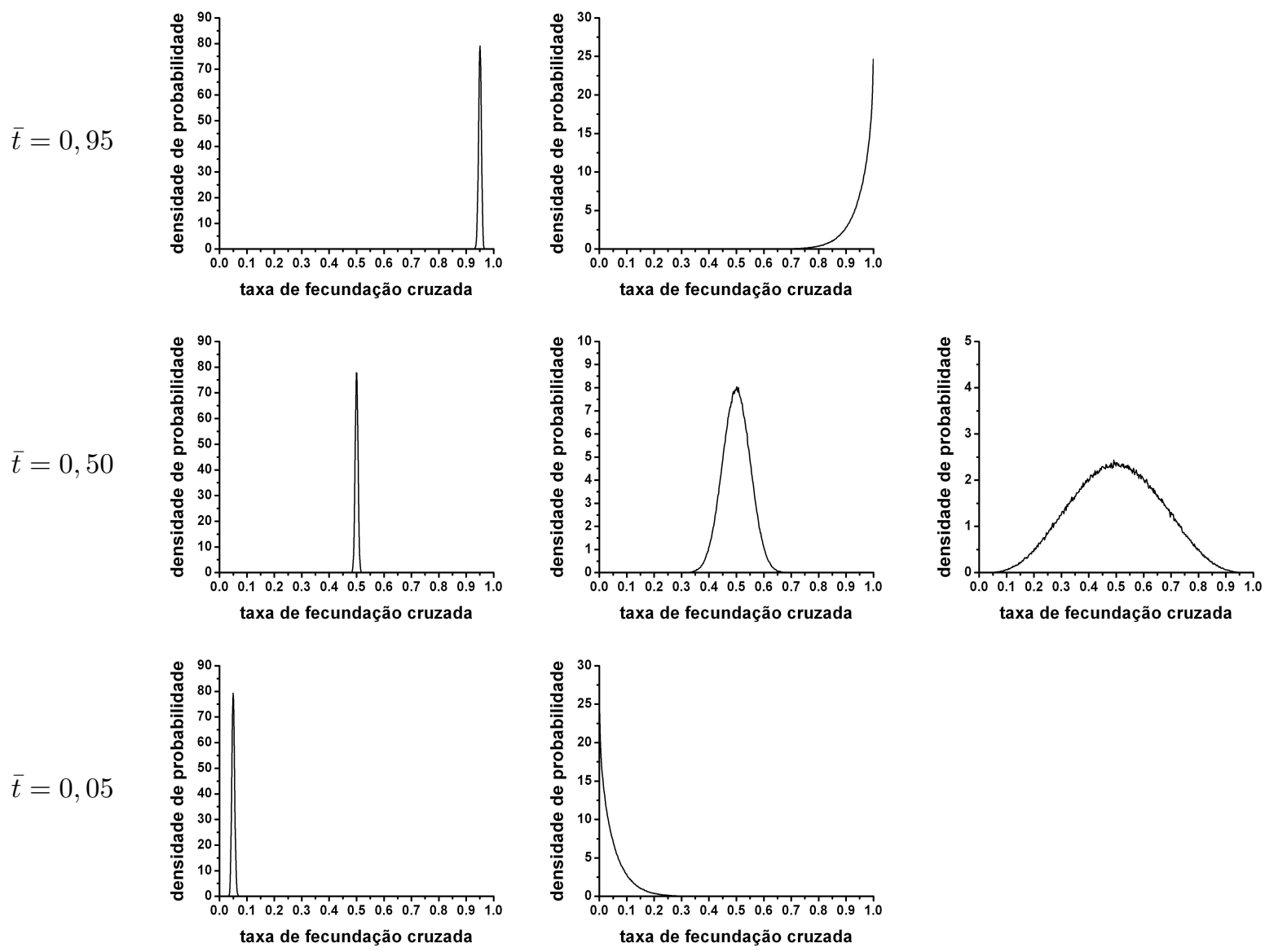

Figura 1 - Distribuições de probabilidade simuladas para diferentes valores atribuídos à média $(\bar{t})$ e à variância $[\operatorname{Var}(t)]$ da taxa de fecundação cruzada.

Os valores simulados para as distribuições Beta foram obtidos segundo procedimento adaptado a partir de Dagpunar (1988).

Considerando o grande tamanho das populações avaliadas, os valores do índice de fixação intrapopulacional foram estimados utilizando-se a expressão:

$$
\hat{f}=\frac{\tilde{h}-\tilde{H}}{\tilde{h}}
$$

em que:

$\tilde{h} \quad$ é a heterozigosidade esperada em condições de equilíbrio de Hardy-Weinberg;

$\tilde{H} \quad$ é a heterozigosidade observada. 


\subsection{Resultados e Discussão}

As Figuras 2, 3 e 4 apresentam os resultados obtidos no que se refere à dinâmica do índice de fixação intrapopulacional nas diferentes condições simuladas. Observa-se que os valores estimados de $f(\hat{f})$ atingem rapidamente a condição de equilíbrio, que em certos casos é representada por um intervalo de variação e não mais por um único ponto. Os valores de $\hat{f}$ obtidos apresentaram uma magnitude de variação crescente para tamanhos populacionais decrescentes, exceção feita à simulação realizada com $t=$ 0,00. A variação na taxa média de fecundação cruzada de diferentes gerações também apresentou uma sensível influência sobre a dinâmica dos valores de $\hat{f}$ obtidos nas simulações, sendo que a magnitude de variação de $\hat{f}$ apresentou-se positivamente associada à variação de $t$. Por outro lado, para as situações em que a taxa de fecundação cruzada foi variável apenas entre indivíduos de uma mesma geração, mantendo-se a média de cada geração constante e um tamanho populacional de 1.000.000 indivíduos, não foi observada uma variação importante nos valores de $\hat{f}$ ao longo das gerações.

As Tabelas 1, 2 e 3 apresentam as estimativas obtidas por simulação para a média e a variância dos valores de $\hat{f}$ ao longo das gerações. Estes resultados sugerem que, nas condições simuladas, a variação nos valores da taxa média de fecundação cruzada $(\bar{t})$ entre gerações exerce uma maior influência no comportamento de $\hat{f}$ do que a variação presente nos valores de $t$ de indivíduos diferentes. A pequena influência da variação nas taxas de fecundação cruzada entre indivíduos de uma mesma geração na dinâmica dos valores de $\hat{f}$ ao longo das gerações deve, no entanto, ser avaliada com cautela. Uma vez evidenciado o efeito da variação na taxa média de fecundação cruzada de diferentes gerações sobre o comportamento de $\hat{f}$, deve-se considerar que em populações de tamanho reduzido a variação ao nível individual de $t$ deve contribuir sensivelmente para o incremento da oscilação dos valores $\bar{t}$, e neste caso, apresentaria um efeito indireto sobre a variância de $\hat{f}$. 

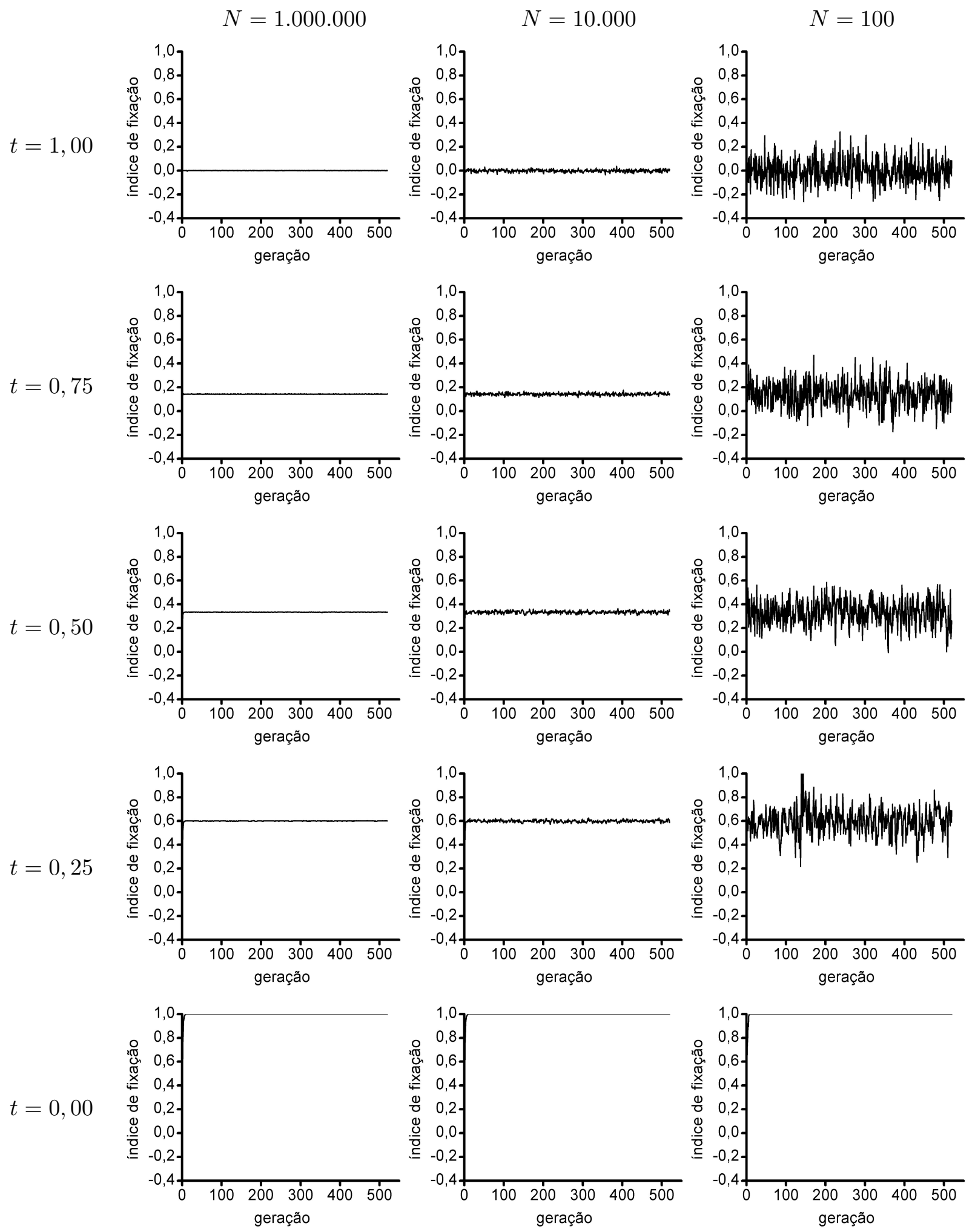

Figura 2 - Valores do índice de fixação intrapopulacional em populações de diferentes tamanhos, com diferentes taxas de fecundação cruzada, ao longo de 520 gerações. 
$\operatorname{Var}(t)=0,000025$

$\operatorname{Var}(t)=0,0025$

$\operatorname{Var}(t)=0,025$
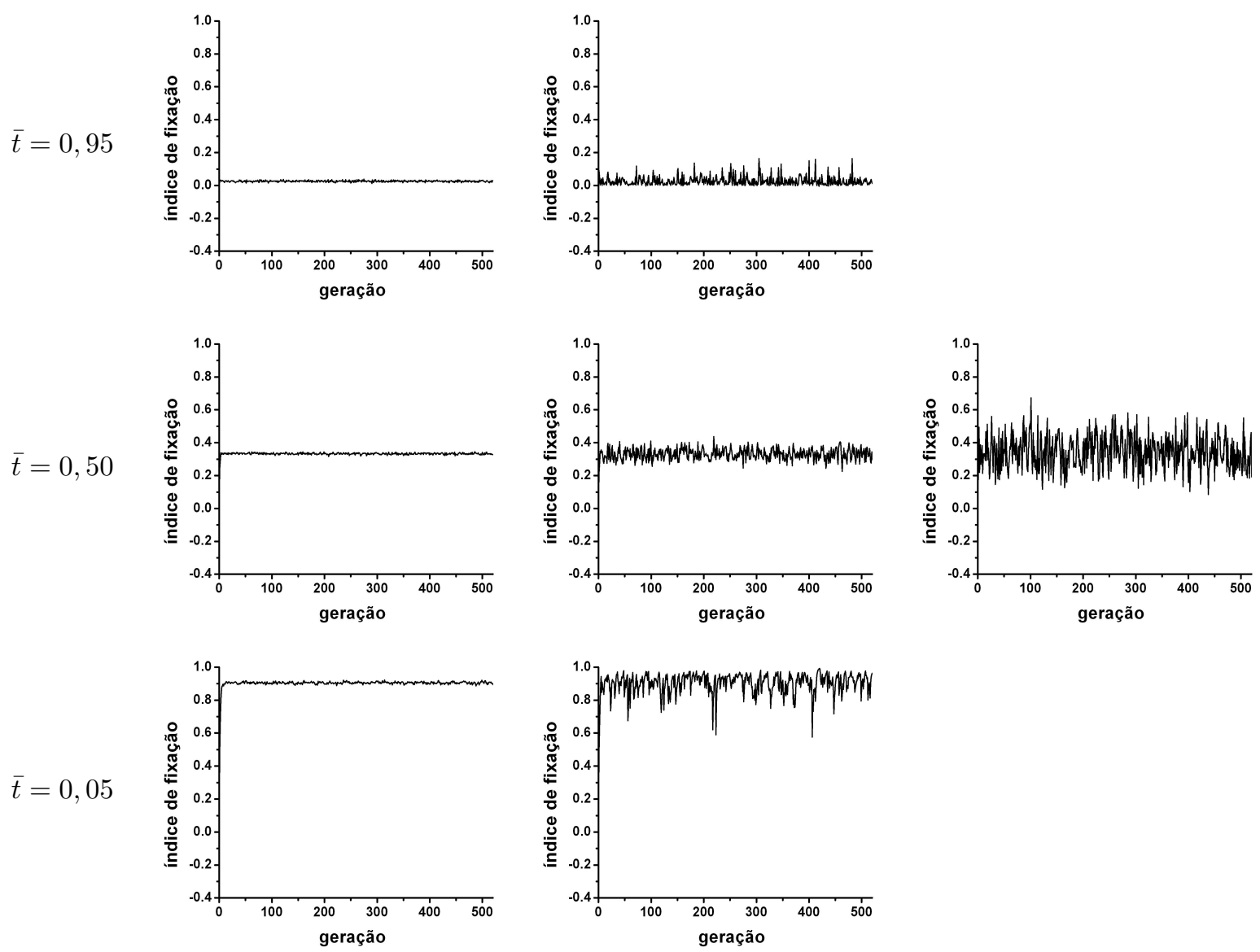

Figura 3 - Valores do índice de fixação intrapopulacional em populações com taxas de fecundação cruzada variáveis entre gerações, com média $\bar{t}$ e variância $\operatorname{Var}(t)$, ao longo de 520 gerações $(N=1.000 .000)$. 


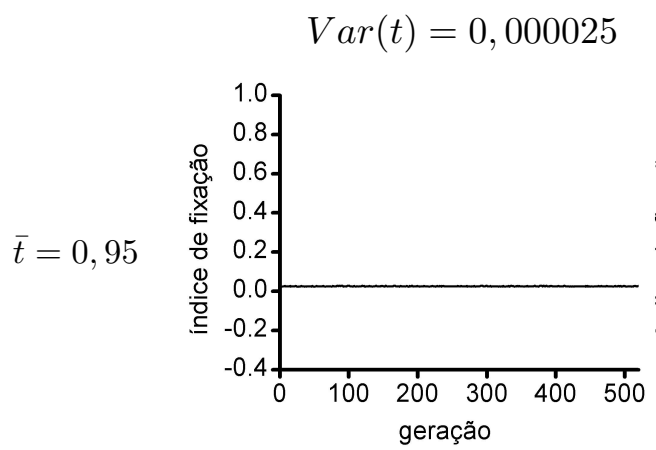

$\operatorname{Var}(t)=0,0025$

$\operatorname{Var}(t)=0,025$
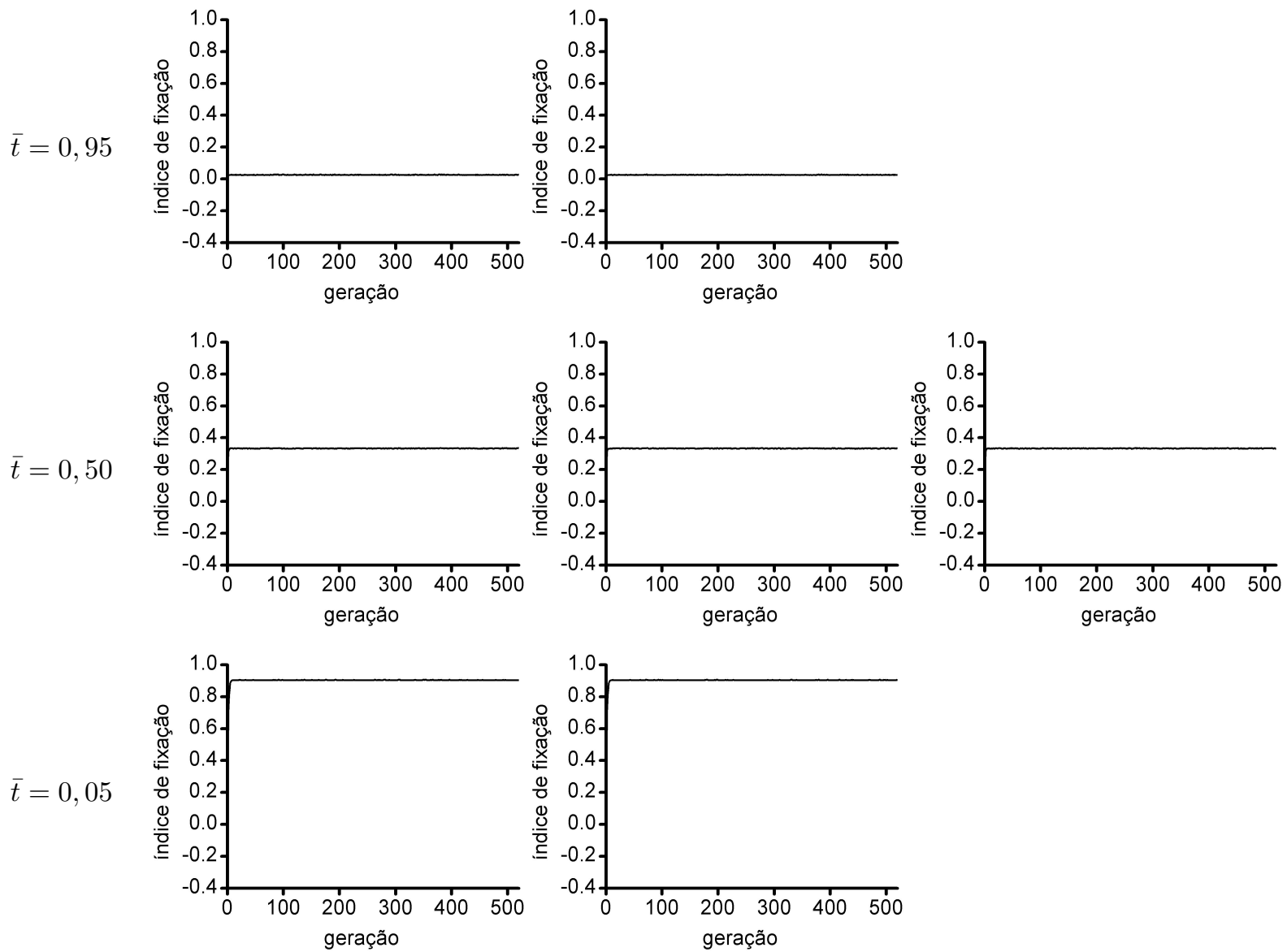

Figura 4 - Valores do índice de fixação intrapopulacional em populações com taxas de fecundação cruzada variáveis entre indivíduos, com média $\bar{t}$ e variância $\operatorname{Var}(t)$, ao longo de 520 gerações $(N=1.000 .000)$. 
Tabela 1. Média $(\overline{\hat{f}})$ e variância $\left(s_{\hat{f}}^{2}\right)$ dos valores estimados do índice de fixação intrapopulacional ao longo de 500 gerações em populações finitas e tamanhos $(N)$ variáveis e diferentes taxas de fecundação cruzada.

\begin{tabular}{rrrrrrr}
\hline & \multicolumn{2}{c}{$N=100$} & \multicolumn{2}{c}{$N=10.000$} & \multicolumn{2}{c}{$N=1.000 .000$} \\
$\bar{t}$ & $\bar{f}^{-}$ & $s_{\hat{f}}^{2}$ & $\bar{f}_{\hat{f}}$ & $s_{\hat{f}}^{2}$ & $s_{\hat{f}}^{2}$ \\
\hline 0,00 & 1,000 & $0,000 \cdot 10^{-2}$ & 1,000 & $0,000 \cdot 10^{-5}$ & 1,000 & $0,000 \cdot 10^{-7}$ \\
0,25 & 0,596 & $1,284 \cdot 10^{-2}$ & 0,600 & $8,262 \cdot 10^{-5}$ & 0,600 & $7,555 \cdot 10^{-7}$ \\
0,50 & 0,330 & $1,124 \cdot 10^{-2}$ & 0,334 & $10,883 \cdot 10^{-5}$ & 0,333 & $9,723 \cdot 10^{-7}$ \\
0,75 & 0,139 & $1,136 \cdot 10^{-2}$ & 0,143 & $9,498 \cdot 10^{-5}$ & 0,143 & $9,425 \cdot 10^{-7}$ \\
1,00 & $-0,006$ & $1,049 \cdot 10^{-2}$ & $-0,001$ & $10,326 \cdot 10^{-5}$ & 0,000 & $10,250 \cdot 10^{-7}$ \\
\hline
\end{tabular}

Tabela 2. Média $(\overline{\hat{f}})$ e variância $\left(s_{\hat{f}}^{2}\right)$ dos valores observados do índice de fixação intrapopulacional ao longo de 500 gerações em populações com taxas médias de fecundação cruzada variáveis entre gerações $(N=1.000 .000)$.

\begin{tabular}{rcccccc}
\hline & \multicolumn{2}{c}{$\operatorname{Var}(t)=0,000025$} & \multicolumn{2}{c}{$\operatorname{Var}(t)=0,0025$} & \multicolumn{2}{c}{$\operatorname{Var}(t)=0,025$} \\
$\bar{t}$ & $\overline{\hat{f}}$ & $s_{\hat{\hat{f}}}^{2}$ & $s_{\hat{f}}^{2}$ & $s_{\hat{f}}^{2}$ \\
\hline 0,05 & 0,904 & $29,864 \cdot 10^{-6}$ & 0,899 & $32,314 \cdot 10^{-4}$ & - & - \\
0,50 & 0,333 & $12,773 \cdot 10^{-6}$ & 0,334 & $11,726 \cdot 10^{-4}$ & 0,336 & $1,167 \cdot 10^{-2}$ \\
0,95 & 0,026 & $7,492 \cdot 10^{-6}$ & 0,024 & $5,724 \cdot 10^{-4}$ & - & - \\
\hline
\end{tabular}

Tabela 3. Média $(\overline{\hat{f}})$ e variância $\left(s_{\hat{f}}^{2}\right)$ dos valores observados do índice de fixação intrapopulacional ao longo de 500 gerações em populações com taxas médias de fecundação cruzada variáveis entre indivíduos $(N=1.000 .000)$.

\begin{tabular}{ccccccc}
\hline & \multicolumn{2}{c}{$\operatorname{Var}(t)=0,000025$} & \multicolumn{2}{c}{$\operatorname{Var}(t)=0,0025$} & \multicolumn{2}{c}{$\operatorname{Var}(t)=0,025$} \\
$\bar{t}$ & $\overline{\hat{f}}$ & $s_{\hat{\hat{f}}}^{2}$ & $s_{\hat{f}}^{2}$ & $s_{\hat{f}}^{2}$ \\
\hline 0,05 & 0,905 & $2,035 \cdot 10^{-7}$ & 0,905 & $2,295 \cdot 10^{-7}$ & - & - \\
0,50 & 0,333 & $9,387 \cdot 10^{-7}$ & 0,333 & $9,839 \cdot 10^{-7}$ & 0,333 & $9,663 \cdot 10^{-7}$ \\
0,95 & 0,026 & $9,849 \cdot 10^{-7}$ & 0,026 & $8,999 \cdot 10^{-7}$ & - & - \\
\hline
\end{tabular}


É importante salientar que a variação detectada nos valores de $\hat{f}$ apresentados não inclui aquela decorrente da amostragem estatística, resultante da avaliação parcial dos indivíduos que compõem as populações. Neste sentido, é interessante observar que mesmo em situações em que a avaliação de todos os indivíduos de uma dada população for possível, deve-se esperar uma oscilação nos valores de $\hat{f}$ de diferentes locos ao longo das gerações, resultante da instabilidade das taxas de fecundação cruzada e dos eventos de amostragem genética de gametas.

A Figura 5 apresenta as distribuições de probabilidade observadas dos valores do índice de fixação intrapopulacional obtidos ao longo das gerações em populações de 10.000 indivíduos, com diferentes taxas de fecundação cruzada. É interessante observar que estas distribuições, obtidas com taxas de fecundação cruzada constantes entre indivíduos e gerações, apresentam forte semelhança com as funções densidade de probabilidade Beta definidas para o intervalo $(0, N)$, com médias iguais aos valores de $t$ simulados e variâncias dadas pela mesma expressão da variância amostral de $\hat{t}$, apresentada em Vencovsky (1994):

$$
\operatorname{Var}(\hat{t})=\frac{4}{(1+f)^{4}} \operatorname{Var}(\hat{f})
$$

sendo

$$
\operatorname{Var}(\hat{f})=\frac{(1-f)^{2}(1-2 f)}{N}+\frac{f(1-f)(2-f)}{2 N p_{u}\left(1-p_{u}\right)}
$$

A função densidade de probabilidade de interesse, expressa em termos de $f$ é dada por:

$$
\phi(\hat{f})=\frac{\Gamma(\alpha+\beta)}{\Gamma(\alpha) \Gamma(\beta)} \frac{\left(\frac{1-\hat{f}}{1+\hat{f}}\right)^{\alpha-1}\left(N-\frac{1-\hat{f}}{1+\hat{f}}\right)^{\beta-1}}{N^{\alpha+\beta-1}}
$$

com parâmetros:

$$
\alpha=\frac{1}{N}\left[\frac{(1-f)^{2}(1+f)^{2}\left(N-\frac{1-f}{1+f}\right)}{4 \cdot \operatorname{Var}(\hat{f})}-\frac{1-f}{1+f}\right] \quad \beta=\frac{N \alpha(1+f)}{1-f}-\alpha
$$

A utilização do intervalo $(0, N)$ se deve ao fato de que os valores de $\hat{f}$ podem ser menores do que zero, fazendo com que os valores de $\hat{t}$ possam ser maiores do que 1 (taxa de fecundação cruzada aparente). 
Tal fato sugere que, nos casos em que a taxa de fecundação cruzada se mantiver relativamente constante ao longo das gerações, o comportamento dos valores de $\hat{f}$ pode ser descrito utilizando-se uma função densidade de probabilidade Beta, definida por parâmetros que são função do tamanho populacional, do valor de $f$ correspondente à taxa de fecundação cruzada e das freqüências alélicas.

A Figura 6 apresenta as distribuições de probabilidade observadas para os valores de $\hat{f}$ obtidos em 10.000 locos avaliados em uma única geração, em populações com 1.000 indivíduos, com diferentes taxas de fecundação cruzada. A figura também apresenta as funções densidade de probabilidade definidas de modo semelhante ao utilizado para descrever o comportamento dos valores de $\hat{f}$ em diferentes gerações. É importante salientar que embora dados de diferentes gerações sejam raros na literatura, as informações disponíveis para diferentes locos poderiam fornecer uma estimativa do número efetivo de indivíduos reprodutivamente ativos em uma dada população $(N)$.
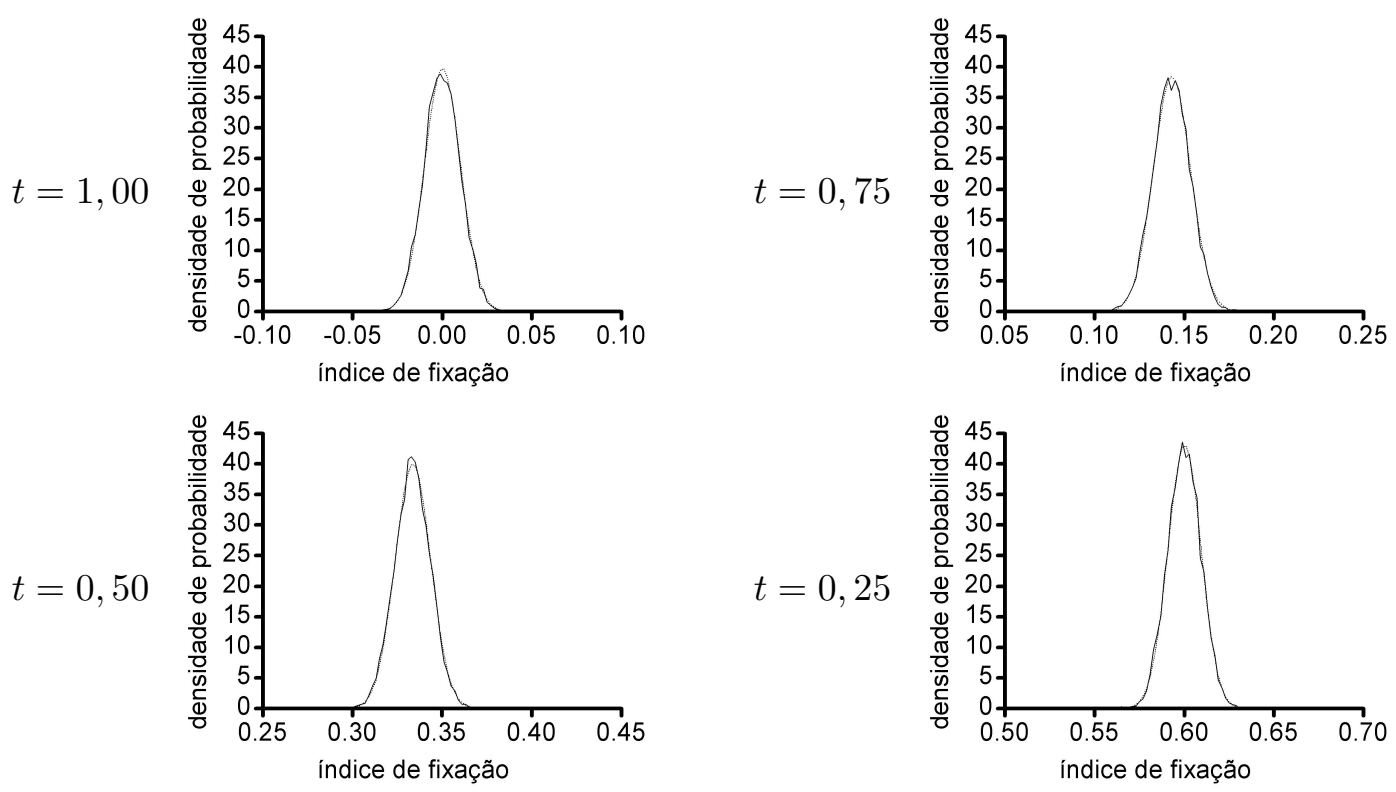

Figura 5 - Distribuições de probabilidade observadas dos valores do índice de fixação intrapopulacional em populações de 10.000 indivíduos, com diferentes taxas de fecundação cruzada, ao longo de 10.000 gerações. A título de comparação, são também apresentadas as funções densidade de probabilidade Beta correspondentes. 

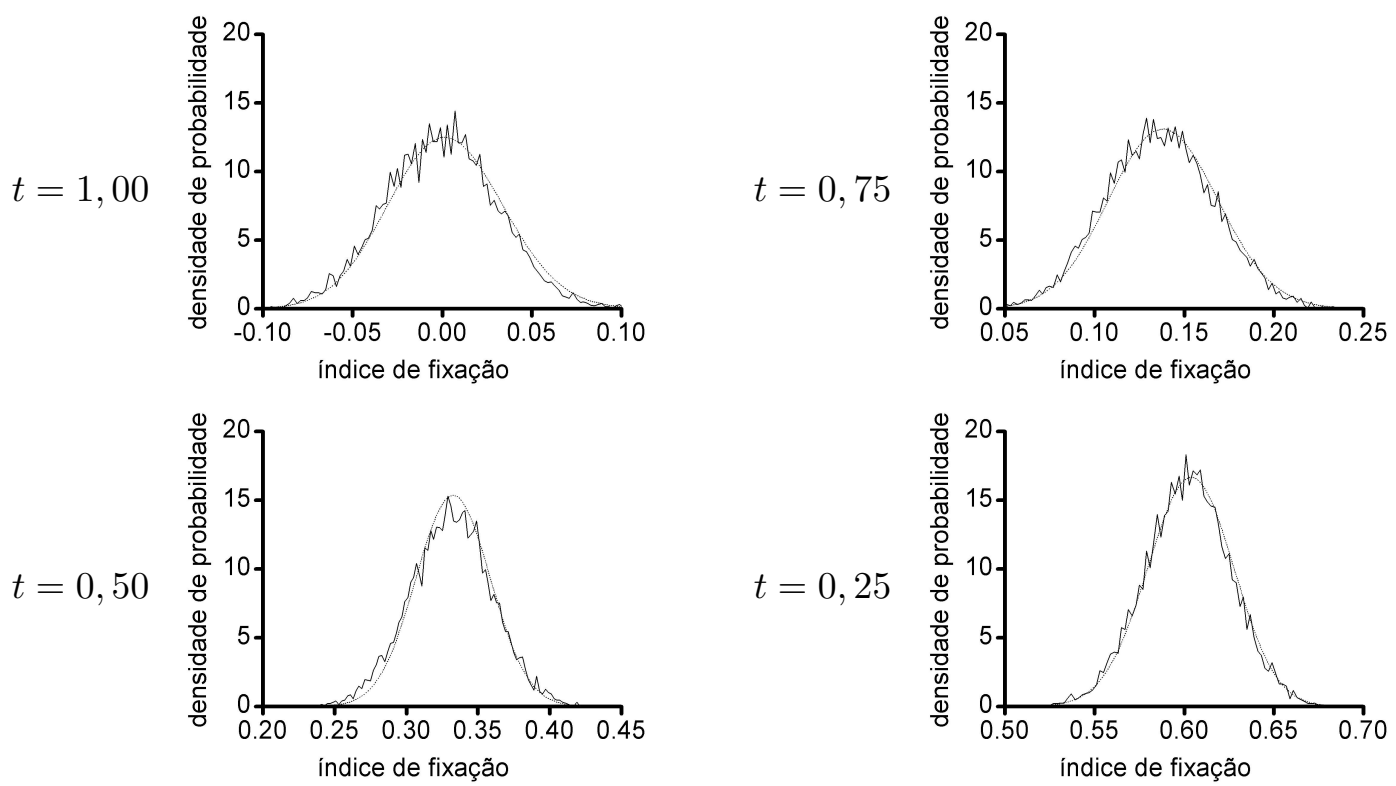

Figura 6 - Distribuições de probabilidade observadas dos valores do índice de fixação intrapopulacional em 10.000 locos de uma população de 1.000 indivíduos, com diferentes taxas de fecundação cruzada. A título de comparação, são também apresentadas as funções densidades de probabilidade Beta correspondentes.

A Figura 7 apresenta valores preditos e observados da variância de $\hat{f}$ entre locos em diferentes situações. Em termos práticos, é importante considerar que a variância dos valores de $\hat{f}$ em questão, não inclui os efeitos resultantes da amostragem estatística, podendo ser melhor interpretada como sendo o componente de variância dos valores de $\hat{f}$ associado a diferentes locos, do que o quadrado médio dos valores amostrais estimados de $\hat{f}$.

As estimativas dos coeficientes de correlação entre os valores de $\hat{f}$ obtidos para diferentes locos ao longo das gerações estão representadas na Figura 8. Observa-se que a magnitude da correlação entre os valores de $\hat{f}$ em locos diferentes ao longo das gerações decresce com o aumento da taxa de fecundação cruzada, atingindo valores próximos a zero sob panmixia. A variação na taxa média de fecundação cruzada ao longo das gera- 
$p=0,50$

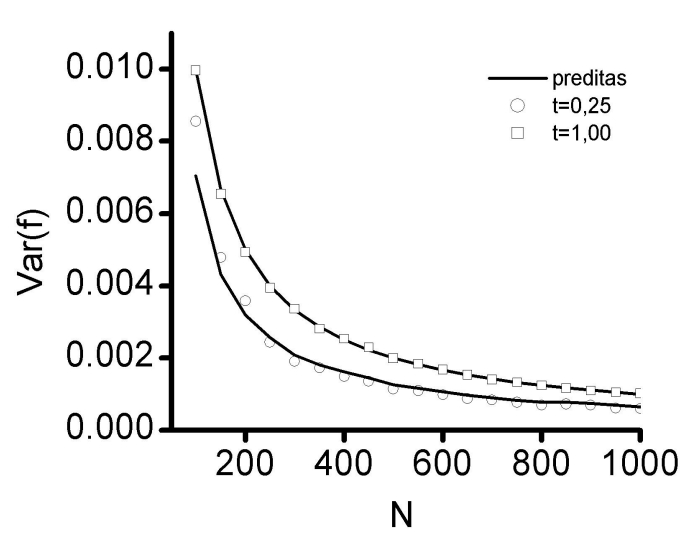

$t=0,75$

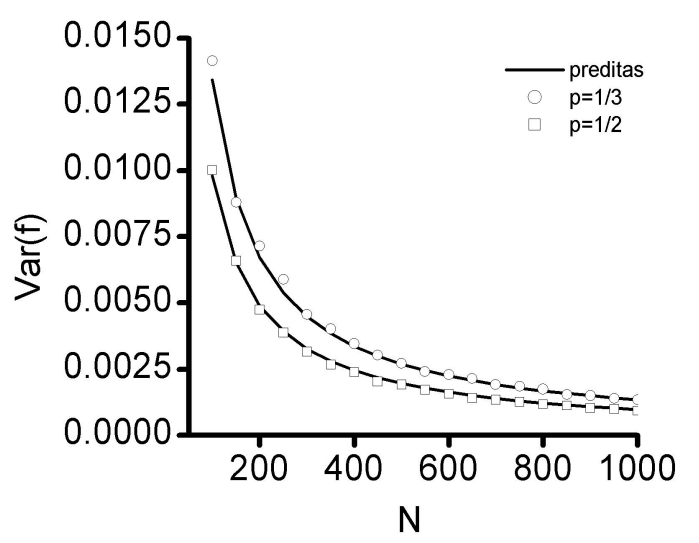

Figura 7 - Valores preditos e observados da variância do índice de fixação intrapopulacional $[\operatorname{Var}(\hat{f})]$ entre locos, avaliados em uma única geração de populações com diferentes valores de taxa de fecundação cruzada $(t)$, freqüência alélica $(p)$ e tamanhos populacionais $(N)$. Valores obtidos a partir de 10.000 locos.

ções, por sua vez, exerce um sensível efeito positivo sobre esta correlação. A Figura 9 ilustra este efeito. Na simulação com uma população de 10.000 indivíduos, com taxa de fecundação cruzada constante e igual a 0,95 , a correlação entre os valores de $\hat{f}$ de locos diferentes foi próxima a zero. A inclusão da variância nas taxas médias ao longo das gerações aumentou a variância de $\hat{f}$ em cerca de 9 vezes, ao mesmo tempo em que fez com que a correlação entre os valores de $\hat{f}$ de locos diferentes subisse a cerca de 0,88 . Tal fato sugere que a variância nas taxas médias de fecundação cruzada entre gerações promove uma maior homogeneidade dos valores de $\hat{f}$ de diferentes locos em uma dada geração, ao mesmo tempo em que diminui a estabilidade destes valores ao longo das gerações.

Do ponto de vista prático, estes resultados sugerem que a condição de tamanho finito das populações, quando associada a uma pequena variação nas taxas de fecundação cruzada, deve ocasionar uma elevada variação nos valores do índice de fixação intrapopulacional de diferentes locos em uma dada geração. Populações pequenas, da ordem de dezenas de indivíduos, e variações nas taxas de fecundação cruzada são condições tipicamente encontradas na natureza e a ação resultante destes fatores podem estar contribuindo para a elevada magnitude de variação nos valores de $\hat{f}$ entre locos avaliados em uma mesma população, comumente reportada na literatura. 
Como uma observação final, é importante ressaltar que os resultados apresentados evidenciam a dificuldade em se realizar uma boa caracterização dos valores do índice de fixação intrapopulacional pelo uso de estimativas pontuais. A presença de uma condição de equilíbrio dinâmico certamente poderia ser melhor caracterizada através de uma abordagem probabilística em que as probabilidades de ocorrência dos diferentes valores de $\hat{f}$ pudessem ser avaliadas. Sem perda de informação, uma abordagem desta natureza nos possibilitaria não só avaliar os valores médios de $\hat{f}$ mas também a sua instabilidade, que parece ser típica em condições naturais.

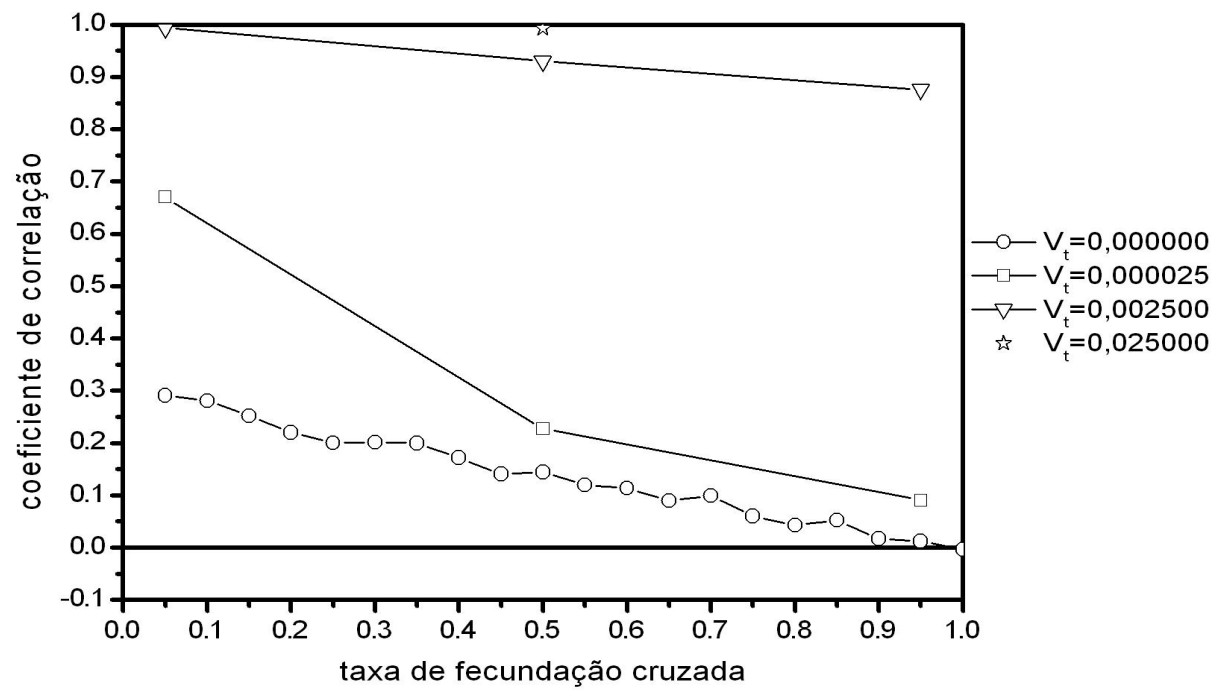

Figura 8 - Coeficientes de correlação observados entre valores de $\hat{f}$ de diferentes locos ao longo de 1.000 gerações de populações com diferentes valores de média e variância das taxas de fecundação cruzada ao longo das gerações $(\mathrm{N}=10.000)$. 
$\operatorname{Var}(t)=0,0000$
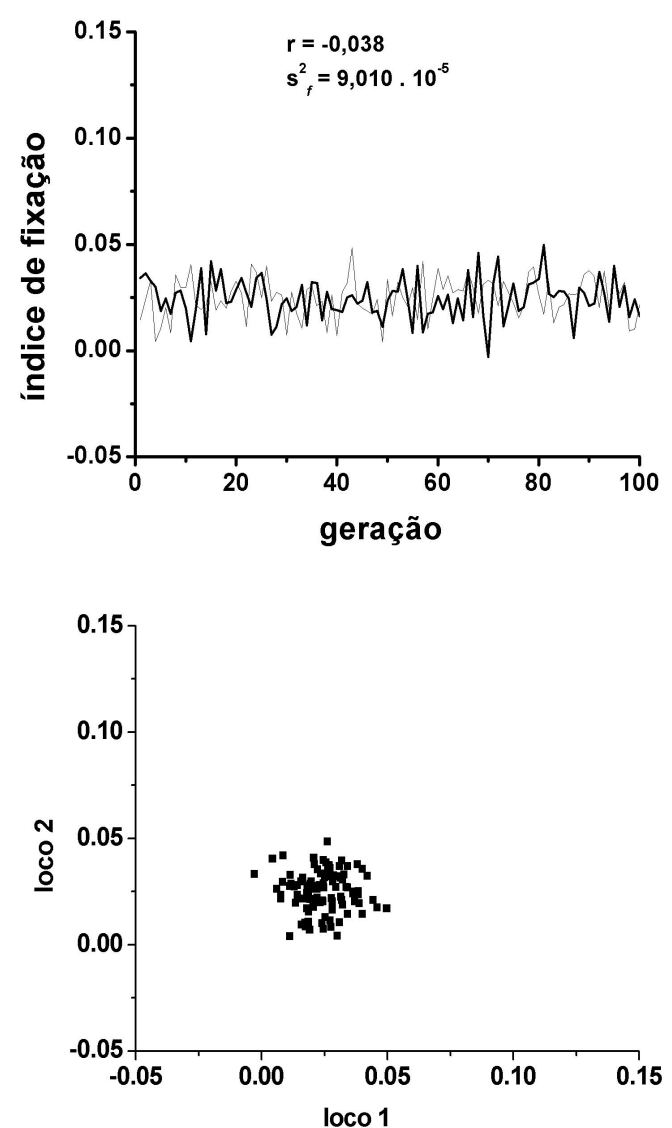

$\operatorname{Var}(t)=0,0025$
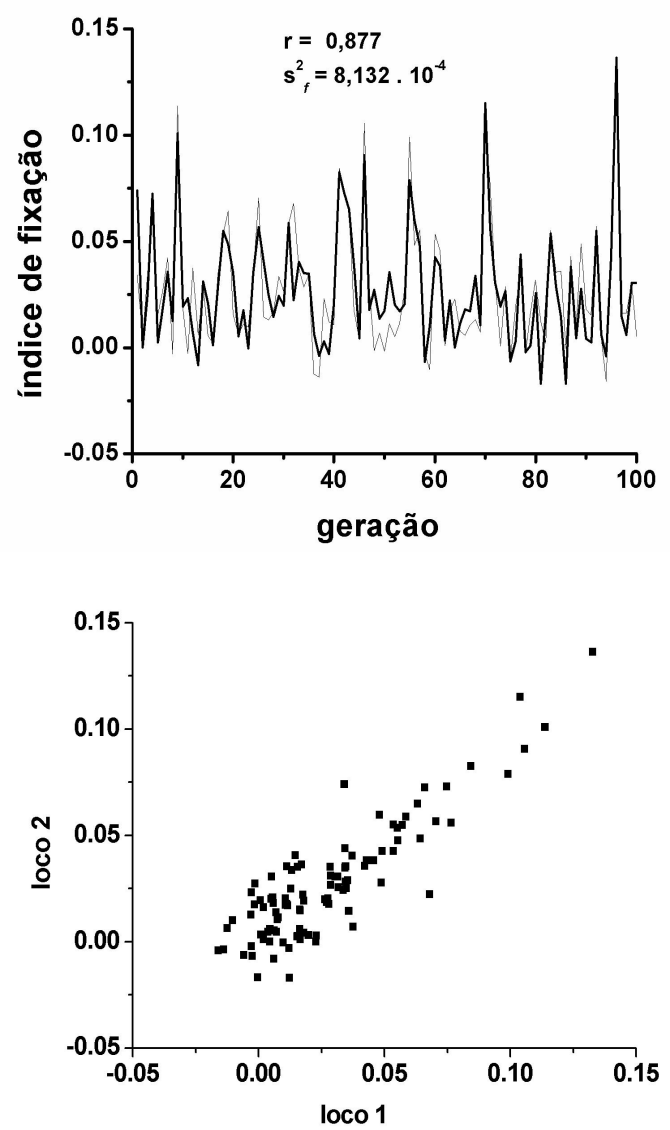

Figura 9 - Dinâmica do índice de fixação intrapopulacional em dois locos de duas populações de mesmo tamanho $(N=10.000)$, mesma taxa média de fecundação cruzada $(\bar{t}=0,95)$ mas diferentes valores da variância de $t$ entre gerações. 


\subsection{Conclusões}

Os resultados apresentados nos permitem concluir que:

a) os valores estimados do índice de fixação intrapopulacional apresentam comportamento dinâmico nas condições de equilíbrio, que é fortemente influenciado pelo tamanho da população e pela variação nas taxas de fecundação cruzada médias ao longo das gerações;

b) em populações finitas, com taxas médias de fecundação cruzada variáveis entre gerações, os valores estimados do índice de fixação intrapopulacional não mais se estabilizam em um único ponto e passam a oscilar ao longo de um intervalo;

c) a correlação entre os valores de $\hat{f}$ de locos diferentes, na ausência de variação nas taxas médias de fecundação cruzada entre gerações é baixa, podendo ser nula na condição de panmixia;

d) a ocorrência de variação na taxa média de fecundação cruzada ao longo das gerações aumenta a magnitude do intervalo de variação dos valores de $\hat{f}$ na condição de equilíbrio, ao mesmo tempo em que aumenta a correlação entre estes valores em locos diferentes;

e) a instabilidade dos valores de $\hat{f}$ de diferentes locos avaliados em uma mesma população, comumente relatada na literatura, pode ser explicada pela condição finita das populações naturais associada a uma pequena instabilidade das taxas de fecundação cruzada ao longo das gerações. 


\section{ESTIMAÇÃO DO ÍNDICE DE FIXAÇÃO INTRAPOPULACIONAL UTILIZAN- DO A INFORMAÇÃO DE MÚLTIPLOS LOCOS NÃO LIGADOS - UMA ABOR- DAGEM BAYESIANA}

\section{Resumo}

Dentre os diversos aspectos geralmente observados na caracterização genética de populações naturais de espécies vegetais, a avaliação do grau de estruturação da variabilidade genética entre e dentro dos indivíduos assume grande importância. $O$ parâmetro de maior interesse neste caso é o índice de fixação intrapopulacional $(f)$, definido como sendo a correlação entre as freqüências alélicas em gametas de um mesmo indivíduo. Empregando uma abordagem Bayesiana, este artigo propõe a utilização de uma metodologia de estimação do índice de fixação intrapopulacional em que a informação proveniente de múltiplos locos não ligados é considerada simultaneamente. Apresentase um modelo hierárquico no qual os valores do índice de fixação de locos diferentes $\left(f_{i}\right)$ são considerados como sendo variáveis aleatórias e dependentes de um conjunto de hiperparâmetros definidos como uma função do sistema reprodutivo predominante na população. Admitindo que os valores $f_{i}$ de diferentes locos seguem uma distribuição relacionada a uma função densidade de probabilidade Beta, o algoritmo de MetropolisHastings é empregado na obtenção das distribuições a posteriori. Sob a hipótese de que as taxas médias de fecundação cruzada são constantes ao longo das gerações e entre indivíduos, a metodologia proposta fornece um procedimento de estimação para o número efetivo de indivíduos reprodutivamente ativos em uma população. A título de exemplo, a metodologia é aplicada a dados reais de marcadores moleculares codominantes e a dados simulados. Os resultados ilustram a aplicabilidade da metodologia e confirmam o grande potencial de utilização da estatística Bayesiana em estudos de genética de populações. 


\section{Summary}

[Estimation of the intrapopulation fixation index using information from multiple unlinked loci - A Bayesian approach.]

Among the various aspects generally considered in the genetic characterization of natural populations of plant species, the evaluation of the degree of genetic structure within and among individuals are of great importance. The main focus in this case is on the intrapopulation fixation index $(f)$, defined as the correlation of allele frequencies in gametes from the same individual. Using a Bayesian approach, a method for estimating the intrapopulation fixation index based on multiple unlinked loci information is proposed. A hierarchical model structure is suggested, the fixation indexes values from different loci $\left(f_{i}\right)$ being taken as random variables, dependent on hyperparameters defined as functions of the population main reproductive system. Admitting that the $f_{i}$ values follow a distribution related to the Beta distribution, a Monte Carlo Markov-Chain algorithm is applied to obtain the posteriori distributions of interest. Under the hypothesis of the mean outcrossing rates being constant over generations and individuals, the proposed method furnishes an estimation procedure for the effective number of reproductively active individuals in a population. Examples using real and simulated data from codominant molecular markers are presented. Results obtained illustrate the applicability of the proposed methods and reveal the great potential of use of Bayesian statistics in population genetic studies.

\subsection{Introdução}

Dentre os diversos aspectos geralmente observados na caracterização genética de populações naturais, a avaliação do grau de estruturação da variabilidade genética entre e dentro dos indivíduos assume grande importância. O estudo do modo com que os genes estão distribuídos nos indivíduos é relevante não só por fornecer subsídios para um melhor conhecimento acerca do sistema reprodutivo vigente em uma determinada espécie, mas por resultar na obtenção de informações básicas que são úteis para o estabelecimento de estratégias mais seguras de coleta e conservação da variabilidade genética.

O parâmetro de maior interesse neste caso é o índice de fixação intrapo- 
pulacional, definido por Wright (1922) como estatística $F_{I S}$, correspondente à correlação entre as freqüências alélicas em genes de um mesmo indivíduo. Outras definições são ainda encontradas na literatura, incluindo aquelas que tratam o índice de fixação como uma medida de endogamia como a de Malécot (1948) em que o valor $f$ representa a probabilidade de que os dois alelos de um mesmo indivíduo sejam idênticos por descendência e a de Cockerham (1969) que define $f$ como sendo o coeficiente de correlação intraclasse entre freqüências alélicas em genes de um mesmo indivíduo.

Conforme salienta Weir (1996), os valores de $f$ podem ser nulos, como no caso de locos em equilíbrio de Hardy-Weinberg, positivos, como no caso de locos em equilíbrio de Wright (equilíbrio resultante das mesmas condições que levam ao equilíbrio de Hardy-Weinberg, exceção feita às taxas de fecundação cruzada, que podem ser menores do que 1,0) ou ainda negativos, como no caso de locos sob seleção favorável aos heterozigotos. O limite inferior dos valores de $f$ é, de modo geral, determinado pela magnitude da menor das freqüências alélicas $\left(p_{\min }\right)$ do loco em questão:

$$
f>\frac{-p_{\min }}{1-p_{\min }}
$$

Bennet \& Binet (1956) demonstram que, nas condições em que os pressupostos de equilíbrio de Wright são válidos, existe uma relação entre o valor da taxa de fecundação cruzada $(t)$ e o valor do índice de fixação intrapopulacional $(f)$, dada por:

$$
f=\frac{1-t}{1+t}
$$

Sendo que nesta condição, $0 \leq f \leq 1$. Esta relação tem permitido a diversos autores o acesso a estimativas de taxas de fecundação cruzada pelo uso de marcadores moleculares codominantes em populações naturais, dispondo-se de dados de uma única geração, procedimento inicialmente sugerido por Fyfe \& Bailey (1951).

Embora o procedimento de estimação dos valores de $f$ tenha atraído a atenção de muitos pesquisadores desde os primórdios dos estudos de genética de populações, um estimador com características ótimas (com variância mínima e ausência de viés, mesmo em amostras pequenas) ainda não foi obtido. Dentre os diversos estimadores de $f$ propostos na literatura, muitos conduzem a resultados muito próximos, como é o caso de parte daqueles revistos por Li \& Horvitz (1953). Outros estimadores com propriedades 
estatísticas melhor definidas foram obtidos pelo uso de diferentes métodos de estimação e são apresentados, por exemplo, em Nei \& Chesser (1983), Robertson \& Hill (1984) e Weir (1996).

Alternativas utilizando a abordagem Bayesiana para este problema foram propostas por Pereira \& Rogatko (1984), Shoemaker et al. (1998) e Ayres \& Balding (1998). Conforme salientam Shoemaker et al. (1999), a abordagem da estatística Bayesiana ao utilizar um paradigma diferente do denominado clássico, freqüentista ou padrão, apresenta vantagens por permitir a avaliação de várias hipóteses alternativas simultaneamente (por exemplo, diferentes valores de $f$ ) e por fornecer um mecanismo que possibilita a incorporação de informações prévias ao procedimento de estimação.

É importante considerar que o grande avanço nas técnicas de avaliação genotípica ocorrido nos últimos anos delineou um cenário em que geralmente se dispõem de informações referentes a múltiplos locos. Estes locos, representados por marcadores genéticos baseados em polimorfismos bioquímicos e moleculares, em geral são considerados como neutros e estando sob efeito das mesmas forças evolutivas. Tal hipótese sugere a idéia de que estes locos poderiam ser caracterizados em conjunto, principalmente se considerado o fato de que o uso da informação proveniente de múltiplos locos resultaria em estimativas com maior grau de precisão.

Embora a informação de múltiplos locos possa, em geral, ser facilmente combinada para fornecer estimativas médias de $f$, modelos probabilísticos multilocos só foram explicitamente sugeridos por Ayres \& Balding (1998).

Um aspecto geralmente não explicitado em todas estas abordagens é o fato de que somente locos polimórficos são utilizados para a estimação de $f$. A não inclusão de locos monomórficos decorre do fato de que freqüências genotípicas destes locos são completamente não informativas no que diz respeito à estimação de $f$. Embora este procedimento de modo geral não traga problemas, em amostras pequenas a não observância desta condicionalidade traz conseqüências negativas ao processo de estimação.

A título de exemplo, consideremos o caso de um único loco $(A)$ com dois alelos $\left(A_{1}\right.$ e $\left.A_{2}\right)$ em uma dada população infinita. Podemos denotar as probabilidades de que o genótipo de um dado indivíduo $i\left(g_{i}\right)$, de uma amostra aleatória de tamanho $n$ desta população, seja igual a $A_{1} A_{1}, A_{1} A_{2}$ e $A_{2} A_{2}$ por $P_{11}, P_{12}$ e $P_{22}$, respectivamente. 
Neste caso, a probabilidade $(w)$ de que uma amostra de tamanho $n$ desta população seja polimórfica para o referido loco é dada por:

$$
w=1-P_{11}^{n}-P_{22}^{n}
$$

sendo $P_{11}^{n}+P_{22}^{n}$ a probabilidade de ocorrência de uma amostra monomórfica nesta condição. As probabilidades de ocorrência dos genótipos $A_{1} A_{1}, A_{1} A_{2}$ e $A_{2} A_{2}$, condicionais ao monomorfismo são dadas por:

$$
\left\{\begin{array}{l}
\operatorname{Pr}\left(g_{i}=A_{1} A_{1} \mid \text { monomorfismo }\right)=\frac{P_{11}^{n}}{P_{11}^{n}+P_{22}^{n}} \\
\operatorname{Pr}\left(g_{i}=A_{1} A_{2} \mid \text { monomorfismo }\right)=0 \\
\operatorname{Pr}\left(g_{i}=A_{2} A_{2} \mid \text { monomorfismo }\right)=\frac{P_{22}^{n}}{P_{11}^{n}+P_{22}^{n}}
\end{array}\right.
$$

em que $\operatorname{Pr}(A \mid B)$ representa a probabilidade de condicional de ocorrência do evento $A$ em relação a $B$, ou seja, denota a probabilidade de ocorrência do evento $A$, dada a ocorrência do evento $B$.

Assim, se $w$ e $1-w$ são as probabilidades de que amostras de tamanho $n$ sejam polimórficas e monomórficas, respectivamente, para o referido loco, pode-se escrever:

$$
\left\{\begin{array}{l}
P_{11}=w \cdot \operatorname{Pr}\left(g_{i}=A_{1} A_{1} \mid \text { polimorfismo }\right)+(1-w) \frac{P_{11}^{n}}{P_{11}^{n}+P_{22}^{n}} \\
P_{12}=w \cdot \operatorname{Pr}\left(g_{i}=A_{1} A_{2} \mid \text { polimorfismo }\right) \\
P_{22}=w \cdot \operatorname{Pr}\left(g_{i}=A_{2} A_{2} \mid \text { polimorfismo }\right)+(1-w) \frac{P_{22}^{n}}{P_{11}^{n}+P_{22}^{n}}
\end{array}\right.
$$

e conseqüentemente,

$$
\left\{\begin{array}{l}
\operatorname{Pr}\left(g_{i}=A_{1} A_{1} \mid \text { polimorfismo }\right)=\frac{P_{11}-(1-w) \frac{P_{11}^{n}}{P_{11}^{n}+P_{22}^{n}}}{w} \\
\operatorname{Pr}\left(g_{i}=A_{1} A_{2} \mid \text { polimorfismo }\right)=\frac{P_{12}}{w} \\
\operatorname{Pr}\left(g_{i}=A_{2} A_{2} \mid \text { polimorfismo }\right)=\frac{P_{22}-(1-w) \frac{P_{22}^{n}}{P_{11}^{n}+P_{22}^{n}}}{w}
\end{array}\right.
$$

ou ainda,

$$
\left\{\begin{array}{l}
\operatorname{Pr}\left(g_{i}=A_{1} A_{1} \mid \text { polimorfismo }\right)=\frac{P_{11}-P_{11}^{n}}{w} \\
\operatorname{Pr}\left(g_{i}=A_{1} A_{2} \mid \text { polimorfismo }\right)=\frac{P_{12}}{w} \\
\operatorname{Pr}\left(g_{i}=A_{2} A_{2} \mid \text { polimorfismo }\right)=\frac{P_{22}-P_{22}^{n}}{w}
\end{array}\right.
$$


A partir destas expressões podem ser obtidas aquelas referentes às probabilidades de que o gene $j$ de um indivíduo $i$ de uma amostra polimórfica de tamanho $n$ desta população seja igual a $A_{1}$ e $A_{2}$, respectivamente:

$$
\left\{\begin{array}{l}
P\left(g_{i j}=A_{1} \mid \text { polimorfismo }\right)=\frac{p_{1}-P_{11}^{n}}{w} \\
P\left(g_{i j}=A_{2} \mid \text { polimorfismo }\right)=\frac{p_{2}-P_{22}^{n}}{w}
\end{array}\right.
$$

em que $p_{1}$ e $p_{2}$ são as probabilidades de ocorrência dos alelos $A_{1}$ e $A_{2}$ na população.

Utilizando as conhecidas expressões de Wright para as freqüências genotípicas dadas por:

$$
\left\{\begin{array}{l}
P_{11}=p_{1}^{2}+p_{1} p_{2} f \\
P_{12}=2 p_{1} p_{2}(1-f) \\
P_{22}=p_{2}^{2}+p_{1} p_{2} f
\end{array}\right.
$$

pode-se demonstrar que o valor do índice de fixação intrapopulacional subjacente ao conjunto de amostras polimórficas da população $\left(f^{*}\right)$ mantém uma relação com o valor de $f$ populacional que pode ser expressa por:

$$
\frac{\left(p_{1}-P_{11}^{n}\right)\left(p_{2}-P_{22}^{n}\right)}{w}\left(1-f^{*}\right)=p_{1} p_{2}(1-f)
$$

Obviamente, $w$ tende a 1,0 na medida em que $n$ tende a infinito, mas para amostras muito pequenas o seu desvio em relação a 1,0 pode ser importante, notoriamente quando os valores de $p_{1}$ e $p_{2}$ se afastam de 0,5. Se tivéssemos, por exemplo, $n=5$, $p_{1}=0,05$ e $f=0,15$ teríamos um valor para $f^{*}$ igual a 0,07 . A Figura 10 apresenta a relação entre os valores de $f^{*}$ para diferentes freqüências alélicas e um valor de $f$ igual a 0,05 .

Neste contexto, o presente trabalho se propõe a formular um modelo de análise que permita a utilização da informação obtida de múltiplos locos para se obter uma estimativa do índice de fixação intrapopulacional, levando-se em conta, ao mesmo tempo, a condicionalidade do processo de estimação ao polimorfismo dos locos analisados. 


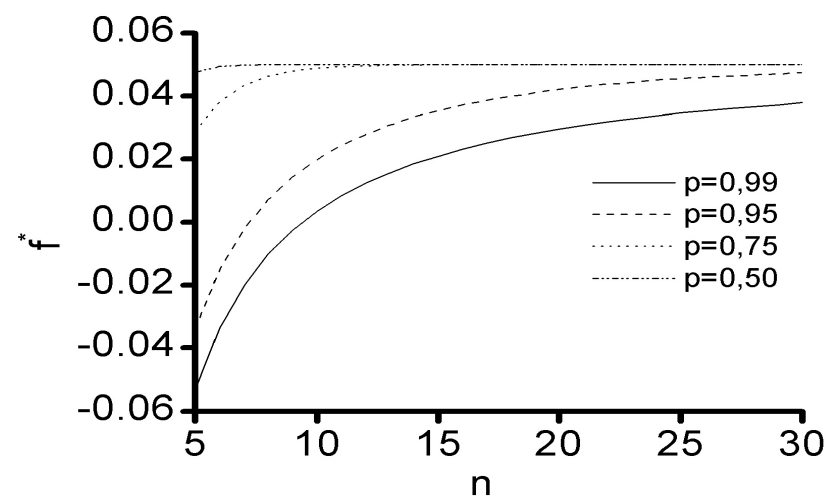

Figura 10 - Valores do índice de fixação intrapopulacional, condicionais ao polimorfismo, para diferentes tamanhos amostrais e freqüências alélicas populacionais.

\subsection{O Modelo Bayesiano}

A abordagem Bayesiana a ser utilizada neste caso, em conformidade com o ponto de vista de Shoemaker et al. (1998), consiste em se obter uma distribuição de probabilidade, associada aos diferentes valores que o parâmetro de interesse pode assumir, de modo a representar o grau de credibilidade associado a cada um deles, dado o conjunto de dados observado. O ponto de partida é uma função densidade de probabilidade, dita a priori, obtida de considerações anteriores à observação dos genótipos. Esta função densidade de probabilidade pode então ser atualizada pela utilização do teorema de Bayes, de modo que as informações contidas nas observações possam exercer sua influência.

Seja $\phi(\theta)$ a função densidade de probabilidade a priori associada a um vetor de parâmetros $(\theta)$. A função densidade de probabilidade a posteriori condicional ao conjunto de dados observados $(X)$, neste caso é expressa por:

$$
\phi(\theta \mid X)=\frac{\phi(\theta) \cdot \phi(X \mid \theta)}{\phi(X)}
$$

A função densidade de probabilidade $a$ priori a ser adotada deve refletir necessariamente o grau de conhecimento disponível acerca dos parâmetros de interesse. É interessante observar que a expressão $\phi(X \mid \theta)$ refere-se à função que descreve a probabilidade de ocorrência dos dados condicional aos valores dos parâmetros que $\operatorname{compõem~} \theta$, e, em termos práticos, tem a mesma forma da função de verossimilhança dos parâmetros.

Diversos métodos têm sido empregados na obtenção das distribuições de 
probabilidade a posteriori $\phi(\theta \mid X)$, incluindo aqueles que, por utilizarem funções densidade de probabilidade a priori adequadas, fornecem expressões algébricas explícitas, como em Shoemaker et al. (1998), e aqueles que obtém distribuições de probabilidade empíricas baseadas em algoritmos de randomização via Cadeias de Markov, como o de Metropolis-Hastings, utilizado em Ayres \& Balding (1998).

Conforme salientam Baldi \& Brunak (1999), o algoritmo de MetropolisHastings, utilizado para a obtenção da distribuição marginal a posteriori de $\theta$ exige somente que a função de verossimilhança seja expressa algebricamente. A função de densidade de probabilidade a priori $\phi(\theta)$ é levada em consideração na obtenção dos estados sugeridos da Cadeia de Markov, enquanto que a expressão algébrica da função $\phi(X)$ não é exigida.

\subsubsection{Modelo Probabilístico de Análise de Locos Individuais}

O modelo aqui descrito para a análise de locos individuais difere daquele apresentado em Ayres \& Balding (1998) por levar em consideração o fato de que somente locos polimórficos são utilizados no processo de estimação.

Neste caso, a estimação das freqüências gênicas, embora não seja de interesse primário, é também necessária para a estimação de $f$. Parâmetros como as freqüências gênicas nesta situação são ditos parâmetros nuisance (Shoemaker et al., 1999). A abordagem Bayesiana dispõe de métodos convenientes de se lidar com estes parâmetros, já que permite a obtenção da distribuição de probabilidade marginal de $f$ levando-se em conta a incerteza na estimação dos parâmetros nuisance (Shoemaker et al., 1998). Dada a condicionalidade ao polimorfismo no modelo a ser descrito, os valores possíveis das freqüências gênicas estão restritos ao intervalo [0;1], excluindo-se os limites do intervalo.

Temos que a função de probabilidade, associada aos diferentes valores que $f$ pode assumir, é dada por:

$$
\phi(f, p \mid X, \mathrm{pol})=\frac{\phi(f, p \mid \mathrm{pol}) \cdot \phi(X \mid f, p, \mathrm{pol})}{\phi(X \mid \mathrm{pol})}
$$

sendo:

$\phi(f, p \mid X, \mathrm{pol})$

a função densidade de probabilidade a posteriori dos parâmetros, condicional aos dados observados e ao polimorfismo; 
$\phi(f, p \mid \mathrm{pol})$

$\phi(X \mid \mathrm{pol})$

$\phi(X \mid f, p, \mathrm{pol})$

a função densidade de probabilidade $a$ priori dos parâmetros, condicional ao polimorfismo;

a probabilidade de ocorrência do conjunto de dados observa$\operatorname{dos} X$ condicional ao polimorfismo;

a probabilidade de ocorrência do conjunto de dados observados $X$ condicional aos valores de $f, p$ e ao polimorfismo, neste caso dada por:

$\phi(X \mid f, p$, pol $)=\frac{\frac{n !}{\prod_{u, v} n_{u v} !} \prod_{u, v} P_{u v}^{n_{u v}}}{1-\sum_{u} P_{u u}^{n}}$

em que:

$n$

$n_{u v}$

$P_{u v}$ é o número de indivíduos observados;

é o valor observado da freqüência absoluta do genótipo uv;

é a probabilidade de ocorrência do genótipo $u v$ na população;

sendo $P_{u v}=p_{u}^{2}+p_{u}\left(1-p_{u}\right) f$ para $u=v$ e $P_{u v}=2 p_{u} p_{v}(1-f)$ para $u \neq v$, com $p_{u}$ representando a probabilidade de ocorrência do alelo $u$ na população.

Com base nestas expressões é possível, de modo análogo ao procedimento adotado em Ayres \& Balding (1998), implementar um algoritmo do tipo Metropolis-Hastings (Metropolis et al., 1953; Hastings, 1970; Smith \& Roberts, 1993), que possibilita a obtenção da função densidade de probabilidade a posteriori utilizando um método de randomização de Monte Carlo via Cadeias de Markov, comumente denominado de algoritmo MCMC (Monte Carlo Markov Chains).

\subsubsection{Modelo Probabilístico de Análise de Múltiplos Locos}

O modelo genético-estatístico adequado para a análise de múltiplos locos deve levar em consideração tanto os efeitos resultantes da amostragem genética, que ocorre ao longo das gerações, quando aqueles decorrentes da amostragem estatística, decorrente do fato de que somente parte dos indivíduos da população são observados. Este modelo pode ser obtido associando-se aos valores de $f$ de locos diferentes uma distribuição de probabilidade. Assim, se $f_{i}$ for considerado como sendo o índice de fixação em um 
dado loco $i$, tem-se que a função densidade de probabilidade associada aos seus possíveis valores pode ser expressa por $\phi\left(f_{i} \mid \theta\right)$, em que $\theta$ representa o conjunto de hiperparâmetros, neste caso, definidos como sendo função do sistema reprodutivo predominante na população.

A especificação completa da distribuição a priori é, neste caso, dada por:

$$
\phi\left(f_{i}, \theta\right)=\phi(\theta) \cdot \phi\left(f_{i} \mid \theta\right)
$$

que, utilizando o teorema de Bayes, fornece a distribuição a posteriori dos parâmetros de interesse, dado o conjunto de valores observados $X$ :

$$
\phi\left(f_{i}, \theta \mid X\right)=\frac{\phi(\theta) \cdot \phi\left(f_{i} \mid \theta\right) \cdot \phi\left(X \mid f_{i}, \theta\right)}{\phi(X)}
$$

A utilização desta abordagem permite que se associe à variação dos valores observados de $f$ dois componentes: um primeiro, resultante da amostragem genética, que promove um comportamento dinâmico nos valores de $f_{i}$ em locos diferentes ao longo das gerações, motivando a distribuição $\phi\left(f_{i} \mid \theta\right)$, e um segundo, resultante da amostragem estatística, expresso em $\phi\left(X \mid f_{i}, \theta\right)$.

Coelho \& Vencovsky ${ }^{1}$ sugerem que uma distribuição adequada para os valores de $f$ em locos diferentes de uma dada população é a distribuição obtida a partir da função densidade de probabilidade Beta definida para os valores da taxa de fecundação cruzada aparente $(t)$ ao longo do intervalo $(0, N)$. A função densidade de probabilidade de interesse, expressa em termos de $f$ é dada por:

$$
\phi\left(f_{i} \mid \alpha, \beta\right)=\frac{\Gamma(\alpha+\beta)}{\Gamma(\alpha) \Gamma(\beta)} \frac{\left(\frac{1-f_{i}}{1+f_{i}}\right)^{\alpha-1}\left(N-\frac{1-f_{i}}{1+f_{i}}\right)^{\beta-1}}{N^{\alpha+\beta-1}}
$$

com hiperparâmetros:

$$
\alpha=\frac{1}{N}\left[\frac{(1-f)^{2}(1+f)^{2}\left(N-\frac{1-f}{1+f}\right)}{4 \cdot \operatorname{Var}\left(f_{i}\right)}-\frac{1-f}{1+f}\right] \quad \beta=\frac{N \alpha(1+f)}{1-f}-\alpha
$$

Cumpre observar que, em condições em que as taxas de fecundação cruzada são tomadas como aproximadamente constantes entre indivíduos e gerações, a variância de $f_{i}$ se deve exclusivamente a efeitos de estocasticidade demográfica e o termo

\footnotetext{
${ }^{1}$ COELHO, A.S.G.; VENCOVSKY, R. Dinâmica do índice de fixação intrapopulacional em populações finitas com taxas variáveis de fecundação cruzada. Scientia Agricola. (Submetido para publicação)
} 
$\operatorname{Var}\left(f_{i}\right)$ pode ser expresso como sendo função do número efetivo de indivíduos reprodutivamente ativos em uma dada população $(N)$ :

$$
\operatorname{Var}\left(f_{i}\right)=\frac{(1-f)^{2}(1-2 f)}{N}+\frac{f(1-f)(2-f)}{2 N p_{u}\left(1-p_{u}\right)}
$$

Fórmula que originalmente foi obtida por Fyfe \& Bailey (1951), para a variância de valores estimados de $f$.

O modelo probabilístico de análise para múltiplos locos, já expressando os hiperparâmetros $\alpha$ e $\beta$ como funções de $f, N$ e das freqüências alélicas $p_{i_{u}}$, e levando-se em conta a condicionalidade ao polimorfismo, pode então ser descrito como:

$$
\phi\left(f_{i}, f, N, p_{i_{u}} \mid X, \mathrm{pol}\right)=\frac{\phi\left(f, N, p_{i_{u}} \mid \mathrm{pol}\right) \cdot \phi\left(f_{i} \mid f, N, p_{i_{u}}, \mathrm{pol}\right) \cdot \phi\left(X \mid f_{i}, f, N, p_{i_{u}}, \mathrm{pol}\right)}{\phi(X, \mathrm{pol})}
$$

\subsubsection{Procedimento de Estimação}

O processo de estimação neste caso consiste na aplicação do algoritmo de Metropolis-Hastings de modo a se produzir a distribuição de probabilidade a posteriori associada aos diferentes valores dos parâmetros de interesse.

$\mathrm{O}$ algoritmo consiste em se produzir um conjunto de valores simulados para a função densidade de probabilidade a posteriori $\phi(\theta \mid X)$, utilizando uma Cadeia de Markov, em que a probabilidade de transição de um determinado estado $(x)$ para um estado subseqüente $\left(x^{\prime}\right)$ é dada por:

$$
\min \left[\frac{\phi\left(x^{\prime}\right) q\left(x \mid x^{\prime}\right)}{\phi(x) q\left(x^{\prime} \mid x\right)}, 1\right]
$$

em que:

$\phi(x) \quad$ é a densidade de probabilidade associada ao estado $x$;

$q\left(x^{\prime} \mid x\right) \quad$ é a probabilidade de que o estado $x^{\prime}$ seja sugerido, estando-se em $x$. De modo geral, se novos estados são sugeridos por uma distribuição uniforme $q\left(x^{\prime} \mid x\right)=$ $q\left(x \mid x^{\prime}\right)$ e os termos se cancelam.

No presente artigo, dada a ausência de informações prévias sobre o comportamento dos parâmetros, utilizou-se uma distribuição uniforme, tanto para os valores de $f$ e $N$, quanto para os possíveis valores das freqüências gênicas. No caso do número 
efetivo de indivíduos reprodutivamente ativos $(N)$ definiu-se uma distribuição uniforme no intervalo $(1,1.000 .000)$. Assim, a partir de um ponto qualquer do espaço paramétrico $(x)$, valores aleatórios eram sugeridos pela distribuição $a$ priori. $\mathrm{O}$ novo estado era então aceito ou não com probabilidade dada pela probabilidade de transição. O conjunto final de valores assim obtidos representa uma amostra de observações da distribuição $a$ posteriori.

As análises foram realizadas utilizando o software $M C M C-f$, desenvolvido especificamente para a aplicação do modelo sugerido. No intuito de se minimizar os efeitos do estado inicial (observado) os 10.000 primeiros passos da Cadeia de Markov (burn-in=10.000) foram eliminados. Considerou-se ainda um intervalo entre "registros"de posição de 100 passos (step=100), afim de se promover a independência entre as observações. No sentido de incrementar a eficiência do caminhamento ao longo do espaço paramétrico, foi adotado um procedimento análogo àquele sugerido em Ayres \& Balding (1998). Sem que as propriedades estatísticas do algoritmo MCMC fossem afetadas, utilizou-se um mecanismo que estabelece o alcance para novos valores sugeridos ao longo da cadeia. A magnitude deste alcance, dada pelo parâmetro $\epsilon$ foi empiricamente estabelecida $(\epsilon=0,01)$. As distribuições a posteriori foram representadas por amostras de 1.000.000 observações.

\subsection{Exemplos de aplicação}

A metodologia sugerida foi aplicada, a título de exemplo, aos dados apresentados em Telles \& Coelho (1998), referentes à análise de quatro locos isoenzimáticos em uma população natural de Araticunzeiro (Annona crassiflora). A Tabela 4 apresenta os valores estimados de $f$ obtidos pelas metodologias de Nei \& Chesser (1983), Robertson \& Hill (1984) e de Máxima Verossimilhança (Weir, 1996).

Os resultados obtidos pela aplicação do modelo sugerido são apresentados nas Figuras 11, 12, 13 e 14 
Tabela 4. Estimativas das heterozigosidades observada $(\hat{H})$ e esperada $(\hat{h})$, do índice de fixação intrapopulacional pelos métodos de Nei \& Chesser $(1983)\left(f_{N C}\right)$, Robertson \& Hill (1984) $\left(f_{R H}\right)$, de Máxima Verossimilhança $\left(f_{M L}\right)$, e dos níveis de significância dos desvios das proporções genotípicas em relação às esperadas na condição de Equilíbrio de Hardy-Weinberg ( $p$ - valor $)$, de quatro locos isoenzimáticos, em uma população natural de Araticunzeiro (Annona crassiflora).

\begin{tabular}{lccccccc}
\hline locos & $n$ & $\hat{H}$ & $\hat{h}$ & $\hat{f}_{N C}$ & $\hat{f}_{R H}$ & $\hat{f}_{M L}$ & $p$-valor \\
\hline 6PGD-1 & 30 & 0,2333 & 0,3045 & 0,2368 & 0,2419 & 0,2208 & 0,2247 \\
6PGD-2 & 30 & 0,2333 & 0,2593 & 0,1018 & 0,1037 & 0,0850 & 0,5045 \\
PGM & 30 & 0,3667 & 0,3045 & $-0,2083$ & $-0,2111$ & $-0,2245$ & 0,5511 \\
LAP & 30 & 0,5667 & 0,4808 & $-0,1823$ & $-0,1848$ & $-0,1986$ & 0,4437 \\
média & 30 & 0,3500 & 0,3373 & $-0,0384$ & $-0,0390$ & $-0,0553$ & 0.4415 \\
\hline
\end{tabular}

Fonte: Telles \& Coelho (1998) 
6PGD-1

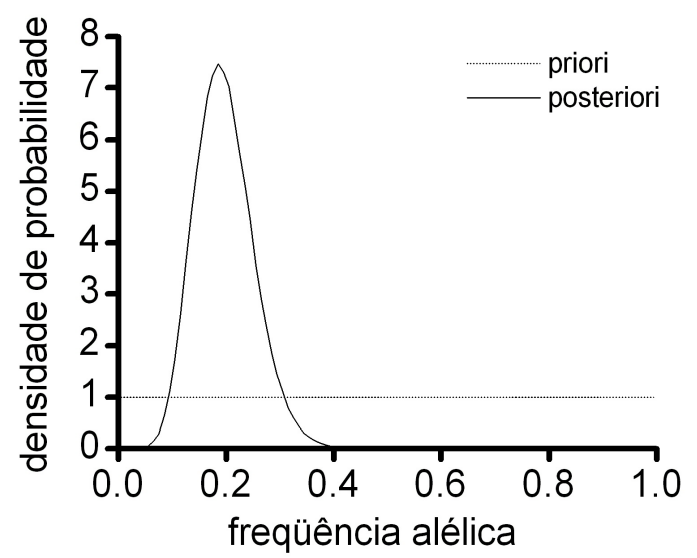

PGM

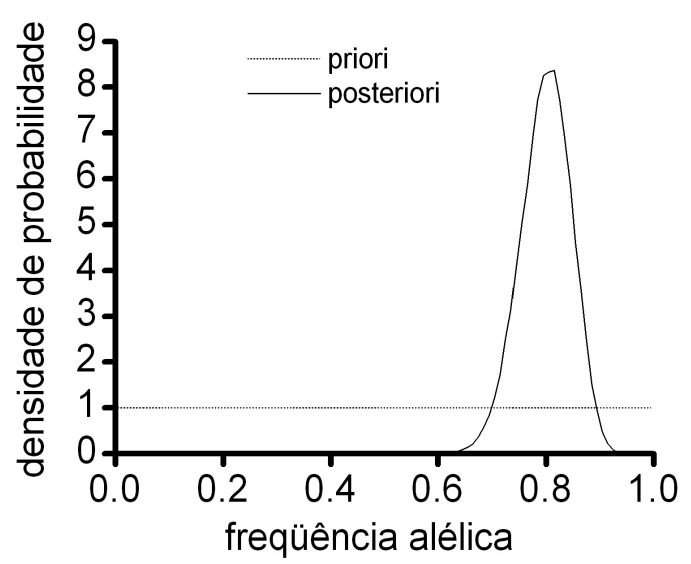

6PGD-2

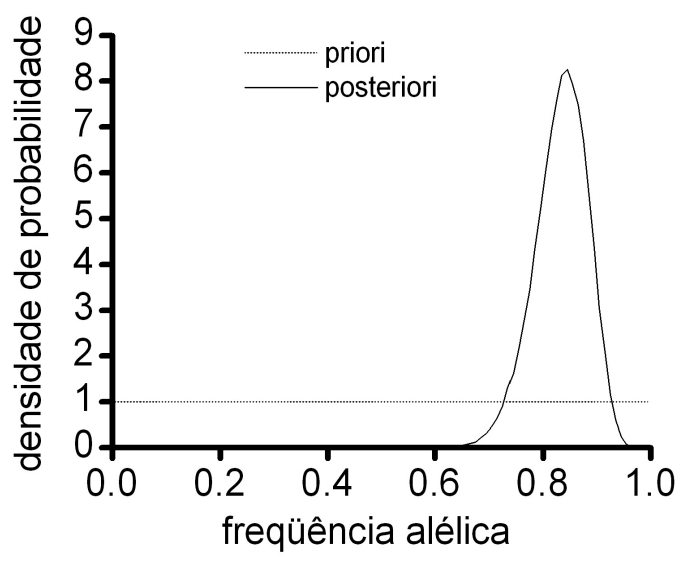

LAP

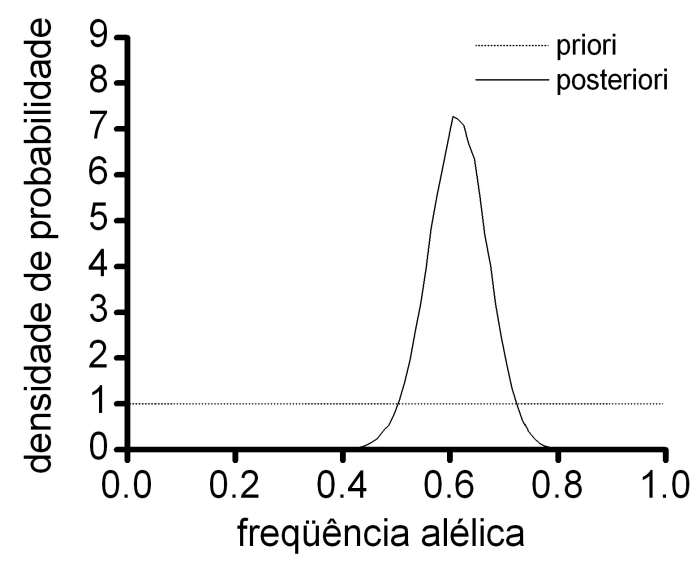

Figura 11 - Distribuições de probabilidade a posteriori associadas aos graus de credibilidade dos diferentes valores das freqüências alélicas (alelo 1) de quatro locos avaliados em uma população natural de Annona crassiflora.

Fonte: Telles \& Coelho (1998) 
6PGD-1

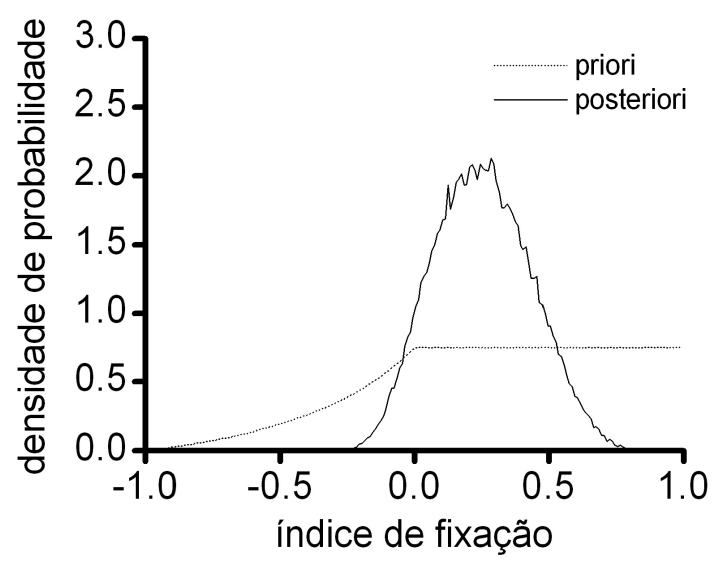

PGM

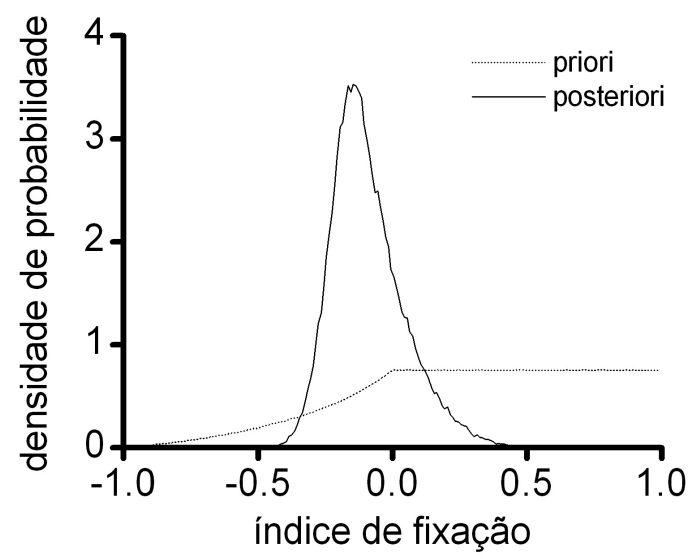

6PGD-2

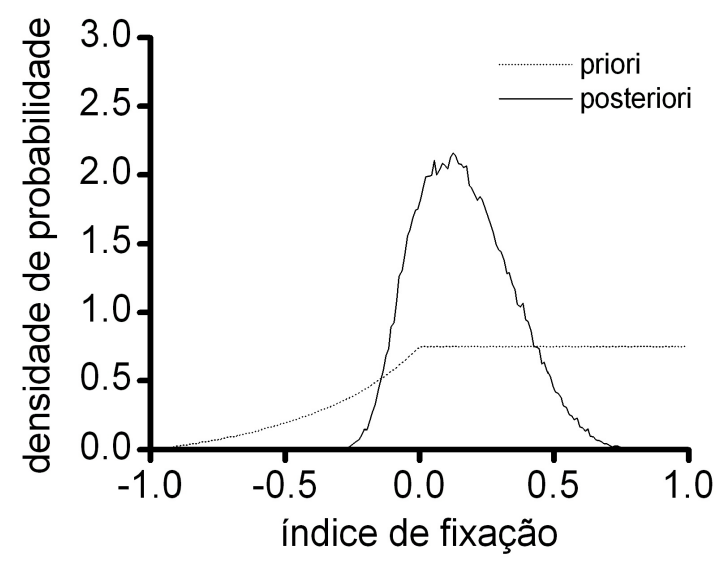

LAP

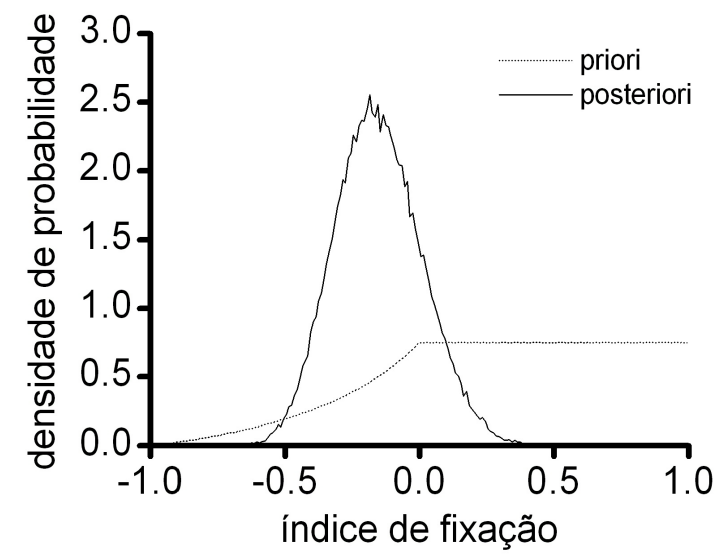

Figura 12 - Distribuições de probabilidade a posteriori associadas aos graus de credibilidade dos diferentes valores do índice de fixação intrapopulacional $\left(f_{i}\right)$, em quatro locos avaliados isoladamente em uma população natural de Annona crassiflora.

Fonte: Telles \& Coelho (1998) 


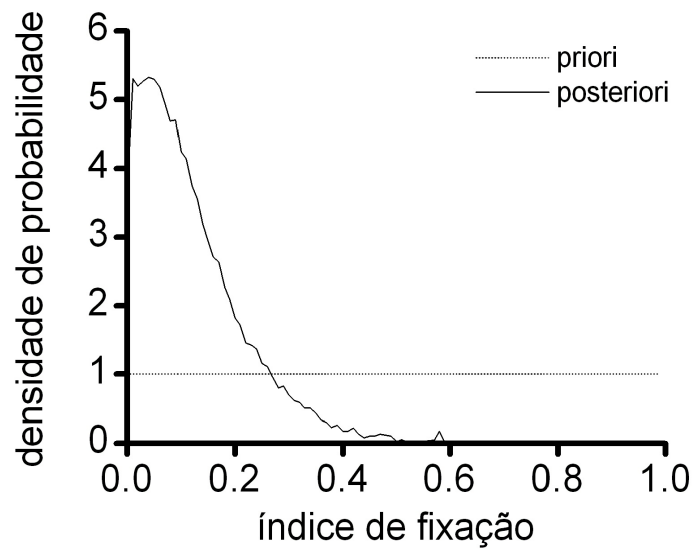

Figura 13 - Distribuição de probabilidade a posteriori associada aos graus de credibilidade dos diferentes valores do índice de fixação intrapopulacional $(f)$, em quatro locos avaliados em uma população natural de Annona crassiflora.

Fonte: Telles \& Coelho (1998)

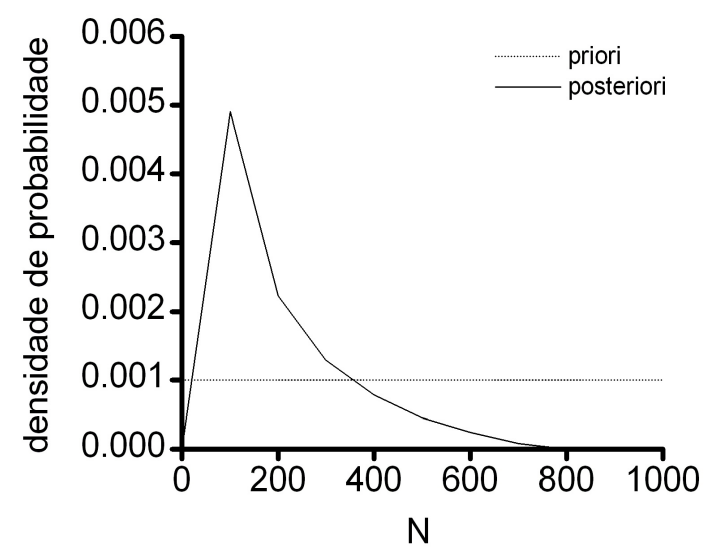

Figura 14 - Distribuição de probabilidade a posteriori associada aos graus de credibilidade dos diferentes valores do número efetivo de indivíduos reprodutivamente ati$\operatorname{vos}(N)$ em uma população natural de Annona crassiflora.

Fonte: Telles \& Coelho (1998) 
Os resultados obtidos pela utilização das diferentes metodologias de estimação de $f$, baseadas na abordagem freqüentista, ainda que tenham apresentado uma relativa concordância em relação às estimativas fornecidas pelos diferentes estimadores, não nos permitem inferir sobre o grau de credibilidade que podemos associar a cada um dos valores apresentados na Tabela 4. A não significância dos desvios observados em relação às proporções esperadas nas condições de equilíbrio de Hardy-Weinberg, sugere que os valores de $f$ obtidos não diferem estatisticamente de zero, embora, pelo reduzido tamanho da amostra utilizada, dificilmente desvios de reduzida magnitude pudessem ter sido detectados como significativos. Neste sentido, uma interpretação cabível seria a de que o real valor de $f$ neste caso deve estar próximo de zero. Mas que grau de credibilidade poderíamos associar aos diferentes valores próximos a zero? A utilização da abordagem Bayesiana ao associar uma distribuição de probabilidade aos diferentes valores que $f$ pode assumir, definida em termos dos diferentes graus de credibilidade que podemos atribuir a cada um destes valores, nos permite avaliar questões desta natureza.

É importante verificar que a análise visual dos gráficos produzidos sugere que um alto grau de incerteza ainda permanece no que diz respeito à determinação do verdadeiro valor de $f$, ainda que, como esperado, a análise de múltiplos locos simultaneamente tenha produzido melhores resultados.

Afim de demonstrar a utilização da metodologia proposta em uma condição com maior disponibilidade de informações, um conjunto de dados simulados foi analisado. A partir da condição inicial de equilíbrio de Hardy-Weinberg, uma população de 500 indivíduos foi submetida ao avanço de 15 gerações utilizando um taxa de fecundação cruzada igual a 0,8. A simulação consistiu na obtenção de dados para 10 locos, com cinco alelos cada, com freqüências alélicas iniciais dadas por 0,500, 0,125, 0,125, 0,125, 0,125, em uma amostra de 100 indivíduos.

A Figura 15 apresenta os resultados para as análises de locos individuais, multilocos e para o número efetivo de indivíduos reprodutivamente ativos. Estes resultados ilustram o ganho em termos da utilização de múltiplos locos simultaneamente e enfatizam a necessidade de que um grande número de indivíduos devem ser avaliados para que boas estimativas de $f$ possam ser obtidas.

É fácil imaginar que de posse da distribuição de probabilidade, associada 
(A)

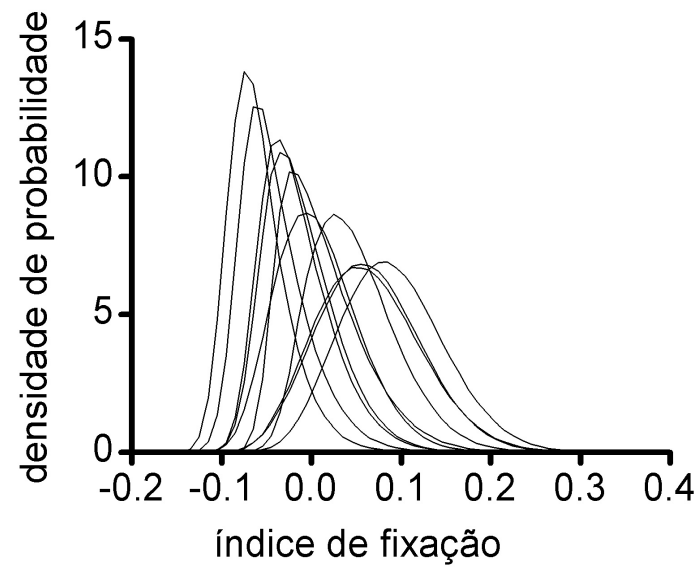

(C)

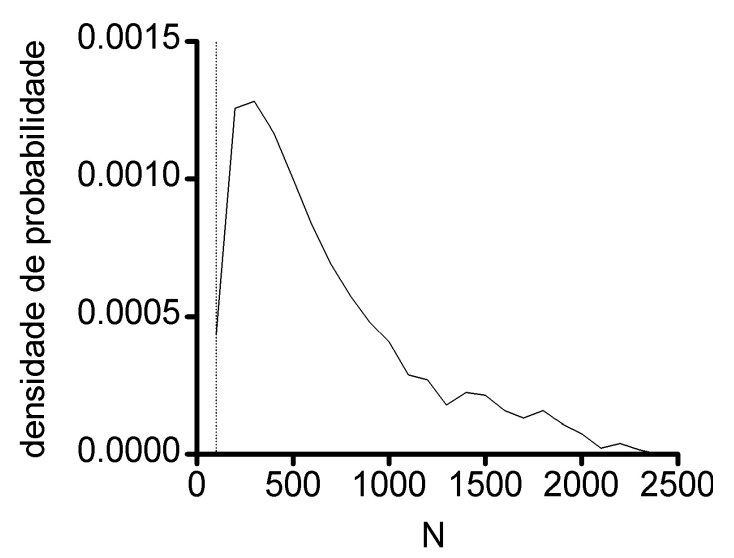

(B)

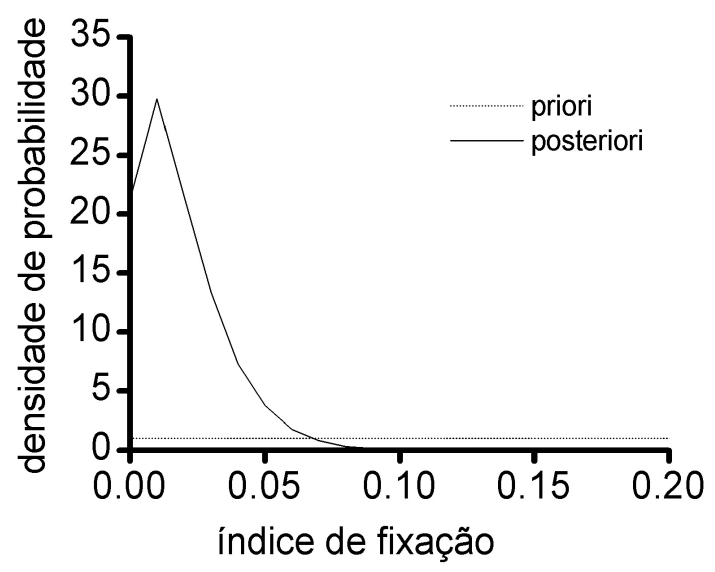

(D)

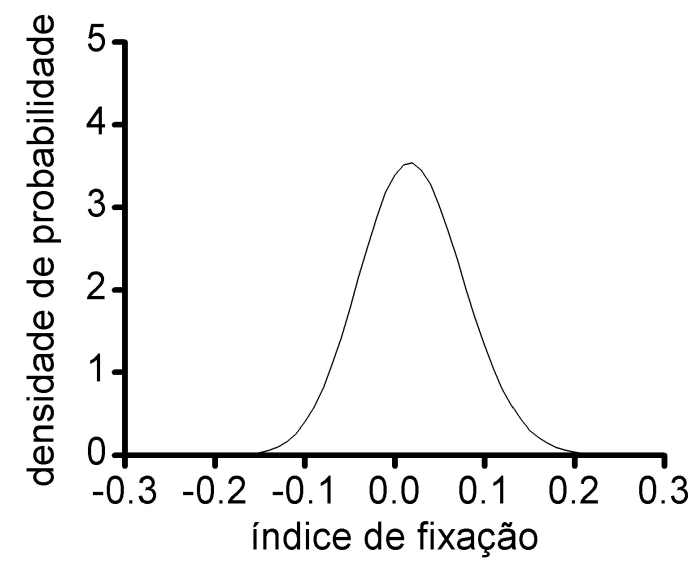

Figura 15 - Distribuições de probabilidade a posteriori associadas aos graus de credibilidade dos diferentes valores do índice de fixação intrapopulacional $(f)$, em 10 locos avaliados isoladamente (A) e em conjunto (B), aos diferentes valores para no número efetivo de indivíduos reprodutivamente ativos $(N)$ (B) e distribuição estimada para os valores de $f$ em diferentes locos (D), utilizando os valores mais prováveis para os hiperparâmetros $f$ e $N$ e os valores médios das freqüências alélicas $p_{i_{u}}$.

aos parâmetros de interesse, regiões de credibilidade podem ser construídas e mesmo regiões de aceitação ou rejeição de hipóteses podem ser delineadas, como apresentado em Pereira \& Rogatko (1984) e Montoya-Delgado et al. (2001). 
No que diz respeito à análise do número médio de indivíduos reprodutivamente ativos, ainda que sob a hipótese de constância das taxas de fecundação cruzada, a metodologia permite a obtenção de uma estimativa inicial do tamanho destas populações em situações em que estas informações são completamente inexistentes.

\subsection{Discussão}

Um método que utiliza a abordagem Bayesiana para o estudo do índice de fixação intrapopulacional é apresentado. O método proposto difere dos presentes na literatura por incluir, ao utilizar a informação de múltiplos locos, um modelo hierárquico em que os efeitos da amostragem genética são isolados daqueles decorrentes da amostragem estatística e por considerar a condicionalidade do processo de avaliação ao polimorfismo dos locos utilizados na análise.

Apesar do enorme potencial de aplicação da abordagem Bayesiana, o emprego destes métodos em estudos de Genética de Populações ainda é tímido (Shoemaker et al., 1999). A abordagem Bayesiana proporciona uma estrutura geral de análise adequada para representar o grau de conhecimento existente acerca de um determinado conjunto de parâmetros de interesse ao incorporar as informações previamente disponíveis (explicitamente) no processo de análise. O resultado é um novo perfil de credibilidade para os diferentes valores de um determinado parâmetro à luz das observações realizadas.

O procedimento descrito para o estudo do índice de fixação intrapopulacional utiliza o algoritmo de Metropolis-Hastings para se obter a distribuição de probabilidade a posteriori empiricamente. A utilização deste tipo de procedimento requer cautela no sentido de que sejam garantidas as condições para que uma boa amostragem do espaço paramétrico possa ser realizada. Neste caso, é fundamental a avaliação dos resultados produzidos pela aplicação do algoritmo com diferentes valores do parâmetro $\epsilon$ (Ayres \& Balding, 1998), principalmente em amostras com grande número de locos multialélicos.

Um ponto em geral considerado como negativo no uso de métodos computacionalmente intensivos, como o aqui descrito, é o tempo de processamento necessário para que o resultado final possa ser obtido. De fato, os métodos tradicionalmente utiliza- 
dos costumam produzir estimativas instantâneas dos parâmetros de interesse. Considerando-se, no entanto, o longo tempo necessário para o processo de coleta de dados, e o contínuo avanço verificado nos últimos anos em termos de recursos computacionais, este problema deve se tornar cada vez mais insignificante.

Um aspecto positivo da abordagem Bayesiana é a possibilidade de que se estabeleçam níveis de credibilidade a cada uma das hipóteses possíveis (diferentes valores do parâmetro de interesse). Neste sentido, convém salientar que métodos de randomização de uso corrente como o de bootstrap não têm esta propriedade, algo que poderia ser sugerido pela forma de apresentação dos resultados. A abordagem Bayesiana produz distribuições de probabilidade associadas aos diferentes valores que o parâmetro pode apresentar, em função do grau de credibilidade atribuído a cada um deles. Esta distribuição de probabilidade é construída com base em um caminhamento no espaço paramétrico. A utilização do método de reamostragem bootstrap produz, por sua vez, uma distribuição de probabilidade para as estimativas de um determinado parâmetro de interesse. Neste caso, a distribuição é construída com base em um caminhamento realizado no espaço amostral, realizando-se as projeções no espaço paramétrico pelo uso de um estimador. A relação entre estas distribuições portanto está na dependência do procedimento de estimação utilizado.

Por fim, cumpre salientar que a caracterização de parâmetros, como o índice de fixação intrapopulacional que exibem um comportamento altamente dinâmico, é sensivelmente melhorada se realizada utilizando distribuições de probabilidade associadas, como aquelas apresentadas na Figura 15, em oposição à utilização de estatísticas pontuais, ainda que a utilização desta abordagem não seja exclusiva à metodologia Bayesiana.

\subsection{Conclusões}

Ainda que computacionalmente intensiva, a metodologia proposta apresenta um forte potencial de utilização em estudos de caracterização genética de populações. A possibilidade de utilizar a informação de múltiplos locos simultaneamente e a disponibilidade de uma metodologia para estimar o número efetivo de indivíduos reprodutivamente ativos em uma dada população complementam em grande parte as abor- 
dagens atualmente disponíveis de estimação do índice de fixação intrapopulacional e de caracterização genética de populações. 


\section{UMA ABORDAGEM BAYESIANA PARA A ESTIMAÇÃO DAS TAXAS DE FECUNDAÇÃO CRUZADA E APOMIXIA UTILIZANDO A INFORMAÇÃO DE MÚLTIPLOS LOCOS NÃO LIGADOS}

\section{Resumo}

Dentre os diversos aspectos normalmente considerados na caracterização genética de espécies vegetais, a determinação do seu sistema reprodutivo predominante figura dentre os de maior importância. O parâmetro de maior interesse neste caso é a taxa de fecundação cruzada. Embora existam na literatura vários métodos para se estimar a taxa de fecundação cruzada, o aqui proposto parece ser o primeiro a considerar a possibilidade de ocorrência de apomixia e a fornecer uma alternativa para se estimar a probabilidade de sua ocorrência. O modelo probabilístico de análise é construído a partir da informação de múltiplos locos não ligados, avaliados em indivíduos de progênies maternas. O método proposto baseia-se na utilização de uma abordagem Bayesiana e do algoritmo de Monte Carlo baseado em Cadeias de Markov (MCMC) de Metropolis-Hastings para obtenção das distribuições a posteriori. A utilização do algoritmo Metropolis-Hastings permite a obtenção de estimativas das distribuições de probabilidade associadas às taxas de fecundação cruzada e de apomixia, além das freqüências dos alelos presentes no pool de pólens durante o evento reprodutivo. As vantagens de utilização da abordagem Bayesiana são discutidas e exemplos numéricos baseados em dados simulados são apresentados. Os resultados sugerem que o método proposto é adequado para se estimar simultaneamente as taxas de fecundação cruzada e de apomixia e fornecem mais evidências de que existe um grande potencial de utilização da estatística Bayesiana em estudos de genética de populações. 


\section{Summary}

[A Bayesian approach for the estimation of oucrossing and apomixis rates using information from multiple unlinked loci.]

Among the various aspects generally considered in the genetic characterization of plant species the identification of its reproductive system stands out as one of the greatest importance. Considerable effort in these situations is focused on the estimation of the outcrossing rate. Although there are many different methods available in literature for estimating the outcrossing rate, the one proposed here seems to be the first to consider the possibility of apomixis and to provide the means to estimate the probability of its occurrence. A probabilistic model is formulated from the information concerning multiple unlinked loci, evaluated in progenies of maternal families. The proposed method is derived using a Bayesian approach and is carried out using the Metropolis-Hastings Monte Carlo algorithm based on Markov Chains (MCMC) to obtain the posteriori distributions. The Metropolis-Hastings algorithm allows the estimation of the probability density functions associated to the outcrossing and apomixis rates, and to the frequency of every allele present in the polen gene pool during the reproduction event. The advantages resulting from the utilization of the Bayesian approach are discussed and numerical examples based on simulated data are presented. Results suggest that the proposed method is adequate to estimate the outcrossing and apomixis rates and provide further evidence of the great potential of utilization of the Bayesian approach in genetic population studies.

\subsection{Introdução}

Dentre os diversos aspectos normalmente considerados na caracterização genética de uma espécie vegetal, a determinação do seu sistema reprodutivo predominante figura dentre os de maior importância. O conhecimento básico do modo com que os indivíduos são produzidos ao longo das gerações se constitui em uma informação valiosa. O sistema reprodutivo predominante de uma espécie determina, em grande parte, todo um conjunto de propriedades genéticas de suas populações. Estas propriedades, em última instância, são as que determinam as estratégias mais adequadas de conservação e melhoramento genético da espécie. 
Embora a maior parte das espécies cultivadas tenha seu sistema reprodutivo razoavelmente bem caracterizado, pouco ainda se conhece sobre as espécies nativas brasileiras. Neste sentido, o desenvolvimento das técnicas de obtenção de marcadores genéticos baseados em polimorfismo avaliado diretamente ao nível de DNA representou um avanço considerável. A utilização de marcadores genéticos para se estimar a taxa de fecundação cruzada em populações naturais, no entanto, não é uma idéia nova. Mas a facilidade com que hoje são obtidas informações genotípicas em espécies nunca antes geneticamente caracterizadas permitiu um avanço considerável no potencial de caracterização genética da flora brasileira.

Do ponto de vista biométrico, avanços consideráveis foram realizados ao longo da década de 1970 e 1980 (Allard et al., 1972; Brown et al., 1975; Clegg et al., 1978; Ritland \& Jain, 1981; Shaw et al., 1981; Cheliak et al., 1983; Yeh \& Morgan, 1987; Ritland, 1989).

Atualmente, a abordagem mais comumente utilizada na obtenção de estimativas de taxas de fecundação cruzada é a metodologia inicialmente proposta em Ritland \& Jain (1981), como por exemplo em Millar et al. (2000) e Bessega et al. (2000). Esta metodologia utiliza a informação de múltiplos locos para se estimar a taxa de fecundação cruzada e possibilita ainda a obtenção de uma série de outros parâmetros indicadores do sistema reprodutivo, como a taxa de fecundação cruzada entre indivíduos aparentados, a proporção dos descendentes de cruzamentos que são irmãos germanos e o grau de estruturação dos eventos de autofecundação nas progênies.

As metodologias atualmente disponíveis, no entanto, não permitem que sejam obtidas estimativas para as taxas de apomixia características de muitas espécies tropicais, ainda que este forma de reprodução assexuada já tenha sido descrita em diversos estudos de biologia floral (Richards, 1998; Wright, 1976). Considerações preliminares a respeito da identificação da ocorrência de apomixia são apresentadas em Murawski \& Hamrick (1992) e Murawski et al. (1994), sem que um tratamento biométrico mais detalhado tenha sido sugerido. É interessante observar que a ocorrência adicional de apomixia, em uma população que se reproduz sexuadamente com taxas intermediárias de fecundação cruzada, não altera as relações entre as proporções genotípicas e gênicas expressas pelas relações esperadas na condição de equilíbrio de Wright. Assim, são ne- 
cessárias informações de mais de uma geração para se detectar a apomixia. Tal fato, no entanto, não representa geralmente um problema sério, tendo em vista que grande parte dos trabalhos de caracterização do sistema reprodutivo de espécies vegetais utiliza dados obtidos em progênies obtidas com controle materno.

Do ponto de vista biométrico, exemplos recentes têm revelado um grande potencial de aplicação da abordagem Bayesiana para estudos genéticos populacionais. Uma revisão sobre este assunto é apresentada em Shoemaker et al. (1999). A abordagem Bayesiana permite que sejam associadas a diferentes hipóteses de interesse, diferentes níveis de credibilidade, fornecendo de uma maneira bastante intuitiva, os elementos necessários para a tomada de decisões. Um aspecto sob controvérsia, neste caso, é o fato de que na abordagem Bayesiana aos parâmetros são atribuídas distribuições de probabilidade, um procedimento inteiramente restrito às variáveis aleatórias no caso da estatística clássica ou freqüentista. Em estudos genéticos populacionais, no entanto, é atraente a idéia de se associar a um determinado parâmetro uma distribuição de probabilidade e não um único valor fixo. Como os elementos sob caracterização, as populações, estão sujeitos a uma série de fatores estocásticos, é natural se imaginar que os parâmetros que os caracterizam não sejam estáticos.

Neste sentido, utilizando uma abordagem Bayesiana, o presente trabalho se propõe a fornecer um método de estimação para as taxas de fecundação cruzada e de apomixia, a partir da informação genotípica de múltiplos locos não ligados avaliados em progênies de origem materna conhecida. Exemplos de aplicação da metodologia são aplicados a dados simulados, permitindo uma avaliação preliminar da metodologia proposta.

\subsection{A Abordagem Bayesiana}

\subsubsection{O Modelo Probabilístico}

A abordagem Bayesiana a ser utilizada neste caso, em conformidade com o ponto de vista de Shoemaker et al. (1998), consiste em se obter uma distribuição de probabilidade, associada aos diferentes valores que o parâmetro de interesse pode assumir, de modo a representar o grau de credibilidade associado a cada um deles, dado o conjunto de dados observado. O ponto de partida é uma função densidade de probabilidade, dita $a$ 
priori, obtida de considerações anteriores à observação dos genótipos. Esta função densidade de probabilidade pode então ser atualizada pela utilização do teorema de Bayes, de modo que as informações obtidas com as observações possam ser consideradas na análise.

Seja $\phi(\theta)$ a função densidade de probabilidade a priori associada a um vetor de parâmetros $(\theta)$. A função densidade de probabilidade a posteriori condicional ao conjunto de dados observados $(X)$, neste caso é expressa por:

$$
\phi(\theta \mid X)=\frac{\phi(\theta) \phi(X \mid \theta)}{\phi(X)}
$$

A função densidade de probabilidade a priori a ser adotada deve refletir necessariamente o grau de conhecimento disponível acerca dos parâmetros de interesse. É interessante observar que a expressão $\phi(X \mid \theta)$ refere-se à função que descreve a probabilidade de ocorrência dos dados condicional aos valores dos parâmetros que compõem $\theta$, e, em termos práticos, tem a mesma forma da função de verossimilhança dos parâmetros.

No que se refere às taxas de fecundação cruzada e de apomixia, o modelo básico utilizado no procedimento de estimação pode ser descrito como:

$$
\phi\left(t, \alpha, p_{i_{u}} \mid X\right)=\frac{\phi\left(t, \alpha, p_{i_{u}}\right) \phi\left(X \mid t, \alpha, p_{i_{u}}\right)}{\phi(X)}
$$

em que:

$\phi\left(t, \alpha, p_{i_{u}} \mid X\right)$ se refere à função densidade de probabilidade a posteriori associada aos parâmetros taxa de fecundação cruzada $(t)$, taxa de apomixia $(\alpha)$ e às freqüências alélicas $\left(p_{i_{u}}\right)$, que neste caso são consideradas parâmetros nuisance;

$\phi\left(t, \alpha, p_{i_{u}}\right) \quad$ se refere à distribuição $a$ priori dos parâmetros;

$\phi\left(X \mid t, \alpha, p_{i_{u}}\right)$ se refere à função que descreve a probabilidade de ocorrência dos dados, condicional aos valores fixados dos parâmetros, que em termos práticos, tem o mesmo formato da função de verossimilhança dos parâmetros;

$\phi(X) \quad$ se refere à função que descreve a probabilidade de ocorrência das observações.

Diversos métodos têm sido empregados na obtenção das distribuições de probabilidade a posteriori $\phi(\theta \mid X)$, incluindo aqueles que, por utilizarem funções densidade de probabilidade a priori adequadas, fornecem expressões algébricas explícitas, 
como em Shoemaker et al. (1998), e aqueles que obtém distribuições de probabilidade empíricas baseadas em algoritmos de randomização via Cadeias de Markov, como o de Metropolis-Hastings, utilizado em Ayres \& Balding (1998).

Conforme salientam Baldi \& Brunak (1999), o algoritmo de MetropolisHastings, utilizado para a obtenção da distribuição marginal a posteriori de $\theta$ exige somente que a função de verossimilhança seja expressa algebricamente. A função densidade de probabilidade a priori $\phi(\theta)$ é levada em consideração na obtenção dos estados sugeridos da Cadeia de Markov, enquanto que a expressão algébrica da função $\phi(X)$ não é exigida.

A função de verossimilhança associada aos parâmetros de interesse, neste caso, apresenta um formato mais conveniente se apresentada utilizando uma notação matricial, similar àquela utilizada em Ritland \& Jain (1981). O uso desta notação requer a definição de um vetor g cujos elementos $g_{i}$ são os "nomes"dos genótipos multilocos. Sendo $\mathbf{u}_{\mathbf{k}}$ o vetor de elementos $u_{k_{i}}$ representando os "nomes"associados a um dado loco $k$, de um conjunto de $L$ locos, temos que:

$$
\mathbf{g}=\mathbf{u}_{\mathbf{1}} \otimes \mathbf{u}_{\mathbf{2}} \otimes \cdots \otimes \mathbf{u}_{\mathbf{L}}
$$

em que $\otimes$ denota o "produto"de Kronecker, que associa os "nomes"de genótipos de locos diferentes. Para 2 locos, $A$ e $B$, contendo cada um dois alelos, por exemplo, tem-se que:

$$
\mathbf{u}_{\mathbf{1}}=\left[\begin{array}{c}
A_{1} A_{1} \\
A_{1} A_{2} \\
A_{2} A_{2}
\end{array}\right] \quad \mathbf{u}_{\mathbf{2}}=\left[\begin{array}{c}
B_{1} B_{1} \\
B_{1} B_{2} \\
B_{2} B_{2}
\end{array}\right] \mathbf{g}=\left[\begin{array}{c}
A_{1} A_{1} B_{1} B_{1} \\
A_{1} A_{1} B_{1} B_{2} \\
A_{1} A_{1} B_{2} B_{2} \\
A_{1} A_{2} B_{1} B_{1} \\
A_{1} A_{2} B_{1} B_{2} \\
A_{1} A_{2} B_{2} B_{2} \\
A_{2} A_{2} B_{1} B_{1} \\
A_{2} A_{2} B_{1} B_{2} \\
A_{2} A_{2} B_{2} B_{2}
\end{array}\right]
$$

Podem ainda ser definidas matrizes $\mathbf{s}_{\mathbf{k}}$ constituídas de elementos $s_{k_{i j}}$ que representam as probabilidades de ocorrência de um genótipo designado dado por $u_{k_{i}}$ em 
uma progênie obtida por autofecundação do genótipo $u_{k_{j}}$. De modo que:

$$
\mathbf{S}=\mathbf{s}_{\mathbf{1}} \otimes \mathbf{s}_{\mathbf{2}} \otimes \cdots \otimes \mathbf{s}_{\mathbf{L}}
$$

representa a matriz de elementos $s_{i j}$, em que $s_{i j}$ representa a probabilidade de ocorrência do genótipo designado pelo $i$-ésimo elemento de g dada a ocorrência de autofecundação do genótipo designado pelo $j$-ésimo elemento de $g$. Para o exemplo de dois locos, com dois alelos cada tem-se que:

$$
\mathbf{s}_{1}=\left[\begin{array}{ccc}
1 & \frac{1}{4} & 0 \\
0 & \frac{1}{2} & 0 \\
0 & \frac{1}{4} & 1
\end{array}\right] \quad \mathbf{s}_{2}=\left[\begin{array}{ccc}
1 & \frac{1}{4} & 0 \\
0 & \frac{1}{2} & 0 \\
0 & \frac{1}{4} & 1
\end{array}\right] \quad \mathbf{S}=\left[\begin{array}{ccccccccc}
1 & \frac{1}{4} & 0 & \frac{1}{4} & \frac{1}{16} & 0 & 0 & 0 & 0 \\
0 & \frac{1}{2} & 0 & 0 & \frac{1}{8} & 0 & 0 & 0 & 0 \\
0 & \frac{1}{4} & 1 & 0 & \frac{1}{16} & \frac{1}{4} & 0 & 0 & 0 \\
0 & 0 & 0 & \frac{1}{2} & \frac{1}{8} & 0 & 0 & 0 & 0 \\
0 & 0 & 0 & 0 & \frac{1}{4} & 0 & 0 & 0 & 0 \\
0 & 0 & 0 & 0 & \frac{1}{8} & \frac{1}{2} & 0 & 0 & 0 \\
0 & 0 & 0 & \frac{1}{4} & \frac{1}{16} & 0 & 1 & \frac{1}{4} & 0 \\
0 & 0 & 0 & 0 & \frac{1}{8} & 0 & 0 & \frac{1}{2} & 0 \\
0 & 0 & 0 & 0 & \frac{1}{16} & \frac{1}{4} & 0 & \frac{1}{4} & 1
\end{array}\right]
$$

De modo análogo, podem ser definidas matrizes $\mathbf{T}=\mathbf{t}_{\mathbf{1}} \otimes \mathbf{t}_{\mathbf{2}} \otimes \cdots \otimes \mathbf{t}_{\mathbf{L}} \mathrm{e}$ $\mathbf{A}=\mathbf{a}_{\mathbf{1}} \otimes \mathbf{a}_{\mathbf{2}} \otimes \cdots \otimes \mathbf{a}_{\mathbf{L}}$ com probabilidades associadas aos genótipos em progênies obtidas por fecundação cruzada e por apomixia, respectivamente. No exemplo em questão, estas matrizes seriam dadas por:

$$
\mathbf{t}_{\mathbf{1}}=\left[\begin{array}{ccc}
p_{11} & \frac{1}{2} p_{11} & 0 \\
p_{12} & \frac{1}{2} & p_{11} \\
0 & \frac{1}{2} p_{12} & p_{12}
\end{array}\right] \quad \mathbf{t}_{2}=\left[\begin{array}{ccc}
p_{21} & \frac{1}{2} p_{21} & 0 \\
p_{22} & \frac{1}{2} & p_{21} \\
0 & \frac{1}{2} p_{22} & p_{22}
\end{array}\right]
$$




$$
\begin{aligned}
& \mathbf{T}=\left[\begin{array}{ccccccccc}
p_{11} p_{21} & \frac{1}{2} p_{11} p_{21} & 0 & \frac{1}{2} p_{11} p_{21} & \frac{1}{4} p_{11} p_{21} & 0 & 0 & 0 & 0 \\
p_{11} p_{22} & \frac{1}{2} p_{11} & p_{11} p_{21} & \frac{1}{2} p_{11} p_{22} & \frac{1}{4} p_{11} & \frac{1}{2} p_{11} p_{21} & 0 & 0 & 0 \\
0 & \frac{1}{2} p_{11} p_{22} & p_{11} p_{22} & 0 & \frac{1}{4} p_{11} p_{22} & \frac{1}{2} p_{11} p_{22} & 0 & 0 & 0 \\
p_{12} p_{21} & \frac{1}{2} p_{12} p_{21} & 0 & \frac{1}{2} p_{21} & \frac{1}{4} p_{21} & 0 & p_{11} p_{21} & \frac{1}{2} p_{11} p_{21} & 0 \\
p_{12} p_{22} & \frac{1}{2} p_{12} & p_{12} p_{21} & \frac{1}{2} p_{22} & \frac{1}{4} & \frac{1}{2} p_{21} & p_{11} p_{22} & \frac{1}{2} p_{11} & p_{11} p_{21} \\
0 & \frac{1}{2} p_{12} p_{22} & p_{12} p_{22} & 0 & \frac{1}{4} p_{22} & \frac{1}{2} p_{22} & 0 & \frac{1}{2} p_{11} p_{22} & p_{11} p_{22} \\
0 & 0 & 0 & \frac{1}{2} p_{12} p_{21} & \frac{1}{4} p_{12} p_{21} & 0 & p_{12} p_{21} & \frac{1}{2} p_{12} p_{21} & 0 \\
0 & 0 & 0 & \frac{1}{2} p_{12} p_{22} & \frac{1}{4} p_{12} & \frac{1}{2} p_{12} p_{21} & p_{12} p_{22} & \frac{1}{2} p_{12} & p_{12} p_{21} \\
0 & 0 & 0 & 0 & \frac{1}{4} p_{12} p_{22} & \frac{1}{2} p_{12} p_{22} & 0 & \frac{1}{2} p_{12} p_{22} & p_{12} p_{22}
\end{array}\right] \\
& \mathbf{a}_{1}=\left[\begin{array}{lll}
1 & 0 & 0 \\
0 & 1 & 0 \\
0 & 0 & 1
\end{array}\right] \quad \mathbf{a}=\left[\begin{array}{lll}
1 & 0 & 0 \\
0 & 1 & 0 \\
0 & 0 & 1
\end{array}\right] \quad \mathbf{A}=\left[\begin{array}{lllllllll}
1 & 0 & 0 & 0 & 0 & 0 & 0 & 0 & 0 \\
0 & 1 & 0 & 0 & 0 & 0 & 0 & 0 & 0 \\
0 & 0 & 1 & 0 & 0 & 0 & 0 & 0 & 0 \\
0 & 0 & 0 & 1 & 0 & 0 & 0 & 0 & 0 \\
0 & 0 & 0 & 0 & 1 & 0 & 0 & 0 & 0 \\
0 & 0 & 0 & 0 & 0 & 1 & 0 & 0 & 0 \\
0 & 0 & 0 & 0 & 0 & 0 & 1 & 0 & 0 \\
0 & 0 & 0 & 0 & 0 & 0 & 0 & 0 & 0 \\
0 & 0 & 0 & 0 & 0 & 0 & 0 & 1 & 1
\end{array}\right]
\end{aligned}
$$

em que $p_{i j}$ representa a freqüência do alelo $j$ no loco $i$.

A função logaritmo da verossimilhança neste caso é dada por:

$$
\left.L=\ln \frac{n !}{\Pi_{i} x_{i j} !}+\mathbf{1}^{\prime}(\mathbf{X} \circ \ln \mathbf{P}) \mathbf{1}\right]
$$

em que:

1

$\mathbf{X}$

$\mathbf{A} \circ \mathbf{B}$ é o vetor de elementos iguais a 1, com dimensão adequada;

é a matriz cujos elementos $x_{i j}$ são definidos como sendo os valores observados para as freqüências absolutas correspondentes à ocorrência do genótipo $g_{i}$ na progênie descendente do genótipo $g_{j}$;

denota o produto de Schur entre matrizes, em que cada elemento da matriz resultante $\left(c_{i j}\right)$ é obtido pelo produto dos elementos correspondentes nas matrizes $\mathbf{A}$ e $\mathbf{B}\left(c_{i j}=a_{i j} b_{i j}\right)$; 
$\ln \mathbf{A} \quad$ denota a matriz que tem como elementos os valores correspondentes ao logaritmo neperiano de cada um dos elementos da matriz $\mathbf{A}$;

$\mathbf{P} \quad$ denota a matriz cujos elementos $r_{i j}$ representam a probabilidade de ocorrência do genótipo $g_{i}$ na progênie descendente do genótipo $g_{j}$.

A matriz $\mathbf{P}$, neste caso, é obtida como sendo função das matrizes T, $\mathbf{S}$ e $\mathbf{A}$ e das taxas de fecundação cruzada $(t)$ e de apomixia $(\alpha)$ :

$$
\mathbf{P}=(1-\alpha)[t \cdot \mathbf{T}+(1-t) \cdot \mathbf{S}]+\alpha \cdot \mathbf{A}
$$

\subsubsection{Procedimento de Estimação}

O procedimento de estimação neste caso consiste na aplicação do algoritmo de Metropolis-Hastings de modo a se produzir a distribuição de probabilidade a posteriori associada aos diferentes valores dos parâmetros de interesse.

O algoritmo consiste em se produzir um conjunto de valores simulados para a função densidade de probabilidade a posteriori $\phi(\theta \mid X)$, utilizando uma Cadeia de Markov, em que a probabilidade de transição de um determinado estado $(x)$ para um estado subseqüente $\left(x^{\prime}\right)$ é dada por:

$$
\min \left[\frac{\phi\left(x^{\prime}\right) q\left(x \mid x^{\prime}\right)}{\phi(x) q\left(x^{\prime} \mid x\right)}, 1\right]
$$

em que:

$\phi(x) \quad$ é a densidade de probabilidade associada ao estado $x$;

$q\left(x^{\prime} \mid x\right) \quad$ é a probabilidade de que o estado $x^{\prime}$ seja sugerido, estando-se em $x$. De modo geral, se novos estados são sugeridos por uma distribuição uniforme $q\left(x^{\prime} \mid x\right)=$ $q\left(x \mid x^{\prime}\right)$ e os termos se cancelam.

No presente artigo, dada a ausência de informações prévias sobre o comportamento dos parâmetros, utilizou-se uma distribuição uniforme para os valores dos parâmetros $t, \alpha$ e para as freqüências alélicas. Assim, a partir de um ponto qualquer do espaço paramétrico $(x)$, valores aleatórios eram sugeridos pela distribuição a priori. $\mathrm{O}$ novo estado era então aceito ou não com probabilidade dada pela probabilidade de transição. O conjunto final de valores assim obtidos representa uma amostra de observações da distribuição a posteriori. 
As análises foram realizadas utilizando o software $M C M C-t$, desenvolvido especificamente para a aplicação do modelo sugerido. No intuito de se minimizar os efeitos do estado inicial (observado) os 1.000 primeiros passos da Cadeia de Markov (burnin=1.000) foram eliminados. Considerou-se ainda um intervalo entre "registros"de posição de 100 passos (step=100), afim de se promover a independência entre as observações. No sentido de incrementar a eficiência do caminhamento ao longo do espaço paramétrico, foi adotado um procedimento análogo àquele sugerido em Ayres \& Balding (1998). Sem que as propriedades estatísticas do algoritmo MCMC fossem afetadas, utilizou-se um mecanismo que estabelece o alcance para novos valores sugeridos ao longo da cadeia. A magnitude deste alcance, dada pelo parâmetro $\epsilon$ foi empiricamente estabelecida $(\epsilon=$ $0,10)$. As distribuições a posteriori foram representadas por amostras de 10.000 observações.

\subsection{Exemplos de aplicação}

Afim de se ilustrar a aplicação da metodologia proposta, foram analisados três conjuntos de dados obtidos por simulação. Os resultados relativos ao primeiro conjunto, obtido admitindo-se a inexistência de apomixia e uma taxa de fecundação cruzada igual a 0,85 são apresentados na Figura 16.

Observa-se neste caso uma boa aderência dos resultados obtidos em rela-

ção aos esperados com base nos parâmetros da simulação. É importante enfatizar que a metodologia proposta permite a obtenção das distribuições de probabilidade a posteriori condicionais marginais para cada um dos parâmetros de interesse, levando-se em consideração a incerteza associada a cada um deles.

Um segundo conjunto de dados simulados foi obtido admitindo-se uma taxa de apomixia igual a 1, 0. Os resultados estão apresentados na Figura 17.

Observa-se neste caso, como esperado, que tanto a taxa de fecundação cruzada quanto as freqüências alélicas são indeterminadas. A ampla ocorrência de apomixia implica em reduzida informação acerca da proporção da reprodução sexuada que se dá por cruzamentos entre indivíduos diferentes. Ao mesmo tempo, não se tem informação, neste caso, a respeito das freqüências alélicas no pool de pólens. 

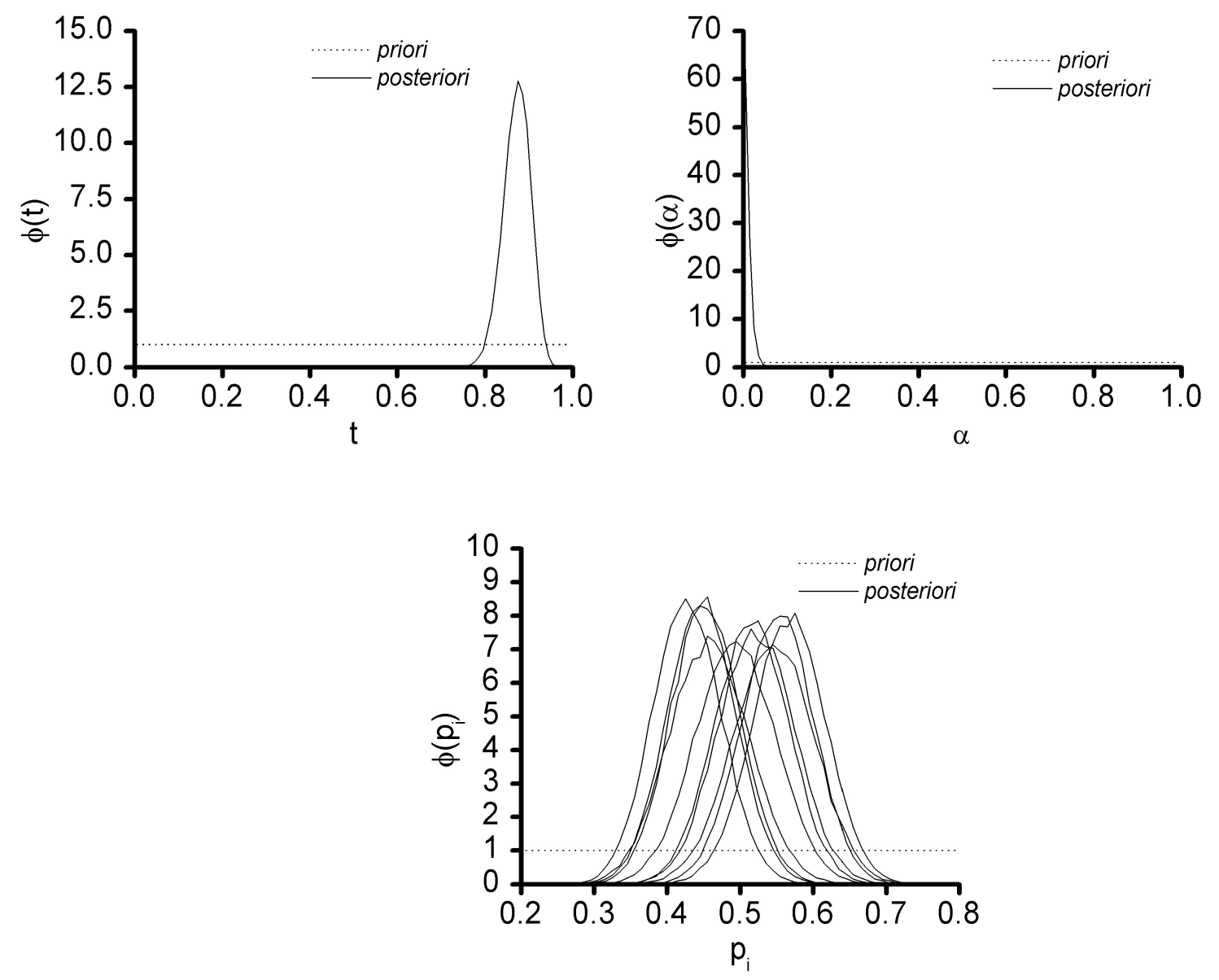

Figura 16 - Distribuições de probabilidade a posteriori associadas aos graus de credibilidade dos diferentes valores da taxa de fecundação cruzada $(t)$, da taxa de apomixia $(\alpha)$ e das freqüências alélicas $(p)$, em 10 locos. Dados obtidos por simulação (10 locos bialélicos em 10 progênies de 15 indivíduos, e parâmetros: $t=0,85, \alpha=0,0$ e $p=0,50)$.

Como um terceiro exemplo, foram analisados dados obtidos admitindo-se uma taxa de fecundação cruzada igual a 0,90 e uma taxa de apomixia de 0,25.

Observa-se novamente, uma forte aderência dos resultados em relação aqueles esperados pelos parâmetros utilizados na simulação (Figura 18). 

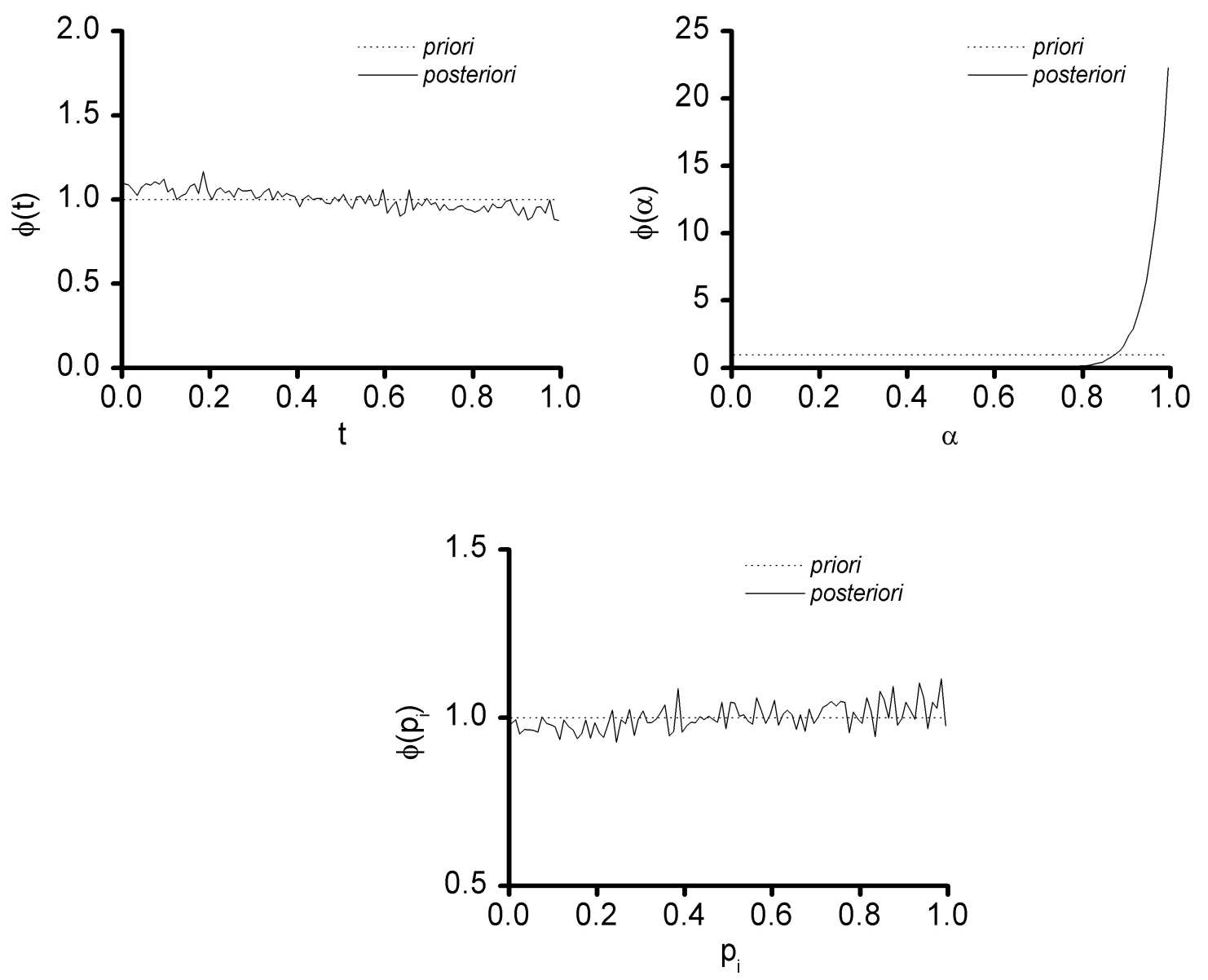

Figura 17 - Distribuições de probabilidade a posteriori associadas aos graus de credibilidade dos diferentes valores da taxa de fecundação cruzada $(t)$, da taxa de apomixia $(\alpha)$ e da freqüência alélica $(p)$, em um loco. Dados obtidos por simulação (3 locos bialélicos em 2 progênies de 15 indivíduos, e parâmetros: $t=0,00$, $\alpha=1,0$ e $p=0,50)$.

\subsection{Discussão}

Embora existam na literatura vários métodos de se estimar a taxa de fecundação cruzada (Allard et al., 1972; Brown et al., 1975; Cheliak et al., 1983; Clegg et al., 1978; Shaw et al., 1981; Ritland \& Jain, 1981; Yeh \& Morgan, 1987), o aqui proposto parece ser o primeiro a considerar explicitamente a ocorrência de apomixia e fornecer uma estimativa para a probabilidade de sua ocorrência. 

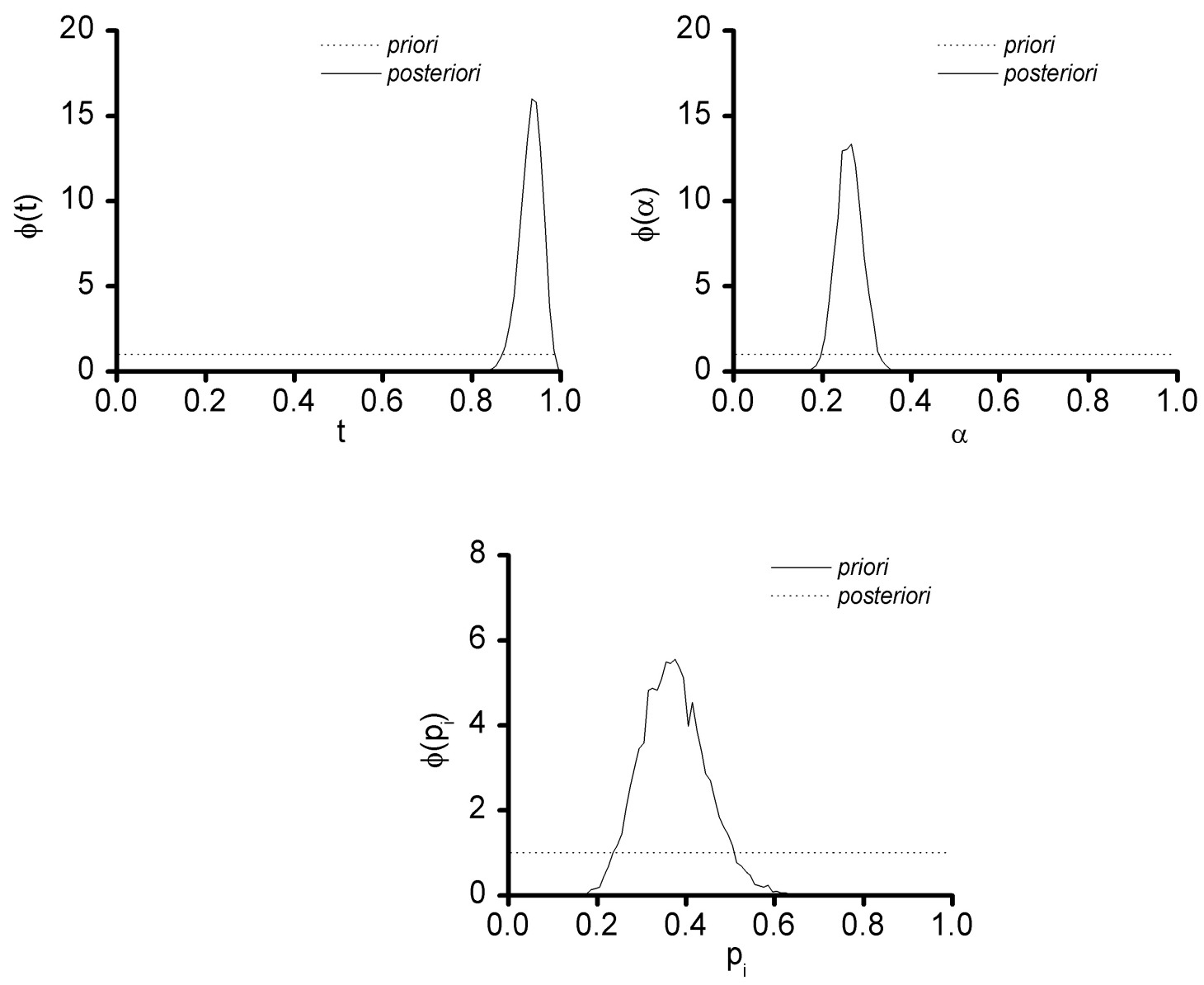

Figura 18 - Distribuições de probabilidade a posteriori associadas aos graus de credibilidade dos diferentes valores da taxa de fecundação cruzada $(t)$, da taxa de apomixia $(\alpha)$ e das freqüências alélicas $(p)$, em 10 locos. Dados obtidos por simulação (10 locos com 5 alelos em 15 progênies de 15 indivíduos, e parâmetros: $t=0,90, \alpha=0,25$ e $p=0,20)$.

É importante observar que a utilização da metodologia apresentada requer o atendimento aos seguintes pressupostos:

i. os alelos de locos diferentes segregam independentemente;

ii. a ocorrência de apomixia ou de autofecundação é independente do genótipo materno;

iii. durante os cruzamentos, os genótipos maternos se combinam com um pool homogêneo de pólens; 
iv. não ocorrem seleção e mutação nos locos considerados na análise no período compreendido entre o evento reprodutivo e a avaliação genotípica das progênies.

Sob o aspecto de implementação das análises sugeridas é fácil perceber que as dimensões das matrizes envolvidas na expressão da função de verossimilhança crescem rapidamente com o aumento do número de locos e de alelos por loco. A ordem destas matrizes é dada por:

$$
\frac{\Pi_{k=1}^{L}\left[m_{k}\left(m_{k}+1\right)\right]}{2^{L}}
$$

em que $L$ é o número de locos $m_{k}$ é o número de alelos do loco $k$. Para oito locos com cinco alelos cada, condições tipicamente encontradas em estudos com marcadores moleculares baseados em polimorfismo de microssatélites, por exemplo, estas matrizes teriam uma ordem gigantesca de $15^{8}=2.562 .890 .625$. Assim, do ponto de vista computacional é essencial que a implementação da metodologia considere somente os genótipos efetivamente amostrados, reduzindo a dimensão destas matrizes ao número de indivíduos avaliados nas progênies.

Ainda que a metodologia proposta pudesse ter sido baseada em outros métodos de estimação, optou-se pela utilização da abordagem Bayesiana por ser esta uma alternativa que conduz mais facilmente à interpretação das hipóteses sob teste. Os resultados neste caso são apresentados como estimativas de distribuições de probabilidade $a$ posteriori que, explicitamente, fornecem respostas para perguntas formuladas como: qual é a estimativa da probabilidade de que a taxa de fecundação cruzada esteja entre 0,90 e 0,95 ? É importante salientar que a resposta para indagações desta natureza são dadas pela estatística freqüentista utilizando o conceito de intervalo de confiança, que é bem menos intuitivo.

As distribuições a posteriori estimadas nos métodos Bayesianos podem ser interpretadas de, pelo menos, duas maneiras distintas. Uma primeira, que se refere ao ponto de vista utilizado por Shoemaker et al. (1988), admite que o procedimento de estimação procura estabelecer níveis de credibilidade para diferentes hipóteses acerca do valor de um determinado parâmetro, que em última análise é considerado desconhecido mas constante. Uma segunda alternativa, mais atraente do ponto de vista biológico, admite que o produto do processo de estimação é uma estimativa da distribuição de pro- 
babilidade associada aos diferentes valores que o parâmetro pode assumir. Neste caso, considera-se que a distribuição de probabilidade a posteriori representa uma aproximação em direção à verdadeira distribuição de probabilidade dos valores do parâmetro, à luz dos dados oriundos da observação. Assume-se portanto, que o parâmetro é intrinsicamente variável, e tem comportamento descrito por uma função densidade de probabilidade. Neste sentido, o aumento da precisão com que são feitas as observações não necessariamente conduziria as estimativas a um único valor, mas sim a uma distribuição de probabilidade que descreve verdadeiramente o comportamento do parâmetro.

Conforme relatam alguns autores (Cruzan et al., 1994; Suso et al., 2001; Rocha \& Aguilar, 2001; Murawski \& Hamrick, 1991) as taxas de fecundação cruzada variam entre indivíduos e entre gerações. Estas variações resultam tanto de alterações em fatores inerentes à própria espécie quanto de processos estocásticos de natureza ecológica. É natural portanto que, ainda que se possa conceber a existência de uma taxa média de fecundação cruzada que possa ser associada a uma determinada população de uma espécie, se considere a taxa de fecundação cruzada como um parâmetro que exibe variação. Um raciocínio análogo poderia ser feito para outros parâmetros genéticos populacionais como a própria taxa de apomixia e para as freqüências alélicas.

\subsection{Conclusões}

Os resultados obtidos demonstram a aplicabilidade da metodologia proposta para a estimação das taxas de fecundação cruzada e de apomixia e sugerem um elevado potencial de utilização da estatística Bayesiana em estudos de caracterização genética de populações. 


\section{CONCLUSÕES GERAIS}

Em termos gerais, os resultados apresentados permitem se concluir que:

i. Em populações finitas, os valores do índice de fixação intrapopulacional apresentam um comportamento dinâmico nas condições de equilíbrio, e passam a se estabilizar ao longo de um intervalo e não mais em um único ponto, como acontece em populações infinitas.

ii. O comportamento do índice de fixação intrapopulacional em diferentes locos é fortemente influenciado por fatores como o tamanho da população e a variação nas taxas de fecundação cruzada médias de diferentes gerações.

iii. A metodologia sugerida para obtenção de estimativas do índice de fixação intrapopulacional mostrou-se adequada por permitir uma caracterização do comportamento dinâmico dos valores deste parâmetro em locos diferentes e por fornecer uma alternativa para estimar o número efetivo de indivíduos reprodutivamente ativos em uma dada população.

iv. A metodologia sugerida para obtenção de estimativas das taxas de fecundação cruzada e de apomixia mostrou-se adequada e tem bom potencial de aplicação na caracterização genética de populações de espécies vegetais.

v. Os resultados apresentados sugerem um elevado potencial de utilização da estatística Bayesiana em estudos de caracterização genética de populações. 


\section{REFERÊNCIAS BIBLIOGRÁFICAS}

ADAMS, R.P.; PANDEY, N.; REZZI, S.; CASANOVA, J. Geographic variation in the Random Amplified Polymorphic DNAs (RAPDs) of Juniperus phoenicea, J. p. var. canariensis, J. p. subsp. eumediterranea, and J. p. var. turbinata. Biochemical Systematics and Ecology, v.30, p.223-229, 2002.

ALLARD, R.W.; KAHLER, A.L.; WEIR, B.S. The effect of selection on esterase allozymes in a barley population. Genetics, v.79, p.115-126, 1972.

AYRES, K.; BALDING, D.J. Measuring departures from Hardy-Weinberg: a Markov chain Monte Carlo method for estimating the inbreeding coefficient. Heredity, v.80, p.769$777,1998$.

BALDI, P.; BRUNAK, S. Bioinformatics: the machine learning approach. Cambridge: The MIT Press, 1999. 351p.

BENNET, J.H.; BINET, F.E. Association between Mendelian factors with mixed selfing and random mating. Heredity, v.10, p.51-55, 1956.

BESSEGA, C.; FERREYRA, L.; JULIO, N.; MONTOYA, S.; SAIDMAN, B.; VILARDI, J.C. Mating system parameters in species of genus Prosopis (Leguminosae). Hereditas, v.132, n.1, p.19-27, 2000.

BLACK-SAMUELSSON, S.; ERIKSSON, G.; GUSTAFSSON, L.; GUSTAFSSON, P. RAPD and morphological analysis of rare plant species Vicia pisiformis (Fabaceae). Biological of the Linnean Society, v.61, p.325-343, 1997.

BROWN, A.H.D.; MATHESON, A.C.; ELDRIDGE, K.G. Estimation of the mating system of Eucalyptus obliqua L'Herit. by using allozyme polymorphisms. Australian Journal of Botany, v.23, p.931-949, 1975. 
CHALMERS, K.J.; WAUGH, R.; SPRENT, J.I.; SIMONS, A.J.; POWELL, W. Detection of genetic variation between and within populations of Gliciridia sepium and G. maculata using RAPD markers. Heredity, v.69, p.465-472, 1992.

CHARLESWORTH, D. The apparent selection on neutral marker loci in partially inbreeding populations. Genetical Research, v.57, p.159-175, 1991.

CHELIAK, W.M.; MORGAN, K; STROBECK, C.; YEH, F.C.H.; DANCIK, B.P. Estimation of mating system parameters in plant populations using the EM algorithm. Theoretical and Applied Genetics, v.65, p.157-161, 1983.

CLEGG, M.T.; KAHLER, A.L.; ALLARD, R.W. Estimation of life cycle components of selection in an experimental plant population. Genetics, v.89, p.765-792, 1978.

COCKERHAM, C.C. Variance of gene frequencies. Evolution, v.23, p.72-84, 1969.

CROW, J.F.; KIMURA, M. An introduction to population genetics theory. New York: Harper \& Row, 1970. 591p.

CRUZAN, M.B.; HAMRICK, J.L.; ARNOLD, M.L.; BENNET, B.D. Mating system variation in hybridizing irises - effects of phenology and floral densities on family outcrossing rates. Heredity, v.72, p.95-105, 1994.

DAGPUNAR, J. Principles of random variate generation. Oxford: Clarendon Press, 1988. $248 p$.

ESSELMAN, E.J.; CRAWFORD, D.J.; BRAUNER, S.; STUESSY, T.F.; ANDERSON, G.J.; SILVA, O.M. RAPD marker diversity within and divergence among species of Dendroseris (Asteraceae: Lactuceae). American Journal of Botany, v.87, n.4, p.591-596, 2000.

EVETT, I.W.; WEIR, B.S. Interpreting DNA evidence: statistical genetics for forensic scientists. Sunderland: Sinauer Associates, 1998. 278p.

FYFE, J.L.; BAILEY, N.T.J. Plant breeding studies in leguminous forage crops. I. Natural cross-breeding in winter beans. Journal of Agricultural Science, v.41, p.371-378, 1951.

GAMERMAN, D. Markov Chain Monte Carlo: stochastic simulation for Bayesian inference. London: Chapman \& Hall, 1997. 245p. 
GILLIES, A.C.M.; CORNELIUS, J.P.; NEWTON, A.C.; NAVARRO, C.; HERNÁNDEZ, M.; WILSON, J. Genetic variation in Costa Rican populations of the tropical timber species Cedrela odorata L., assessed using RAPDs. Molecular Ecology, v.6, p.1133-1145, 1997.

HASTINGS, W.K. Monte Carlo sampling methods using Markov Chains and their applications. Biometrika, v.57, p.97-109, 1970.

HILL, W.G.; BABIKER, H.A.; RANFORD-CARTWRIGHT, L.C.; WALLIKER, D. Estimation of inbreeding coefficients from genotypic data on multiple alleles, and application to estimation of clonality in malaria parasites. Genetical Research, v.65, p.53-61, 1995.

LI, C.C.; HORVITZ, D.G. Some methods of estimating the inbreeding coefficient. The American Journal of Human Genetics, v.5, n.2, p.107-117, 1953.

LUO, S.; HE, P.; ZHENG, X.; ZHOU, P. Inheritance of RAPD markers in an interspecific $F_{1}$ hybrid of grape between Vitis quinquangularis and V. vinifera. Scientia Horticulturae, v.93, p.19-28, 2002.

LYNCH, M.; MILLIGAN, B.G. Analysis of population genetic structure with RAPD markers. Molecular Ecology, v.3, p.91-99, 1994.

MALÉCOT, G. Les mathématiques de l'hérédité. Paris: Masson et Compagnie, 1948. $63 \mathrm{p}$.

METROPOLIS, N.; ROSENBLUTH, A.W.; ROSENBLUTH, M.N.; TELLER, A.H.; TELLER, E. Equation of state calculations by fast computing machines. Journal of Chemical Physics, v.21, p.1087-1092, 1953.

MILLAR, M.A.; BYRNE, M.; COATES, D.J.; STUKELY, M.J.C.; McCOMB, J.A. Mating system studies in jarrah, Eucalyptus marginata (Myrtaceae). Australian Journal of Botany, v.48, n.4, p.475-479, 2000.

MONTOYA-DELGADO, L.E.; IRONY, T.Z.; PEREIRA, C.A.; WHITTLE, M.R. An unconditional exact test for the Hardy-Weinberg equilibrium law: sample-space ordering using Bayes factor. Genetics, v.158, p.875-883, 2001.

MURAWSKI, D.A.; HAMRICK, J.L. The effect of the density of flowering individuals on the mating system of nine tropical tree species. Heredity, v.67, p.167-174, 1991. 
MURAWSKI, D.A.; HAMRICK, J.L. Mating system and phenology of Ceiba pentandra (Bombacaceae) in central Panama. Journal of Heredity, v.83, n.6, p.401-404, 1992.

MURAWSKI, D.A.; DAYANANDAN, B.; BAWA, K.S. Outcrossing rates of two endemic Shorea species from Sri Lankan tropical rain forest. Biotropica, v.26, n.1, p.23-29, 1994.

NEI, M. Analysis of gene diversity in subdivided populations. Proceedings of the National Academy of Sciences of the United States of America, v.70, n.2, p.3321-3323, 1973.

NEI, M. F-statistics and analysis of gene diversity in subdivided populations. Annals of Human Genetics, v.41, p.225-233, 1977.

NEI, M. Definition and estimation of fixation indices. Evolution, v.40, p.643-645, 1986.

NEI, M.; CHESSER, R. K. Estimation of fixation indices and gene diversities. Annals of Human Genetics, v.47, p.253-259, 1983.

PALACIOS, C.; GONZÁLEZ-CANDELAS, F. Analysis of population genetic structure and variability using RAPD markers in the endemic and endangered Limonium $\mathrm{du}$ fourii (Plumbaginaceae). Molecular Ecology, v.6, p.1107-1121, 1997.

PEREIRA, C.A.B.; ROGATKO, A. The Hardy-Weinberg equilibrium under a Bayesian perspective. Revista Brasileira de Genética, v.7, n.4, p.689-707, 1984.

RICHARDS, P.W. The tropical rain forest. 2.ed. Cambridge: Cambridge University Press, 1998. 575p.

RITLAND, K. Correlated matings in the partial selfer, Mimulus guttatus. Evolution, v.43, p.848-859, 1989.

RITLAND, K. A series of FORTRAN computer programs for estimating plant mating systems. Journal of Heredity, v.81, p.235-237, 1990.

RITLAND, K.; EL-KASSABY. The nature of inbreeding in a seed orchard of Douglas-fir as shown by an efficient multilocus model. Theoretical and Applied Genetics, v.71, p.375-384, 1985.

RITLAND, K.; JAIN, S.K. A model for the estimation of outcrossing rate and gene frequencies using $\mathrm{n}$ independent loci. Heredity, v.47, p.35-52, 1981. 
ROBERTSON, A.; HILL, W.G. Deviations from Hardy-Weinberg proportions: sampling variances and use in estimation of inbreeding coefficients. Genetics, v.107, p.703-718, 1984.

ROCHA, O.J.; AGUILAR, G. Variation in the breeding behavior of the dry forest tree Enterolobium cyclocarpum (Guanacaste) in Costa Rica. American Journal of Botany, v.88, n.9, p.1600-1606, 2001.

SHAW, D.V.; KAHLER, A.L.; ALLARD, R.W. A multilocus estimator of mating system parameters in plant populations. Proceedings of the National Academy of Sciences of the United States of America, v.78, p.1298-1302, 1981.

SHOEMAKER, J.S.; PAINTER, I.; WEIR, B.S. A Bayesian characterization of Hardy-Weinberg disequilibrium. Genetics, v.149, p.2079-2088, 1998.

SHOEMAKER, J.S.; PAINTER, I.S.; WEIR, B.S. Bayesian statistics in genetics: a guide for the uninitiated. Trends in Genetics, v.15, n.9, p.354-358, 1999.

SMITH, A.F.M.; ROBERTS, G.O. Bayesian computation via the Gibbs sampler and related Markov Chain Monte Carlo methods. Journal of the Royal Statistical Society Series B-Methodological, v.55, p.3-23, 1993.

SUSO, M.J.; PIERRE, J.; MORENO, M.T.; ESNAULT, R.; LE GUEN, J. Variation in outcrossing levels in faba bean cultivars: role of ecological factors. Journal of Agriculture Science, v.136, p.399-405, 2001.

TELLES, M.P.C.; COELHO, A.S.G. Caracterização genética de populações naturais de Araticum (Annona crassiflora). Genetics and Molecular Biology, v.22, p.198, 1998. Suplemento. / Apresentado ao 44. Congresso Nacional de Genética, Águas de Lindóia, 1998 - Resumo/

VENCOVSKY, R. Variance of an estimate of outcrossing rate. Brazilian Journal of Genetics, v.17, n.3, p.349-351, 1994.

VOS, P.; HOGERS, R.; BLEEKER, M.; REIJANS, M.; VAN DE LEE, T.; HORNES, M.; FRITJERS, A.; POT, J.; PELMAN, J.; KUIPER, M.; ZABEAU, M. AFLP: A new technique for DNA fingerprinting. Nucleic Acids Research, v.23, p.4407-4414, 1995. 
WEIR, B.S. Genetic Data Analysis II: methods for discrete population genetic data. Sunderland: Sinauer Associates, 1996. 445p.

WEIR, B.S.; COCHERHAM, C.C. Mixed selfing and random mating at two loci. Genetical Research, v.21, p.247-262, 1973.

WILLIAMS, J.G.K.; KUBLELIK, A.R.; LIVAK, K.J.; RAFALSKI, J.A.; TINGEY, S.V. DNA polymorphisms amplified by arbitrary primers are useful as genetic markers. Nucleic Acid Research, v.18, p.6531-6535, 1990.

WRIGHT, J.W. Introduction to forest genetics. New York: Academic Press, 1976. 463p.

WRIGHT, S. Systems of mating. Genetics, v.6, p.111-178, 1921.

WRIGHT, S. Coefficients of inbreeding and relationship. American Naturalist, v.56, p.330$338,1922$.

WRIGHT, S. The genetical structure of populations. Annals of Eugenics, v.15, p.323-354, 1951.

WRIGHT, S. The interpretation of population structure by F-statistics with special regard to systems of mating. Evolution, v.19, p.395-420, 1965.

YEH, F.C.; MORGAN, K. Mating system and multilocus associations in a natural population of Pseudotsuga menziesii (Mirb.) Franco. Theoretical and Applied Genetics, v.73, p.799-808, 1987. 